Cochrane Database of Systematic Reviews

\title{
Sodium valproate versus phenytoin monotherapy for epilepsy: an individual participant data review (Review)
}

Nevitt SJ, Marson AG, Weston J, Tudur Smith C

Nevitt SJ, Marson AG, Weston J, Tudur Smith C.

Sodium valproate versus phenytoin monotherapy for epilepsy: an individual participant data review.

Cochrane Database of Systematic Reviews 2018, Issue 8. Art. No.: CD001769.

DOI: 10.1002/14651858.CD001769.pub4.

www.cochranelibrary.com 
TABLE OF CONTENTS

HEADER

ABSTRACT

PLAIN LANGUAGE SUMMARY

SUMMARY OF FINDINGS

BACKGROUND

OBJECTIVES

METHODS

RESULTS

Figure 1.

Figure 2.

Figure 3.

Figure 4.

Figure 5.

Figure 6.

Figure 7.

Figure 8.

Figure 9.

Figure 10.

Figure 11.

Figure 12.

Figure 13.

Figure 14.

Figure 15.

DISCUSSION

AUTHORS' CONCLUSIONS

ACKNOWLEDGEMENTS

REFERENCES

CHARACTERISTICS OF STUDIES

DATA AND ANALYSES

Analysis 1.1. Comparison 1 Sodium valproate versus phenytoin, Outcome 1 Time to treatment failure (any reason related to the treatment).

Analysis 1.2. Comparison 1 Sodium valproate versus phenytoin, Outcome 2 Time to treatment failure due to adverse events. .. Analysis 1.3. Comparison 1 Sodium valproate versus phenytoin, Outcome 3 Time to treatment failure due to lack of efficacy. ..

Analysis 1.4. Comparison 1 Sodium valproate versus phenytoin, Outcome 4 Time to treatment failure (any reason related to the treatment) - by epilepsy type.

Analysis 1.5. Comparison 1 Sodium valproate versus phenytoin, Outcome 5 Time to treatment failure due to adverse events by epilepsy type.

Analysis 1.6. Comparison 1 Sodium valproate versus phenytoin, Outcome 6 Time to treatment failure due to lack of efficacy by epilepsy type.

Analysis 1.7. Comparison 1 Sodium valproate versus phenytoin, Outcome 7 Time to first seizure.

Analysis 1.8. Comparison 1 Sodium valproate versus phenytoin, Outcome 8 Time to first seizure - by epilepsy type.

Analysis 1.9. Comparison 1 Sodium valproate versus phenytoin, Outcome 9 Time to first seizure - epilepsy type reclassified to focal for generalised and age of onset $>30$ years.

Analysis 1.10. Comparison 1 Sodium valproate versus phenytoin, Outcome 10 Time to first seizure - epilepsy type reclassified to uncertain for generalised and age of onset $>30$ years.

Analysis 1.11. Comparison 1 Sodium valproate versus phenytoin, Outcome 11 Time to achieve 12-month remission. ............. Analysis 1.12. Comparison 1 Sodium valproate versus phenytoin, Outcome 12 Time to achieve 12-month remission - by epilepsy type.

Analysis 1.13. Comparison 1 Sodium valproate versus phenytoin, Outcome 13 Time to achieve six-month remission.

Analysis 1.14. Comparison 1 Sodium valproate versus phenytoin, Outcome 14 Time to achieve six-month remission - by epilepsy type. 
[Intervention Review]

\section{Sodium valproate versus phenytoin monotherapy for epilepsy: an individual participant data review}

Sarah J Nevitt ${ }^{1}$, Anthony G Marson ${ }^{2}$, Jennifer Weston ${ }^{2}$, Catrin Tudur Smith 1

1Department of Biostatistics, University of Liverpool, Liverpool, UK. 2Department of Molecular and Clinical Pharmacology, Institute of Translational Medicine, University of Liverpool, Liverpool, UK

Contact address: Sarah J Nevitt, Department of Biostatistics, University of Liverpool, Block F, Waterhouse Building, 1-5 Brownlow Hill, Liverpool, L69 3GL, UK. sjn16@liverpool.ac.uk.

Editorial group: Cochrane Epilepsy Group.

Publication status and date: New search for studies and content updated (no change to conclusions), published in Issue 8, 2018.

Citation: Nevitt SJ, Marson AG, Weston J, Tudur Smith C. Sodium valproate versus phenytoin monotherapy for epilepsy: an individual participant data review. Cochrane Database of Systematic Reviews 2018, Issue 8. Art. No.: CD001769. DOI:

10.1002/14651858.CD001769.pub4.

Copyright @ 2018 The Cochrane Collaboration. Published by John Wiley \& Sons, Ltd.

\section{A B S T R A C T}

\section{Background}

Epilepsy is a common neurological condition in which abnormal electrical discharges from the brain cause recurrent unprovoked seizures. It is believed that with effective drug treatment up to $70 \%$ of individuals with active epilepsy have the potential to become seizure-free, and to go into long-term remission shortly after starting drug therapy with a single antiepileptic drug in monotherapy.

Worldwide, sodium valproate and phenytoin are commonly used antiepileptic drugs for monotherapy treatment. It is generally believed that phenytoin is more effective for focal onset seizures, and that sodium pvalproate is more effective for generalised onset tonic-clonic seizures (with or without other generalised seizure types). This review is one in a series of Cochrane Reviews investigating pair-wise monotherapy comparisons. This is the latest updated version of the review first published in 2001, and updated in 2013 and 2016.

\section{Objectives}

To review the time to treatment failure, remission and first seizure of sodium valproate compared to phenytoin when used as monotherapy in people with focal onset seizures or generalised tonic-clonic seizures (with or without other generalised seizure types).

\section{Search methods}

We searched the Cochrane Epilepsy Group's Specialised Register, the Cochrane Central Register of Controlled Trials (CENTRAL), MEDLINE, ClinicalTrials.gov and the World Health Organization (WHO) International Clinical Trials Registry Platform ICTRP on 19 February 2018. We handsearched relevant journals, contacted pharmaceutical companies, original trial investigators and experts in the field.

\section{Selection criteria}

Randomised controlled trials (RCTs) comparing monotherapy with either sodium valproate or phenytoin in children or adults with focal onset seizures or generalised onset tonic-clonic seizures

\section{Data collection and analysis}

This was an individual participant data (IPD) review. Our primary outcome was time to treatment failure and our secondary outcomes were time to first seizure post-randomisation, time to six-month, and 12-month remission, and incidence of adverse events. We used Cox proportional hazards regression models to obtain trial-specific estimates of hazard ratios (HRs) with 95\% confidence intervals (Cls), using the generic inverse variance method to obtain the overall pooled $\mathrm{HR}$ and $95 \% \mathrm{Cl}$. 


\section{Main results}

We included 11 trials in this review and IPD were available for 669 individuals out of 1119 eligible individuals from five out of 11 trials, $60 \%$ of the potential data. Results apply to focal onset seizures (simple, complex and secondary generalised tonic-clonic seizures), and generalised tonic-clonic seizures, but not other generalised seizure types (absence or myoclonus seizure types). For remission outcomes, a HR of less than 1 indicates an advantage for phenytoin, and for first seizure and treatment failure outcomes a HR of less than 1 indicates an advantage for sodium valproate.

The main overall results were: time to treatment failure for any reason related to treatment (pooled HR adjusted for seizure type 0.88 , $95 \% \mathrm{Cl} 0.61$ to 1.27 ; 5 studies; 528 participants; moderate-quality evidence), time to treatment failure due to adverse events (pooled HR adjusted for seizure type $0.77,95 \% \mathrm{Cl} 0.44$ to 1.37 ; 4 studies; 418 participants; moderate-quality evidence), time to treatment failure due to lack of efficacy (pooled HR for all participants 1.16 (95\% Cl 0.71 to 1.89; 5 studies; 451 participants; moderate-quality evidence). These results suggest that treatment failure for any reason related to treatment and treatment failure due to adverse events may occur earlier on phenytoin compared to sodium valproate, while treatment failure due to lack of efficacy may occur earlier on sodium valproate than phenytoin; however none of these results were statistically significant.

Results for time to first seizure (pooled HR adjusted for seizure type $1.08,95 \% \mathrm{Cl} 0.88$ to 1.33 ; 5 studies; 639 participants; low-quality evidence) suggest that first seizure recurrence may occur slightly earlier on sodium valproate compared to phenytoin. There were no clear differences between drugs in terms of time to 12-month remission (pooled HR adjusted for seizure type 1.02, 95\% $\mathrm{Cl} 0.81$ to $1.28 ; 4$ studies; 514 participants; moderate-quality evidence) and time to six-month remission (pooled HR adjusted for seizure type $1.05,95 \% \mathrm{Cl} 0.86$ to 1.27; 5 studies; 639 participants; moderate-quality evidence).

Limited information was available regarding adverse events in the trials and we could not make comparisons between the rates of adverse events on sodium valproate and phenytoin. Some adverse events reported with both drugs were drowsiness, rash, dizziness, nausea and gastrointestinal problems. Weight gain was also reported with sodium valproate and gingival hypertrophy/hyperplasia was reported on phenytoin.

The methodological quality of the included trials was generally good, however four out of the five trials providing IPD for analysis were of an open-label design, therefore all results were at risk of detection bias. There was also evidence that misclassification of seizure type may have confounded the results of this review, particularly for the outcome 'time to first seizure' and heterogeneity was present in analysis of treatment failure outcomes which could not be explained by subgroup analysis by epilepsy type or by sensitivity analysis for misclassification of seizure type. Therefore, for treatment failure outcomes we judged the quality of the evidence to be moderate to low, for 'time to first seizure' we judged the quality of the evidence to be low, and for remission outcomes we judged the quality of the evidence to be moderate.

\section{Authors' conclusions}

We have not found evidence that a significant difference exists between valproate and phenytoin for any of the outcomes examined in this review. However detection bias, classification bias and heterogeneity may have impacted on the results of this review. We did not find any outright evidence to support or refute current treatment policies. We recommend that future trials be designed to the highest quality possible with consideration of masking, choice of population, classification of seizure type, duration of follow-up, choice of outcomes and analysis, and presentation of results.

\section{PLAIN LANGUAGE SUMMARY}

\section{Sodium valproate versus phenytoin monotherapy (single drug treatment) for epilepsy}

This is an updated version of the Cochrane Review previously published in Issue 4, 2016 of the Cochrane Database of Systematic Reviews.

\section{Background}

Epilepsy is a common neurological disorder in which abnormal electrical discharges from the brain cause recurrent seizures. We studied two types of epileptic seizures in this review: generalised onset seizures, in which electrical discharges begin in one part of the brain and move throughout the brain; and focal onset seizures, in which the seizure is generated in and affects one part of the brain (the whole hemisphere of the brain or part of a lobe of the brain). Focal seizures may become generalised (secondary generalisation) and move from one part of the brain throughout the brain. For around $70 \%$ of people with epilepsy, a single antiepileptic medication can control generalised onset or focal onset seizures.

\section{Objective}

Sodium valproate and phenytoin are commonly used treatments for individuals with epilepsy. The aim of this review was to compare how effective these drugs are at controlling seizures and whether individuals choose to stop taking these treatments (treatment failure), to inform a choice between these drugs.

\section{Methods}


The last search for trials for this review was 19 February 2018. We assessed the evidence from 11 randomised controlled clinical trials comparing sodium valproate to phenytoin and we were able to combine data for 699 people from five of the 11 trials; for the remaining 450 people from six trials, data were not available to use in this review.

\section{Key results}

This review of trials found no difference between these two drugs for the seizure types studied for the outcomes of treatment failure (withdrawal from treatment) and controlling seizures (recurrence of seizures or achievement of a seizure-free period (remission) of 6 months or 12 months). The review also found no evidence to support or refute the policy of using sodium valproate for generalised onset tonic-clonic seizures and phenytoin for focal onset seizures.

However, up to $49 \%$ of people within the trials classified as having generalised seizures may have had their seizure type wrongly diagnosed and these people may have been experiencing focal seizures or an uncertain seizure type, and this misclassification may have influenced the results of this review. We were unable to address the issue of preferring sodium valproate for generalised onset seizure types other than tonic-clonic, such as absence or myoclonic seizures.

\section{Quality of the evidence}

We judged the quality of the evidence as moderate to low for the evidence of treatment failure, moderate for remission outcomes and low for seizure outcomes as it is likely that misclassification of seizure type influenced the results of the review. Within four of the five trials providing data for this review, the design of the trial meant that the people and treating clinicians knew which medication they were taking. This design may have influenced the results.

\section{Conclusions}

Sodium valproate and phenytoin are commonly used treatments for individuals with epilepsy, but we found no difference between these treatments for the outcomes of this review or between seizure types. More information is needed and we recommend that all future trials comparing these medications, or any other antiepileptic medications, should be designed using high-quality methods. Seizure types of people included in trials should also be classified very carefully to ensure that the results are also of high quality. 


\section{SUMMARY OF FINDINGS}

\section{Summary of findings for the main comparison. Sodium valproate compared with phenytoin monotherapy for epilepsy (primary outcome)}

Sodium valproate compared with phenytoin monotherapy for epilepsy

Patient or population: adults and children with newly-onset focal onset or generalised tonic-clonic seizures

Settings: outpatients

Intervention: sodium valproate

Comparison: phenytoin

\begin{tabular}{|c|c|c|c|c|c|c|}
\hline \multirow[t]{3}{*}{ Outcomes } & \multicolumn{2}{|c|}{ Illustrative comparative risks ${ }^{\star}(95 \% \mathrm{CI})$} & \multirow{3}{*}{$\begin{array}{l}\text { Relative effect } \\
(95 \% \mathrm{CI})\end{array}$} & \multirow{3}{*}{$\begin{array}{l}\text { No. of Partici- } \\
\text { pants } \\
\text { (studies) }\end{array}$} & \multirow{3}{*}{$\begin{array}{l}\text { Quality of the } \\
\text { evidence } \\
\text { (GRADE) }\end{array}$} & \multirow[t]{3}{*}{ Comments } \\
\hline & Assumed risk & Corresponding risk & & & & \\
\hline & Phenytoin & Sodium valproate & & & & \\
\hline $\begin{array}{l}\text { Time to treatment } \\
\text { failure (any reason } \\
\text { related to treat- } \\
\text { ment) } \\
\text { All participants } \\
\text { Range of follow-up: } 0 \\
\text { to } 4256 \text { days }\end{array}$ & $\begin{array}{l}\text { The median } \\
\text { time to treat- } \\
\text { ment failure was } \\
2361 \text { days in the } \\
\text { phenytoin group }\end{array}$ & $\begin{array}{l}\text { The median time to } \\
\text { treatment failure } \\
\text { was } 2545 \text { days ( } 184 \\
\text { days longer) in the } \\
\text { sodium valproate } \\
\text { group }\end{array}$ & $\begin{array}{l}\text { HR } 0.88 \\
(0.61 \text { to } 1.27)^{a}\end{array}$ & $\begin{array}{l}528 \\
\text { (5 studies) }\end{array}$ & $\begin{array}{l}\oplus \oplus \oplus \ominus \\
\text { Moderate } b\end{array}$ & $\begin{array}{l}\mathrm{HR}<1 \text { indicates a clinical advantage for val- } \\
\text { proate } \\
\text { There was also no statistically significant } \\
\text { difference between drugs in treatment fail- } \\
\text { ure due to adverse events: HR } 0.77 \text { ( } 95 \% \mathrm{Cl} \\
0.44 \text { to } 1.37, \mathrm{P}=0.38 \text { ) or treatment failure } \\
\text { due to lack of efficacy: HR } 1.16 \text { ( } 95 \% \mathrm{Cl} 0.71 \\
\text { to } 1.89, \mathrm{P}=0.55)\end{array}$ \\
\hline $\begin{array}{l}\text { Time to treatment } \\
\text { failure (any reason } \\
\text { related to treat- } \\
\text { ment) } \\
\text { Subgroup: focal onset } \\
\text { seizures } \\
\text { Range of follow-up: } 0 \\
\text { to } 4256 \text { days }\end{array}$ & $\begin{array}{l}\text { The median } \\
\text { time to treat- } \\
\text { ment failure was } \\
1838 \text { days in the } \\
\text { phenytoin group }\end{array}$ & $\begin{array}{l}\text { The median time to } \\
\text { treatment failure } \\
\text { was } 1772 \text { days ( } 66 \\
\text { days shorter) in the } \\
\text { sodium valproate } \\
\text { group }\end{array}$ & $\begin{array}{l}\text { HR } \mathbf{0 . 8 3} \\
(0.50 \text { to } 1.38)\end{array}$ & $\begin{array}{l}187 \\
\text { (4 studies) }\end{array}$ & $\begin{array}{l}\oplus \oplus \oplus \ominus \\
\text { Moderate }^{b}\end{array}$ & $\begin{array}{l}\mathrm{HR}<1 \text { indicates a clinical advantage for val- } \\
\text { proate } \\
\text { There was also no statistically significant } \\
\text { difference between drugs in treatment fail- } \\
\text { ure due to adverse events: HR } 0.81(95 \% \mathrm{Cl} \\
0.34 \text { to } 1.90, \mathrm{P}=0.62) \text { or treatment failure } \\
\text { due to lack of efficacy: HR } 1.01 \text { ( } 95 \% \mathrm{Cl} 0.55 \\
\text { to } 1.85, \mathrm{P}=0.98)\end{array}$ \\
\hline $\begin{array}{l}\text { Time to treatment } \\
\text { failure (any reason } \\
\text { related to treat- } \\
\text { ment) }\end{array}$ & $\begin{array}{l}\text { The 25th per- } \\
\text { centile }{ }^{\star \star} \text { of } \\
\text { time to treat- } \\
\text { ment failure was }\end{array}$ & $\begin{array}{l}\text { The } 25 \text { th percentile } \\
\text { of time to treatment } \\
\text { failure was } 1778 \text { days } \\
\text { ( } 290 \text { days longer) in }\end{array}$ & $\begin{array}{l}\text { HR } 0.94 \\
(0.55 \text { to } 1.61)\end{array}$ & $\begin{array}{l}341 \\
\text { (5 studies) }\end{array}$ & $\begin{array}{l}\oplus \oplus \oplus \ominus \\
\mathbf{L o w}^{\mathrm{b}, \mathrm{c}}\end{array}$ & $\begin{array}{l}\mathrm{HR}<1 \text { indicates a clinical advantage for val- } \\
\text { proate } \\
\text { There was also no statistically significant } \\
\text { difference between drugs in treatment fail- }\end{array}$ \\
\hline
\end{tabular}


* Illustrative risks in the sodium valproate and phenytoin groups are calculated at the median time to treatment failure (i.e. the time to $50 \%$ of participants failing or withdrawing from allocated treatment) within each group across all trials. The relative effect (pooled HR) shows the comparison of 'time to treatment failure' between the treatment groups.

** The 25 th percentile of time to treatment failure (i.e. the time to $25 \%$ of participants failing or withdrawing from allocated treatment) is presented for the subgroup with generalised seizures as less than $50 \%$ of participants failed/withdrew from treatment, therefore the median time could not be calculated.

Abbreviations: $\mathrm{Cl}$ : confidence interval; HR: hazard ratio.

GRADE Working Group grades of evidence

High quality: further research is very unlikely to change our confidence in the estimate of effect.

Moderate quality: further research is likely to have an important impact on our confidence in the estimate of effect and may change the estimate.

Low quality: further research is very likely to have an important impact on our confidence in the estimate of effect and is likely to change the estimate.

Very low quality: we are very uncertain about the estimate.

a Pooled HR for all participants adjusted for seizure type.

bDowngraded once as risk of bias judged high for three unblinded studies (De Silva 1996; Heller 1995; Ramsay 1992); lack of blinding may have impacted on the withdrawal rates and treatment failure rates in the trials.

cDowngraded once due to inconsistency: a large amount of heterogeneity is present within analysis $\left(I^{2}=59 \%\right)$ which could not be explained by sensitivity analysis for potential misclassification of epilepsy type.

\section{Summary of findings 2. Sodium valproate compared with phenytoin monotherapy for epilepsy (secondary outcomes)}

\section{Valproate compared with phenytoin monotherapy for epilepsy}

Patient or population: adults and children with newly-onset focal onset or generalised tonic-clonic seizures

Settings: outpatients

Intervention: sodium valproate

Comparison: phenytoin

\begin{tabular}{|c|c|c|c|c|c|}
\hline \multirow[t]{2}{*}{ Outcomes } & \multicolumn{2}{|c|}{ Illustrative comparative risks* $(95 \% \mathrm{CI})$} & \multirow{2}{*}{$\begin{array}{l}\text { Relative effect } \\
(95 \% \mathrm{Cl})\end{array}$} & \multirow{2}{*}{$\begin{array}{l}\text { No. of Partici- } \\
\text { pants } \\
\text { (studies) }\end{array}$} & \multirow{2}{*}{$\begin{array}{l}\text { Quality of the } \\
\text { evidence } \\
\text { (GRADE) }\end{array}$} \\
\hline & Assumed risk & Corresponding risk & & & \\
\hline
\end{tabular}




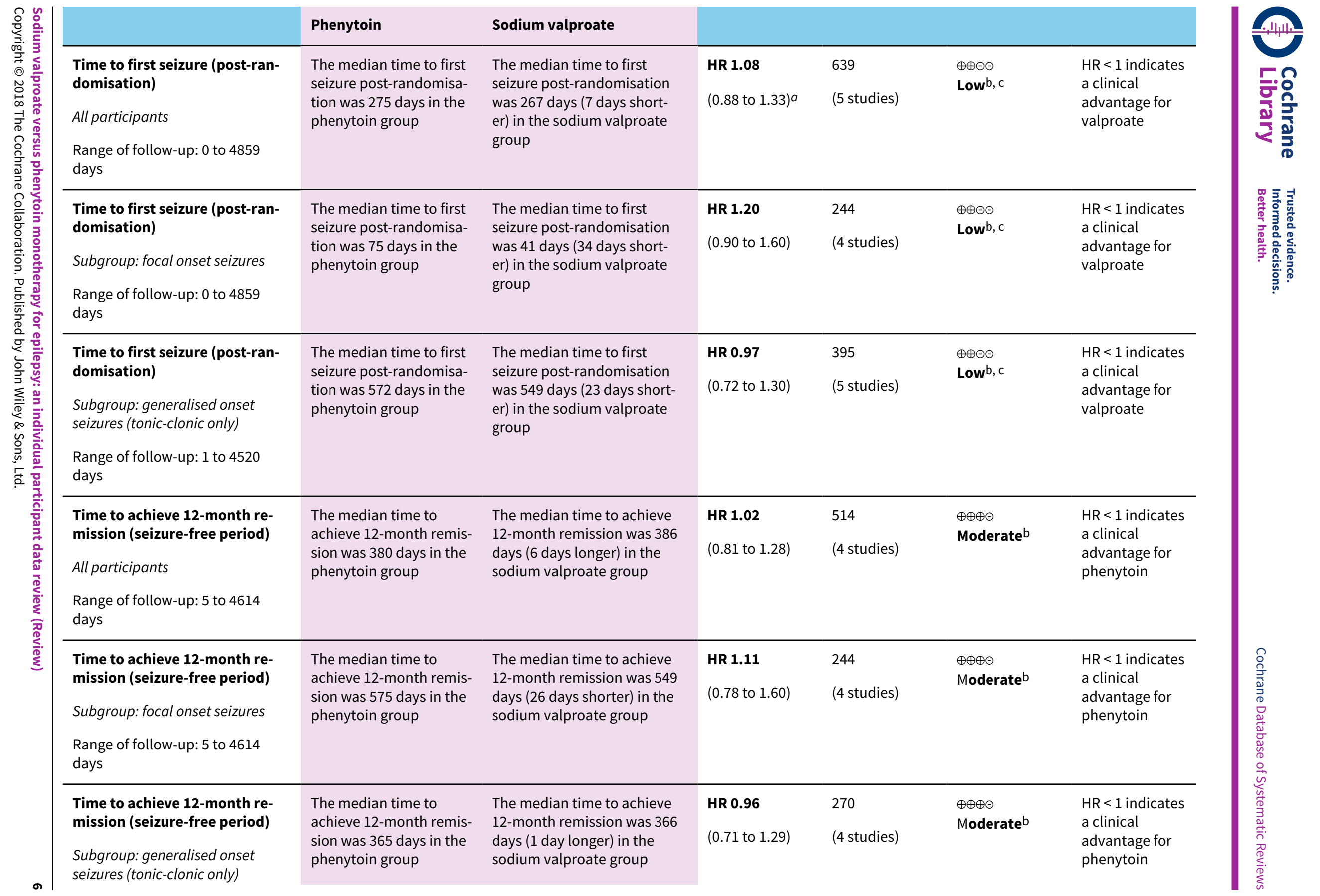


* Illustrative risks in the phenytoin and sodium valproate groups are calculated at the median time to first seizure or time to 12 -month remission (i.e. the time to $50 \%$ of participants experiencing a first seizure or 12 months of remission) within each group across all trials. The relative effect (pooled HR) shows the comparison of 'time to first seizure' or 'time to 12-month remission' between the treatment groups.

Abbreviations: CI: confidence interval; HR: hazard ratio.

GRADE Working Group grades of evidence

High quality: further research is very unlikely to change our confidence in the estimate of effect.

Moderate quality: further research is likely to have an important impact on our confidence in the estimate of effect and may change the estimate.

Low quality: further research is very likely to have an important impact on our confidence in the estimate of effect and is likely to change the estimate.

Very low quality: we are very uncertain about the estimate.

a Pooled HR for all participants adjusted for seizure type.

bDowngraded once as risk of bias judged high for four unblinded studies (Craig 1994; De Silva 1996; Heller 1995; Ramsay 1992).

cDowngraded once due to applicability: as up to $49 \%$ in the 5 trials classified as experiencing generalised onset seizures may have had their seizure type wrongly classified;

sensitivity analyses show misclassification has an impact on results and conclusions. 


\section{B A C K G R O U N D}

This is an updated version of the original Cochrane review published in 2001 (Tudur Smith 2001), updated in 2013 and 2016 (Nolan 2013a; Nolan 2016a).

\section{Description of the condition}

Epilepsy is a common neurological condition in which abnormal electrical discharges from the brain cause recurrent unprovoked seizures. Epilepsy is a disorder of many heterogenous seizure types, with an estimated incidence of 33 to 57 per 100,000 person-years worldwide (Annegers 1999; Hirtz 2007; MacDonald 2000; Olafsson 2005; Sander 1996), accounting for approximately $1 \%$ of the global burden of disease (Murray 1994). The lifetime risk of epilepsy onset is estimated to be 1300 to 4000 per 100,000 person-years (Hauser 1993; Juul Jenson 1983), and the lifetime prevalence could be as large as 70 million people worldwide (Ngugi 2010). It is believed that with effective drug treatment, up to $70 \%$ of individuals with active epilepsy have the potential to go into long-term remission shortly after starting drug therapy (Cockerell 1995; Hauser 1993; Sander 2004), and around $70 \%$ of individuals can achieve seizure freedom using a single antiepileptic drug in monotherapy (Cockerell 1995). Current National Institute for Health and Care Excellence (NICE) guidelines recommend that both adults and children with epilepsy should be treated with monotherapy wherever possible (NICE 2012). The remaining 30\% of individuals experience refractory or drug-resistant seizures, which often require treatment with combinations of antiepileptic drugs or alternative treatments, such as epilepsy surgery (Kwan 2000).

We studied two seizure types in this review: generalised onset seizures in which electrical discharges begin in one part of the brain and move throughout the brain, and focal onset seizures in which the seizure is generated in and affects one part of the brain (the whole hemisphere of the brain or part of a lobe of the brain).

\section{Description of the intervention}

The majority of people with epilepsy have their seizures controlled by a single drug (monotherapy) (Cockerell 1995). Worldwide, sodium valproate and phenytoin are commonly used antiepileptic drugs licensed for monotherapy. Phenytoin is used as a firstline drug in low- and middle-income countries as it is a lowcost drug and can be given as a single daily dose, but is no longer considered a first-line agent in the USA and much of Europe due to worries over adverse events (Wallace 1997; Wilder 1995). Phenytoin is associated with long-term cosmetic changes including gum hyperplasia, acne and coarsening of the facial features (Mattson 1985; Scheinfeld 2003), as well as low folic acid levels, predisposing participants to megaloblastic anaemia (Carl 1992), and is associated with congenital abnormalities (Gladstone 1992; Morrow 2006; Meador 2008; Nulman 1997), particularly foetal hydantoin syndrome (Scheinfeld 2003). Furthermore, due to the pharmacokinetic profile of phenytoin, the plasma concentrations are difficult to predict and dosing will usually need to be informed by measuring plasma concentration. Sodium valproate has also been shown to have teratogenic properties (Canger 1999; Morrow 2006; Tomson 2011), and is particularly associated with spina bifida and cardiac, craniofacial, skeletal and limb defects known as 'valproate syndrome' (Ornoy 2009). Systematic reviews have found sodium valproate to have the highest incidence of congenital malformations of standard antiepileptic drugs (Meador
2008; Weston 2017), and recent studies have shown an increased prevalence of neurodevelopmental disorders following prenatal sodium valproate exposure (Bromley 2013; Bromley 2014). Sodium valproate is also associated with weight gain in adults and children (Dinesen 1984; Easter 1997; Egger 1981; Novak 1999).

\section{How the intervention might work}

It is generally believed that sodium valproate monotherapy is more effective than phenytoin monotherapy in generalised onset seizures (generalised tonic-clonic seizures, absence, and myoclonus), while phenytoin monotherapy is more effective than sodium valproate monotherapy in focal onset seizures (simple focal, complex focal, and secondary generalised tonicclonic seizures) (Chadwick 1994), although there is no conclusive evidence from individual randomised controlled trials (RCTs) to support this belief. Evidence in favour of sodium valproate for generalised seizures is predominantly anecdotal from observational studies, suggesting a dramatic benefit with sodium valproate in juvenile myoclonic epilepsy (Delgado-Escueta 1984; Penry 1989), and reports of efficacy of sodium valproate against absence seizures (Bourgeois 1987; Jeavons 1977). The results of two RCTs, recruiting children indicate that sodium valproate may be better tolerated in children than phenytoin (De Silva 1996; Thilothammal 1996); twice as many children experienced at least one side effect on phenytoin than sodium valproate in Thilothammal 1996, and phenytoin was more likely to be withdrawn due to unacceptable side effects than sodium valproate in De Silva 1996.

Some animal models have suggested that phenytoin has either no effect in absence seizures or may in fact worsen seizures (Liporace 1994). There is also anecdotal evidence that phenytoin may cause paradoxical intoxication (increased seizure frequency with increased anticonvulsant dose) and encephalopathy (Troupin 1975; Vallarta 1974).

\section{Why it is important to do this review}

Accepting that phenytoin should not be a drug of first choice for individuals experiencing absence, myoclonic and atonic seizures, we still have insufficient evidence from RCTs to guide a choice between sodium valproate and phenytoin for individuals with generalised onset tonic-clonic seizures or focal onset seizures. The aim of this review, therefore, is to summarise efficacy and tolerability data from existing trials comparing valproate and phenytoin when used as monotherapy treatments.

There are difficulties in undertaking a systematic review of epilepsy monotherapy trials, as the important efficacy outcomes require analysis of time-to-event data (for example, time to first seizure after randomisation). Although methods have been developed to synthesise time-to-event data using summary information (Parmar 1998; Williamson 2002), the appropriate statistics are not commonly reported in published epilepsy trials (Nolan 2013d; Williamson 2000).

Furthermore, although seizure data have been collected in most epilepsy monotherapy trials, there has been no uniformity in the definition and reporting of outcomes. For example, trials may report time to 12 -month remission but not time to first seizure or vice versa, or some trials may define time to first seizure from the date of randomisation, while others use date of 
achieving maintenance dose. Trial investigators have also adopted differing approaches to the analysis, particularly with respect to the censoring of time-to-event data. For these reasons, we performed this review using individual participant data (IPD) which helps to overcome these problems. This review is one in a series of Cochrane IPD reviews investigating pair-wise monotherapy comparisons (Marson 2000; Nevitt 2017b; Nolan 2013b; Nolan 2013c; Nolan 2016b; Nolan 2016c; Nevitt 2018). These data have also been included in IPD network meta-analyses of antiepileptic drug monotherapy (Nevitt 2017a; Tudur Smith 2007).

\section{OB JECTIVES}

To review the time to treatment failure, remission and first seizure of sodium valproate compared to phenytoin when used as monotherapy in people with focal onset seizures or generalised tonic-clonic seizures (with or without other generalised seizure types).

\section{METHOD S}

\section{Criteria for considering studies for this review}

\section{Types of studies}

- Randomised controlled trials (RCTs) using either:

* an adequate method of allocation concealment (e.g. sealed opaque envelopes); or

* a 'quasi' method of randomisation (e.g. allocation by date of birth).

- Studies may be double-blind, single-blind or unblinded.

- Studies must include a comparison of sodium valproate monotherapy with phenytoin monotherapy in individuals with epilepsy.

\section{Types of participants}

- We included children or adults with focal onset seizures (simple focal, complex focal or secondarily generalised tonic-clonic seizures) or generalised onset tonic-clonic seizures, with or without other generalised seizure types (in other words, those who had only generalised tonic-clonic seizures and those who had both generalised onset tonic-clonic seizures and generalised seizures of other types (e.g. absence, myoclonic etc.)).

- We excluded individuals with other generalised seizure types alone without generalised tonic-clonic seizures (e.g. those who had only absence seizures without any generalised clonic tonicseizures) due to differences in first-line treatment guidelines for other generalised seizure types (NICE 2012).

- We included individuals with a new diagnosis of epilepsy, or who have had a relapse following withdrawal of antiepileptic monotherapy.

\section{Types of interventions}

Sodium valproate or phenytoin as monotherapy. For brevity, sodium valproate is referred to a 'valproate' herein.

\section{Types of outcome measures}

Below is a list of outcomes investigated in this review. Reporting of these outcomes in the original trial report was not an eligibility requirement for inclusion in this review.

\section{Primary outcomes}

- Time to treatment failure (retention time).

This is a combined outcome reflecting both efficacy and tolerability, as the following may have lead to failure of treatment: continued seizures, side effects, noncompliance or the initiation of additional add-on treatment. This is an outcome to which the participant makes a contribution and is the primary outcome measure recommended by the Commission on Antiepileptic Drugs of the International League Against Epilepsy (ILAE 1998; ILAE 2006).

Time to treatment failure is considered according to three definitions.

- Time to treatment failure, for any treatment-related reason (continued seizures, side effects, noncompliance or the initiation of additional add-on treatment).

- Time to treatment failure, due to adverse events (i.e. side effects).

- Time to treatment failure, due to lack of efficacy (i.e. continued seizures).

\section{Secondary outcomes}

- Time to first seizure (post-randomisation).

- Time to achieve 12-month remission (seizure-free period).

- Time to achieve six-month remission (seizure-free period).

- Incidence of adverse events.

\section{Search methods for identification of studies}

\section{Electronic searches}

We searched the following databases. We did not impose any language restrictions.

- The Cochrane Epilepsy Group's Specialised Register (19 February 2018) using the search strategy outlined in Appendix 1.

- The Cochrane Central Register of Controlled Trials (CENTRAL; 2018, Issue 2) in the Cochrane Library (searched 19 February 2018) using the search strategy outlined in Appendix 2.

- MEDLINE (Ovid, 1946 to 19 February 2018) using the search strategy outlined in Appendix 3.

- SCOPUS (last search 19 February 2013) using the search strategy outlined in Appendix 4. We searched SCOPUS as an alternative to Embase, but this is no longer necessary, because randomised and quasi-RCTs in Embase are now included in CENTRAL, so we will not be updating the SCOPUS search.

- ClinicalTrials.gov (19 February 2018) using the search terms 'phenytoin AND valproate | Epilepsy'.

- WHO International Clinical Trials Registry Platform ICTRP (19 February 2018) using the search terms 'valproate and phenytoin and epilepsy'.

\section{Searching other resources}

In addition, we handsearched relevant journals, reviewed the reference lists of retrieved studies to search for additional reports of relevant studies, contacted Sanofi (manufacturers of valproate in Europe), Abbott (manufacturers of valproate in the USA), ParkeDavis (manufacturers of phenytoin), and experts in the field for information about any ongoing studies. 


\section{Data collection and analysis}

\section{Selection of studies}

Two review authors (SJN and AGM) independently assessed trials for inclusion, resolving any disagreements by mutual discussion.

\section{Data extraction and management}

We requested the following individual participant data (IPD) for all trials meeting our inclusion criteria.

- Trial methods

- method of generation of random list

- method of concealment of randomisation

- stratification factors

- blinding methods

- Participant covariates

- gender

- age

- seizure types

- time between first seizure and randomisation

- number of seizures prior to randomisation (with dates)

- presence of neurological signs

- electroencephalographic (EEG) results

- computerised tomography/magnetic resonance imaging (CT/MRI) results

- Follow-up data

- treatment allocation

- date of randomisation

- dates of follow-up

- dates of seizures post-randomisation or seizure frequency data between follow-up visits

- dates of treatment withdrawal or treatment failure and reasons for treatment withdrawal or treatment failure

- dose

- dates of dose changes

For each trial for which IPD were not obtained, we carried out an assessment to see whether any relevant aggregate level data had been reported. If possible, SJN extracted any aggregate level data from publications and extracted data were verified by JW.

For three trials, seizure data were provided in terms of the number of seizures recorded between clinic visits rather than specific dates of seizures (Craig 1994; Ramsay 1992; Turnbull 1985). To enable time-to-event outcomes to be calculated, we applied linear interpolation to approximate the dates on which seizures occurred. For example, if four seizures were recorded between two visits which occurred on 1 March and 1 May (an interval of 61 days), then date of first seizure would be approximately 13 March. This allowed an estimate of the time to achieve six-month and 12-month remission and the time to first seizure to be computed.

We calculated time to achieve six-month and 12-month remission from the date of randomisation to the date (or estimated date) the individual had first been free of seizures for six or 12 months, respectively. If the person had one or more seizure(s) in the titration period, a six-month or 12-month seizure-free period could also occur between the estimated date of the last seizure in the titration period and the estimated date of the first seizure in the maintenance period.

We calculated time to first seizure from the date of randomisation to the date that their first seizure was estimated to have occurred. If seizure data were missing for a particular visit, these outcomes were censored at the previous visit. These outcomes were also censored if the individual died or if follow-up ceased prior to the occurrence of the event of interest. These methods had been used in the remaining two trials for which outcome data were provided directly (De Silva 1996; Heller 1995).

Treatment failure data were not available for one trial (Craig 1994). For two trials, we extracted dates and reason for treatment failure from trial case report forms for the original review (De Silva 1996; Heller 1995). Two review authors (SJN and AGM) independently extracted data from all case report forms, resolving disagreements by discussion and reconsidering the case report forms. For the remaining trials (Ramsay 1992; Turnbull 1985), data on length of time spent in trial and reason for withdrawal from treatment or treatment failure were provided directly.

Time to treatment failure was calculated as date of randomisation to date of treatment failure. For the analysis of time-to-event, we defined an 'event' as treatment failure because of reasons related to the treatment (i.e. lack of efficacy, adverse events, or both lack of efficacy and adverse events), non-compliance with the treatment regimen, withdrawal of consent from the trial, etc.). We censored the outcome if treatment failure or withdrawal of treatment was for reasons not related to the trial treatment: i.e. loss to follow-up, death (not treatment or epilepsy-related), withdrawal of treatment due to remission, etc. We also censored individuals who were still on allocated treatment at the date of the end of follow-up. We considered documented reasons for treatment failure or treatment withdrawal on a case-by-case basis in relation to treatment; two authors (SJN and AGM) independently classified reasons for treatment failure as 'events' or 'censored' and resolved any disagreements by discussion.

For the analysis of 'time to treatment failure due to adverse events,' only treatment failures which were documented to be due to adverse events (either as a sole reason or due to both a lack of efficacy and adverse events) were classed as an 'event' within timeto-event analyses and all other reasons for treatment failure were censored. Similarly, for the analysis of 'time to treatment failure due to lack of efficacy' only treatment failures which were documented to be due to lack of efficacy (i.e. continued seizures, either as a sole reason or due to both a lack of efficacy and adverse events) were classed as an 'event' within time-to-event analyses and all other reasons for treatment failure were censored.

Two trials presented times at which the allocated drug was withdrawn and the reason for treatment failure in the trial publication for each individual (Forsythe 1991; Shakir 1981). Hence, these two trials could be incorporated into the analysis of 'time to treatment failure'; one of the trials also presented information by seizure type (focal onset or generalised onset seizures) and therefore could also be included in the stratified analysis for 'time to treatment failure' (Shakir 1981).

Shakir 1981 presents 'time on trial drug' in months for each participant; therefore to calculate 'time to treatment failure', we assumed that if 'time spent on trial drug' was five months, the 
individual spent five full months (152 full days) on the trial drug before treatment failure. Forsythe 1991 presents 'withdrawal and time of occurrence by month' for each participant; therefore to calculate 'time to treatment failure', we assumed that if treatment failure occurred during the fifth month, that the treatment failure occurred halfway between the fifth and sixth month (i.e. participants spent 167 full days on treatment before treatment failure).

\section{Assessment of risk of bias in included studies}

Two review authors (SJN and JW) independently assessed the risk of bias for each trial using the Cochrane 'Risk of bias' tool, as described in the Cochrane Handbook for Systematic Reviews of Interventions (Higgins 2011). We rated each of the following six domains as low, unclear or high risk of bias: method of generating random sequence, allocation concealment, blinding methods, incomplete outcome data, selective outcome reporting and other sources of bias. Any discrepancies in risk of bias judgements of the two review authors were resolved by discussion. In the event of the presence of high risk of bias in included trials (due to inadequate allocation concealment or lack of blinding), we planned sensitivity analyses excluding these trials.

\section{Measures of treatment effect}

We measured all outcomes in this review as time-to-event outcomes with the hazard ratio (HR) and 95\% confidence interval (Cl) used as the measure of treatment effect. We calculated outcomes from IPD provided, where possible, or extracted from published trials if possible.

\section{Unit of analysis issues}

We did not have any unit of analysis issues. The unit of allocation and analysis was the individual for all included trials; and no trials included in meta-analyses were of a repeated measures (longitudinal) nature or of a cross-over design.

\section{Dealing with missing data}

For each trial that supplied IPD, we reproduced results from trial results where possible and performed the following consistency checks.

- We cross-checked trial details against any published report of the trial and contacted original trial authors if we found missing data, errors or inconsistencies. If trial authors could not resolve inconsistencies between the IPD and the published data, depending on the extent of the inconsistencies, we planned to perform sensitivity analysis or excluded the data from the metaanalysis.

- We reviewed the chronological randomisation sequence and checked the balance of prognostic factors, taking account of factors stratified for in the randomisation procedure.

\section{Assessment of heterogeneity}

We assessed heterogeneity statistically using the $\mathrm{Q}$ test $(\mathrm{P}<$ 0.10 for significance) and the $\mathrm{I}^{2}$ statistic (greater than $50 \%$ indicating considerable heterogeneity; Higgins 2003), and visually by inspecting forest plots.

\section{Assessment of reporting biases}

Two review authors (SJN and JW) undertook all full quality and risk of bias assessments. In theory, a review using IPD should overcome issues of reporting biases, as unpublished data can be provided and unpublished outcomes calculated. Any selective reporting bias detected could be assessed with the ORBIT classification system (Kirkham 2010).

\section{Data synthesis}

We carried out our analysis on an intention-to-treat basis (that is, we analysed participants in the group to which they were randomised, irrespective of which treatment they actually received). Therefore, for the time-to-event outcomes, 'time to sixmonth remission', 'time to 12 -month remission', 'time to 24 month remission' and 'time to first seizure post-randomisation', we did not censor participants if treatment was withdrawn or if treatment failure occurred but follow-up within the trial continued (e.g. if a participant continued to be followed up on a different treatment).

For all outcomes, we investigated the relationship between the time-to-event and treatment effect of the antiepileptic drugs. We used Cox proportional hazards regression models to obtain trialspecific estimates of log (HR) or treatment effect and associated standard errors in Stata Statistical Software, version 14 (Stata 2015). The model assumes that the ratio of hazards (risks) between the two treatment groups is constant over time (i.e. hazards are proportional). We tested this proportional hazards assumption of the Cox regression model for each outcome of each trial by testing the statistical significance of a time varying covariate in the model. We evaluated overall pooled estimates of HRs (with 95\% Cls) using the generic inverse variance method. We expressed results as a HR and a $95 \% \mathrm{Cl}$.

By convention, a HR greater than 1 indicates that an event is more likely to occur earlier on valproate than on phenytoin. Hence, for time to treatment failure or time to first seizure, a HR less than 1 indicates a clinical advantage for valproate (e.g. $\mathrm{HR}=0.8$ would suggest a $20 \%$ reduction in hazard of treatment failure from valproate compared to phenytoin), and for time to achieve sixmonth and 12-month remission, a HR less than 1 indicates a clinical advantage for phenytoin.

\section{Subgroup analysis and investigation of heterogeneity}

Due to the strong clinical belief that valproate is more effective in generalised onset seizures, while phenytoin is more effective in focal onset seizures, we have stratified all analyses by seizure type (focal onset versus generalised onset), according to the classification of main seizure type at baseline. We classified focal seizures (simple or complex) and focal secondarily generalised seizures as 'focal epilepsy'. We classified primarily generalised seizures as 'generalised epilepsy'. We conducted a Chi ${ }^{2}$ test of interaction between treatment and epilepsy type.

If we found significant statistical heterogeneity to be present, we performed meta-analysis with a random-effects model in addition to a fixed-effect model, presenting the result of both models and performing sensitivity analyses to investigate differences in study characteristics. 


\section{Sensitivity analysis}

One trial recruited only individuals with generalised onset tonicclonic seizures, some of whom were experiencing other generalised seizure types, such as absence or myoclonus (Ramsay 1992), and all generalised seizure types were recorded during follow-up for this trial. The remaining four trials recruited individuals with focal onset seizures (simple/complex focal or secondarily generalised tonicclonic) and individuals with generalised onset tonic-clonic seizures. For the individuals with generalised onset tonic-clonic seizures recruited into these four trials, other generalised seizure types were not recorded during follow-up. As a result, the majority of the data from the five trials does not address the treatment of generalised seizure types, such as absence or myoclonus, but applies only to generalised onset tonic-clonic seizures. In our primary analysis, we use only the data for generalised onset tonic-clonic seizures during follow-up as this is the most consistent approach; we also report a sensitivity analysis which includes data on all generalised seizure types from Ramsay 1992 for the outcomes 'time to first seizure' and 'time to six-month remission' (Ramsay 1992 was less than one year duration so does not contribute to 'time to-12 month remission').

Misclassification of seizure type is a recognised problem in epilepsy, whereby some people with generalised seizures have been mistakenly classed as having focal onset seizures and vice versa. There is clinical evidence that individuals with generalised onset seizures are unlikely to have an 'age of onset' greater than 25 to 30 years (Malafosse 1994). Such misclassification impacted upon the results of three reviews in our series of pair-wise reviews for monotherapy in epilepsy comparing carbamazepine to phenobarbitone, phenytoin and sodium valproate in which around $30 \%$ to $50 \%$ of participants analysed may have had their seizure type misclassified as generalised onset (Marson 2000; Nolan 2016c; Nevitt 2017b). Given the potential biases introduced into those reviews, we examined the distribution of age at onset for individuals with generalised seizures in the trials included in this review, to assess the potential impact of misclassification of seizure type on the outcomes:

- 84 out of 86 individuals classified as having generalised onset seizures (98\%) in Craig 1994;

- 37 out of 71 individuals (52\%) in Heller 1995;

- 30 out of 136 (22\%) in Ramsay 1992;

- 2 out of $14(14 \%)$ in Shakir 1981; and

- 35 out of 77 (45\%) in Turnbull 1985.

Therefore, a total of up to 188 out of 384 individuals (49\%) classified as having generalised onset seizures may have had their seizure type misclassified (De Silva 1996 was a paediatric trial so no individuals over the age of 30 were recruited). Such a misclassification could bias our results against finding an interaction between treatment and seizure types (focal onset versus generalised onset). We undertook the following two analyses to investigate misclassification.
- We reclassified all individuals with generalised seizures and age at onset greater than 30 into an 'uncertain seizure type' group.

- We reclassified individuals with generalised seizures and age at onset greater than 30 as having focal onset seizures.

\section{Summary of findings and quality of the evidence (GRADE)}

For the 2013 update, in a post hoc change from protocol, we have added two 'Summary of findings' tables to the review (outcomes in the tables decided before the update started based on clinical relevance).

Summary of findings for the main comparison reports the primary outcome of 'time to treatment failure' in the subgroups of participants with focal onset seizures, generalised onset seizures and overall adjusted by epilepsy type.

Summary of findings 2 reports the secondary outcomes of 'time to first seizure' and 'time to 12-month remission' in the subgroups of participants with focal onset seizures, generalised onset seizures and overall adjusted by epilepsy type.

We determined the quality of the evidence using the GRADE approach (Schünemann 2013), where we downgraded evidence in the presence of high risk of bias in at least one trial, indirectness of the evidence, unexplained heterogeneity or inconsistency, imprecision of results and high probability of publication bias. We downgraded evidence by one level if the limitation was considered serious and two levels if considered very serious, as judged by the review authors.

\section{RE S U L T S}

\section{Description of studies}

\section{Results of the search}

We identified 334 records from the databases and search strategies outlined in Electronic searches. We found no further records by searching other resources. We removed 126 duplicate records and screened 208 records (title and abstract) for inclusion in the review. We excluded 178 records based on title and abstract and assessed 30 full-text articles for inclusion in the review. We excluded 19 studies from the review (see Excluded studies below) and included 11 trials in the review (see Included studies below). We updated the searches in May 2015, resulting in 35 hits. We removed seven duplicate records and screened 28 records (title and abstract); we excluded all 28 records.

For the 2018 update of this review we identified 129 records from the databases and search strategies outlined in Electronic searches. We removed 21 duplicate records and screened 108 records (title and abstract) for inclusion in the review. All 108 records were clearly irrelevant and we excluded them.

See Figure 1 for PRISMA study flow diagram for the eligibility screening of all studies identified in searches for all versions of this review (previous searches and the most recent search in February 2018). 
Figure 1. Study flow diagram.

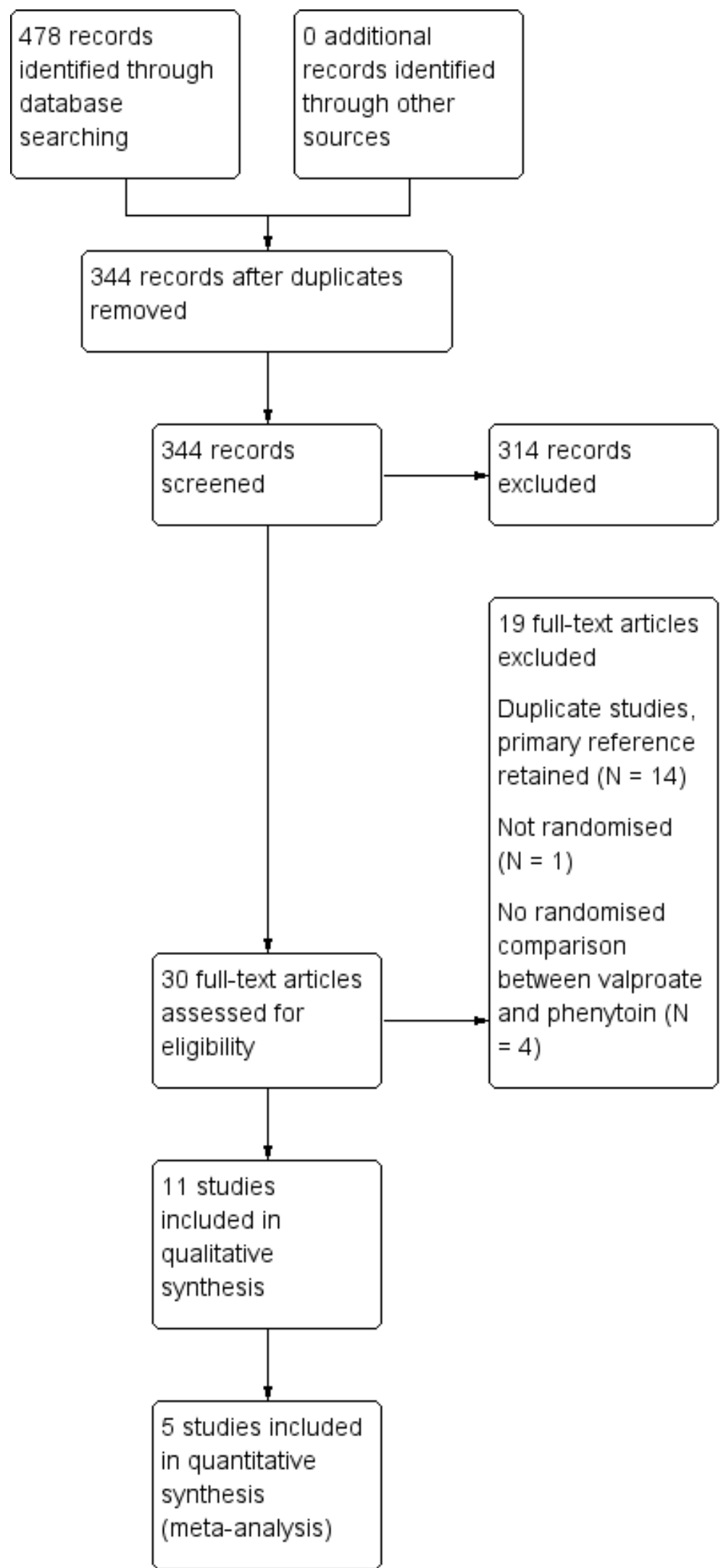




\section{Included studies}

We included 11 trials in the review (Callaghan 1985; Czapinski 1997a; Craig 1994; De Silva 1996; Forsythe 1991; Heller 1995; Ramsay 1992; Rastogi 1991; Shakir 1981; Thilothammal 1996; Turnbull 1985). One trial was available in abstract form only (Czapinski 1997a).

Four trials recruited individuals of all ages (Callaghan 1985; Ramsay 1992; Rastogi 1991; Shakir 1981), three trials recruited adults only (Czapinski 1997a; Heller 1995; Turnbull 1985), three trials recruited children only (De Silva 1996; Forsythe 1991; Thilothammal 1996), and one trial recruited elderly individuals only (Craig 1994).

One trial recruited individuals with focal onset seizures only (Czapinski 1997a), two trials recruited individuals with generalised onset seizures only (Ramsay 1992; Thilothammal 1996), seven trials recruited individuals with focal onset seizures and generalised onset seizures (Callaghan 1985; Craig 1994; De Silva 1996; Heller 1995; Rastogi 1991; Shakir 1981; Turnbull 1985), and one trial did not provide information on the seizure types of individuals recruited (Forsythe 1991).

Nine trials recruited individuals with new onset seizures only (Callaghan 1985; Craig 1994; Czapinski 1997a; De Silva 1996; Forsythe 1991; Heller 1995; Ramsay 1992; Thilothammal 1996; Turnbull 1985), 64\% of individuals in one trial had new onset seizures, while the remaining individuals had uncontrolled seizures on current therapy (Shakir 1981), and one trial did not specify whether individuals were newly diagnosed (Rastogi 1991). Seven trials were conducted in Europe (Callaghan 1985; Craig 1994; Czapinski 1997a; De Silva 1996; Forsythe 1991; Heller 1995; Turnbull 1985), one trial in the USA (Ramsay 1992), two trials in India (Rastog 1991; Thilothammal 1996), and one trial in two centres in Europe and New Zealand (Shakir 1981).

Individual participant data (IPD) were provided by trial authors for five trials which recruited a total of 669 participants, representing $60 \%$ of individuals from all 1119 eligible participants identified in eligible trials (Craig 1994; De Silva 1996; Heller 1995; Ramsay 1992; Turnbull 1985). Data were converted from paper format to computer datasets in two trials (Ramsay 1992; Turnbull 1985), computerised data were provided directly in one trial (Craig 1994), and a combination of both (although mostly computerised) were supplied by the authors of two trials (De Silva 1996; Heller 1995).
Data were available for the following participant characteristics (percentage of participants with data available): seizure type (100\%); gender (99.6\%) age at randomisation (99.3\%); number of seizures in the six months prior to randomisation (79\%); and epilepsy duration (i.e. time since first seizure to randomisation, $73 \%$ ). Electroencephalographic (EEG) data had been recorded for all five trials, but only computerised in two trials (Craig 1994; Turnbull 1985). Similar difficulties were encountered with computerised tomography/magnetic resonance imaging (CT/MRI) data available for only one trial (Turnbull 1985), and neurological examination findings, available for only two trials (De Silva 1996; Heller 1995). See the Characteristics of included studies tables, Table 1 and Table 2 for further details.

IIPD were not provided for the remaining six of these trials (Callaghan 1985; Czapinski 1997a; Forsythe 1991; Rastogi 1991; Shakir 1981; Thilothammal 1996), in which a total of 450 individuals had been randomised to either phenytoin or valproate. Sufficient participant level data were presented in the trial publications of Forsythe 1991 and Shakir 1981 to include these studies within the analysis of 'time to treatment failure' (see Data extraction and management and Effects of interventions). We could not extract sufficient aggregate data from the trial publication in any other trial, or for any other outcomes to include in data synthesis. Full details of outcomes considered and a summary of results of each trial for which IPD were not available to us can be found in Table 3 .

\section{Excluded studies}

We excluded 14 duplicate trials (Berg 1993; Callaghan 1981; Callaghan 1983; Callaghan 1984; Craig 1993; Czapinski 1997b; Czapinski 1997c; Goggin 1984; Goggin 1986; Shakir 1980; Tallis 1994a; Tallis 1994b; Turnbull 1982; Wilder 1983), and we retained the most relevant primary reference for each trial in the review. One trial was not randomised (Zeng 2010), and four did not make a randomised comparison between valproate and phenytoin (Jannuzzi 2000; Kaminow 2003; Sabers 1995; Schmidt 2007; see Characteristics of excluded studies for detailed reasons for exclusion).

\section{Risk of bias in included studies}

For further details see Characteristics of included studies, Figure 2 and Figure 3. 
Figure 2. 'Risk of bias' graph: review authors' judgements about each risk of bias item presented as percentages across all included studies.

Random sequence generation (selection bias)

Allocation concealment (selection bias)

Blinding of participants and personnel (performance bias)

Blinding of outcome assessment (detection bias)

Incomplete outcome data (attrition bias)

Selective reporting (reporting bias)

Other bias
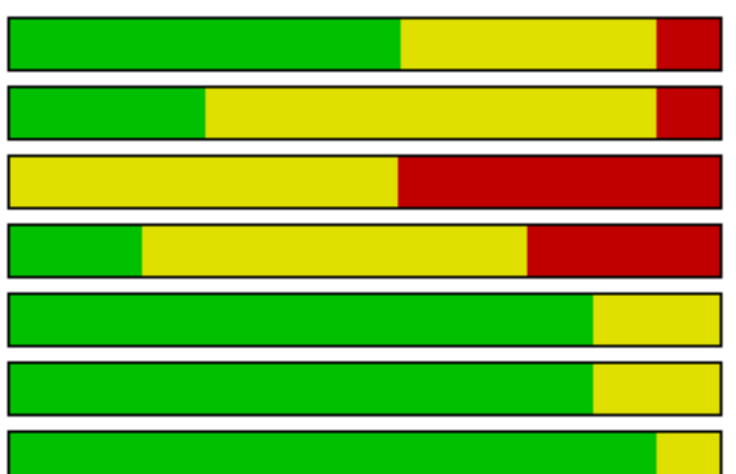

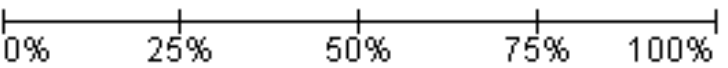

Low risk of bias

Unclear risk of bias

High risk of bias 
Figure 3. 'Risk of bias' summary: review authors' judgements about each risk of bias item for each included study.

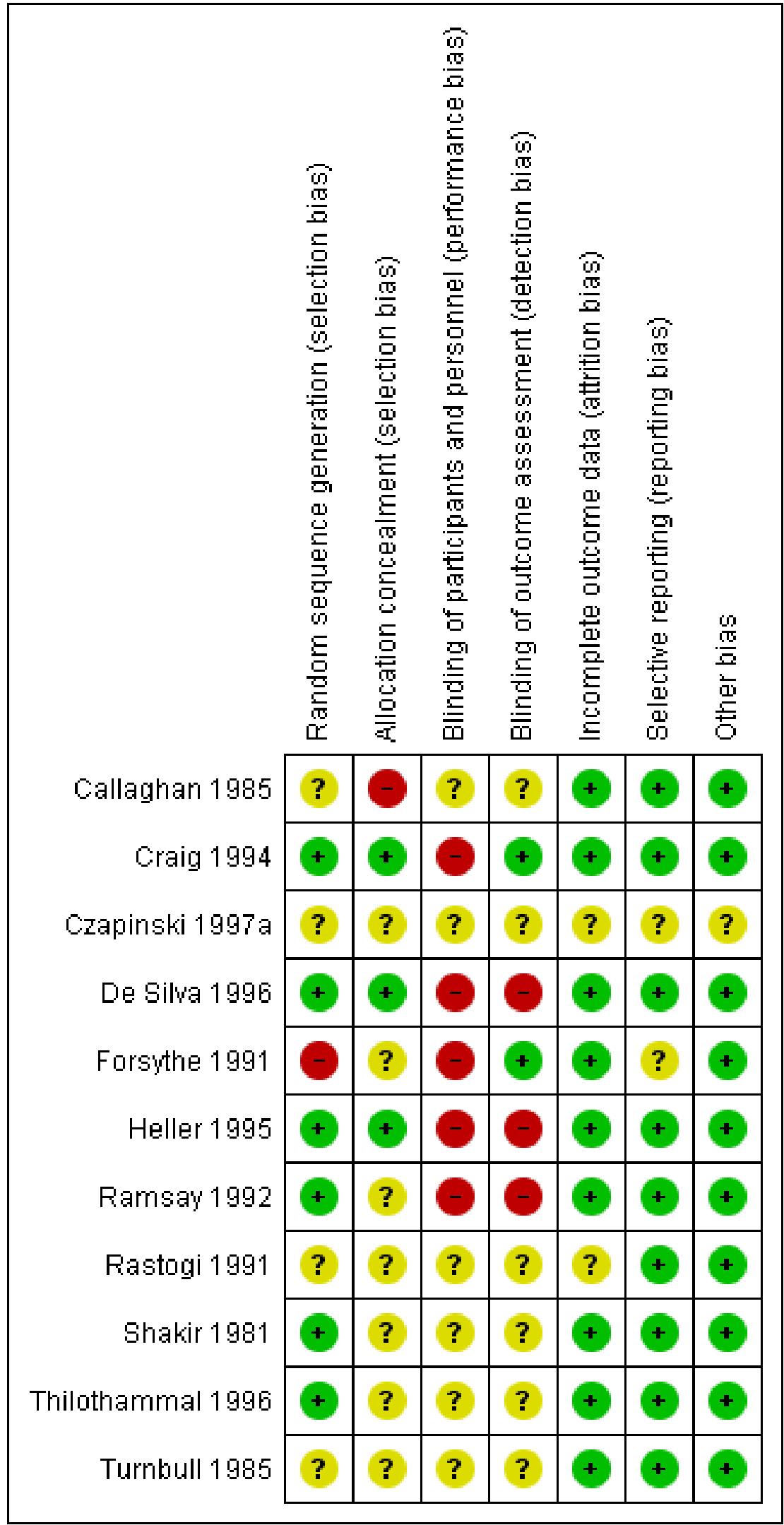

Sodium valproate versus phenytoin monotherapy for epilepsy: an individual participant data review (Review) 


\section{Allocation}

\section{(1) Trials for which individual participant data (IPD) were provided}

Three trials reported adequate methods of randomisation and allocation concealment; two trials used permuted blocks to generate a random list and concealed allocation by using sealed opaque envelopes (De Silva 1996; Heller 1995). One trial used a computer minimisation programme and a pharmacy-controlled allocation (Craig 1994); we judged these trials to be at low risk of bias for random sequence generation and allocation concealment. One trail reported that random number tables were used but did not report sufficient information about methods of allocation concealment (Ramsay 1992). One trial did not report sufficient information about methods of randomisation and allocation concealment (Turnbull 1985).

\section{(2) Trials for which no IPD were available}

Two trials reported adequate methods of randomisation: telephone randomisation in Shakir 1981, and a computergenerated list of randomised numbers in Thilothammal 1996; we judged these studies at low risk of bias for random sequence generation. Two trials reported no information on methods of randomisation (Czapinski 1997a; Rastogi 1991) (unclear risk of bias), one trial reported unclear information on randomisation (Callaghan 1985) (unclear risk of bias), and one trial reported an inadequate method of randomisation, i.e. quota allocation (Forsythe 1991) (high risk of bias). We judged five of the six trials to be at unclear risk of bias as they reported no information on allocation concealment (Czapinski 1997a; Forsythe 1991; Rastogi 1991; Shakir 1981; Thilothammal 1996), and one trial at high risk of bias as it reported an inadequate method of allocation concealment based on 'drug of first preference' (Callaghan 1985).

\section{Blinding}

\section{(1) Trials for which IPD were provided}

One trial was single-blinded (outcome assessor for cognitive testing) (Craig 1994) (low risk of bias), three trials were unblinded for "practical and ethical reasons" (De Silva 1996; Heller 1995; Ramsay 1992) (high risk of bias), and one trial provided no information on blinding (Turnbull 1985) (unclear risk of bias).

\section{(2) Trials for which no IPD were available}

One trial was described as double-blinded (Thilothammal 1996) but it was unclear who was blinded, one trial was single-blinded (outcome assessor for cognitive testing) (Forsythe 1991), and no information was provided on blinding in the other trials (Callaghan 1985; Czapinski 1997a; Rastogi 1991; Shakir 1981).

\section{Incomplete outcome data}

\section{(1) Trials for which IPD were provided}

In theory, a review using IPD should overcome issues of attrition bias, as unpublished data can be provided, unpublished outcomes calculated and all randomised participants can be analysed by an intention-to-treat approach. All five trials reported attrition rates and provided IPD for all randomised individuals (Craig 1994; De Silva 1996; Heller 1995; Ramsay 1992; Turnbull 1985); we judged all five trials at low risk of attrition bias.

\section{(2) Trials for which no IPD were available}

Four trials reported attrition rates and analysed all randomised participants using an intention-to-treat approach (Callaghan 1985; Forsythe 1991; Shakir 1981; Thilothammal 1996); low risk of attrition bias. Two trials did not provide sufficient information to assess attrition bias (Czapinski 1997a; Rastogi 1991); unclear risk of attrition bias.

\section{Selective reporting}

The authors of Craig 1994 provided a protocol; the outcomes specified in the protocol were consistent with the outcomes reported in the publication, and we therefore judged the risk of selective reporting bias to be low. Protocols were not available for any of the other 10 included trials so we made a judgement of the risk of bias based on the information included in the publications (see Characteristics of included studies for more information). We judged eight of the other 10 studies at low risk of reporting bias; Czapinski 1997a and Forsythe 1991 were judged at unclear risk of reporting bias.

\section{(1) Trials for which IPD were provided}

In theory, a review using IPD should overcome issues of reporting biases, as unpublished data can be provided and unpublished outcomes calculated. Sufficient IPD were provided to calculate the four outcomes: 'time to treatment failure', 'time to achieve sixmonth remission', 'time to achieve 12-month remission' and 'time to first seizure' for four of the five trials (De Silva 1996; Heller 1995; Ramsay 1992; Turnbull 1985). Treatment failure information was not provided for one trial (Craig 1994), so we could not calculate 'time to treatment failure', but we had sufficient information to calculate the other three outcomes.

\section{(2) Trials for which no IPD were available}

Seizure outcomes and adverse events were well reported in four trials (Callaghan 1985; Rastogi 1991; Shakir 1981; Thilothammal 1996); low risk of reporting bias. One trial reported cognitive outcomes and adverse events, but no seizure outcomes (Forsythe 1991); however as no protocol was available for this trial we do not know whether seizure outcomes were planned a priori, and we judged this trial at unclear risk of reporting bias. One trial was in abstract form only and did not provide sufficient information to assess selective reporting bias (Czapinski 1997a); also judged at unclear risk of reporting bias.

\section{Other potential sources of bias}

We detected no other potential sources of bias in any of the 10 of the 11 trials included in the review, however limited information was available for Czapinski 1997a which was only available as an abstract so we judged this trial to be at unclear risk of other bias.

\section{Effects of interventions}

See: Summary of findings for the main comparison Sodium valproate compared with phenytoin monotherapy for epilepsy (primary outcome); Summary of findings 2 Sodium valproate compared with phenytoin monotherapy for epilepsy (secondary outcomes)

A summary of the outcomes reported in trials for which no IPD were available are reported in Table 3. 
See Table 4 for details regarding the number of individuals (with IPD) contributing to each analysis, Summary of findings for the main comparison for a summary of the results for the primary outcome 'time to treatment failure' (stratified by epilepsy type), and Summary of findings 2 for a summary of results for the secondary outcomes 'time to first seizure' and 'time to 12-month remission'. Survival curve plots are shown in Figure 4; Figure 5; Figure 6; Figure 7; Figure 8; Figure 9; Figure 10; Figure 11; Figure 12; Figure 13; Figure 14 and Figure 15. All survival curve plots were produced in Stata software version 14 (Stata 2015). using data from all trials providing IPD combined.

Figure 4. Time to treatment failure - any reason related to the treatment (PHT: phenytoin; SV: sodium valproate)

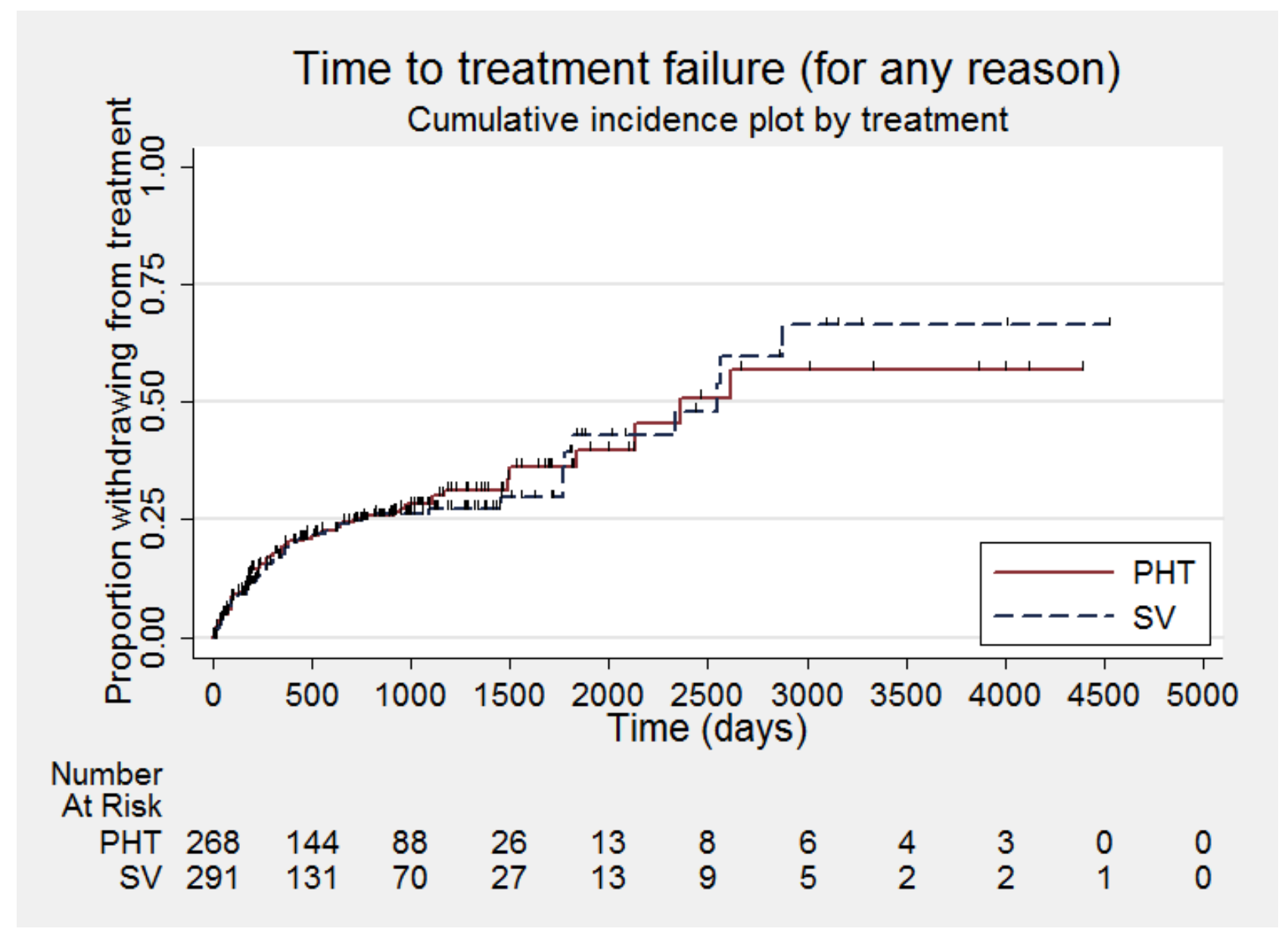


Figure 5. Time to treatment failure - any reason related to the treatment, by epilepsy type (PHT: phenytoin; SV: sodium valproate)

\section{Time to treatment failure (for any reason) \\ Cumulative incidence plot by treatment}
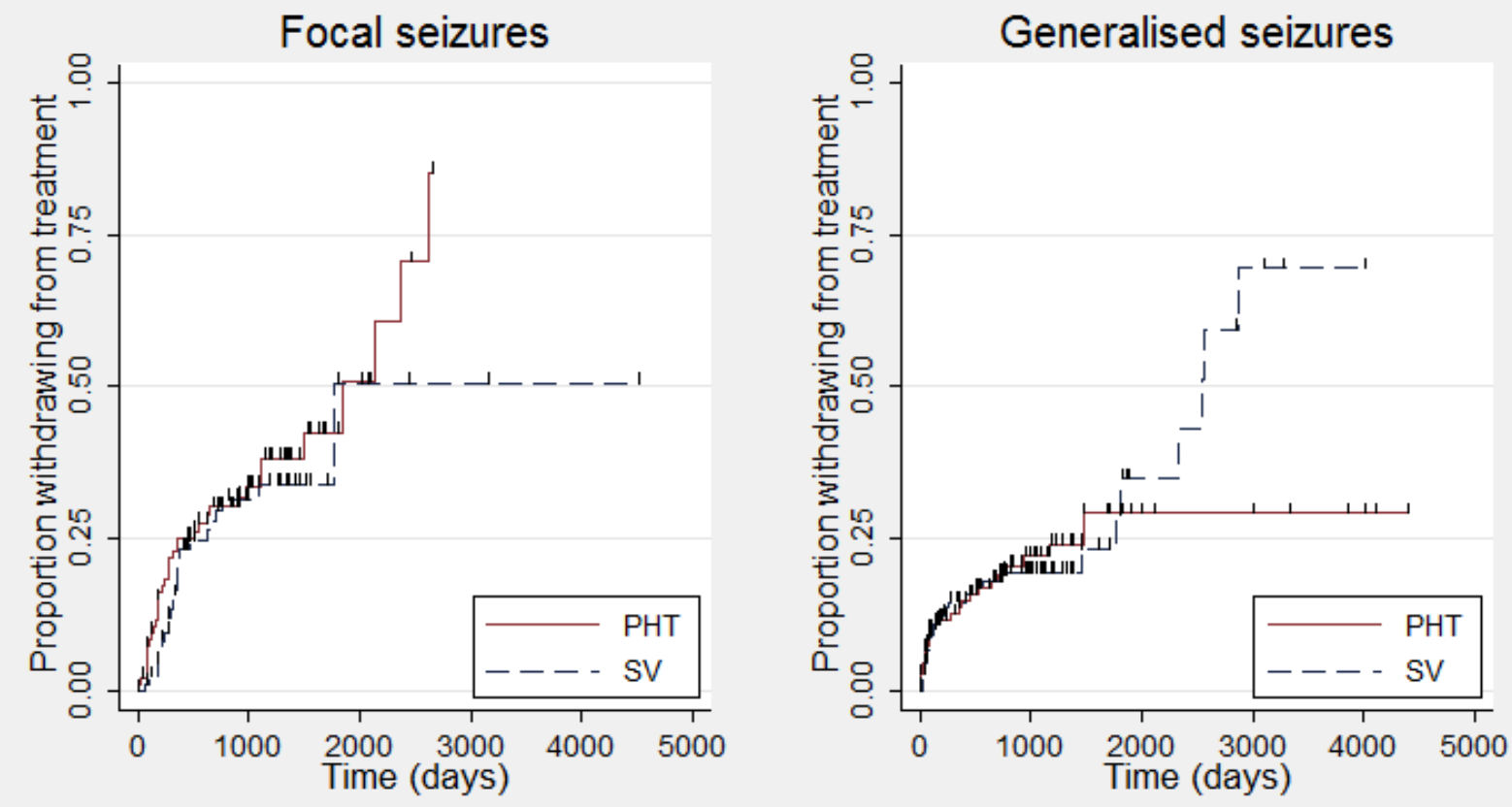

Number

At Risk

PHT 97

SV 90

38

6

0

$\begin{array}{ll}0 & 0 \\ 1 & 0\end{array}$

Number

At Risk

PHT151

SV180

50

7

6 
Figure 6. Time to treatment failure due to adverse events (PHT: phenytoin; SV: sodium valproate)

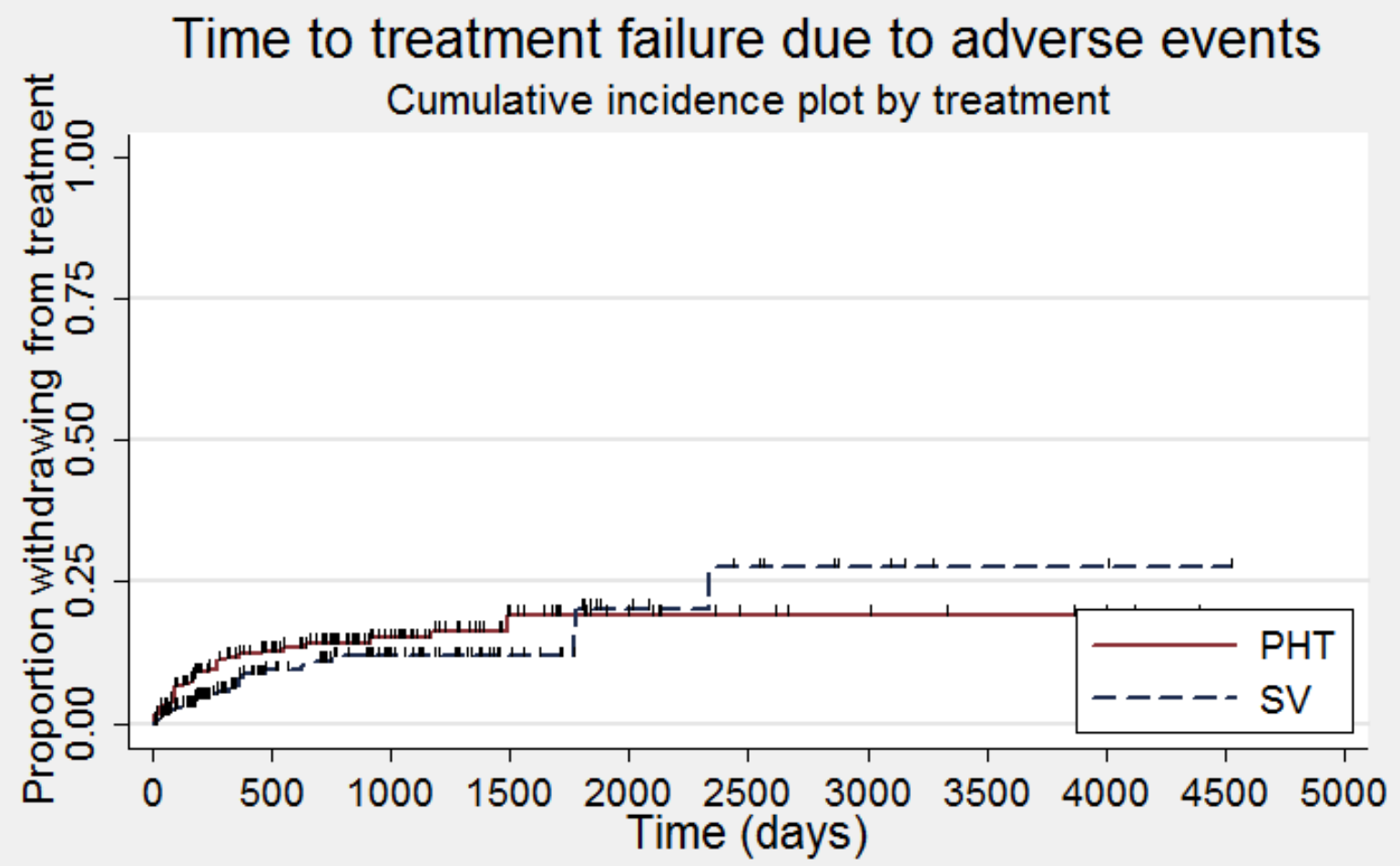

Number

At Risk

$\begin{array}{rlllllllllll}\text { PHT } & 268 & 144 & 88 & 26 & 13 & 8 & 6 & 4 & 3 & 0 & 0 \\ \text { SV } & 291 & 131 & 70 & 27 & 13 & 9 & 5 & 2 & 2 & 1 & 0\end{array}$


Figure 7. Time to treatment failure due to adverse events, by epilepsy type (PHT: phenytoin; SV: sodium valproate)

\section{Time to treatment failure due to adverse events Cumulative incidence plot by treatment}
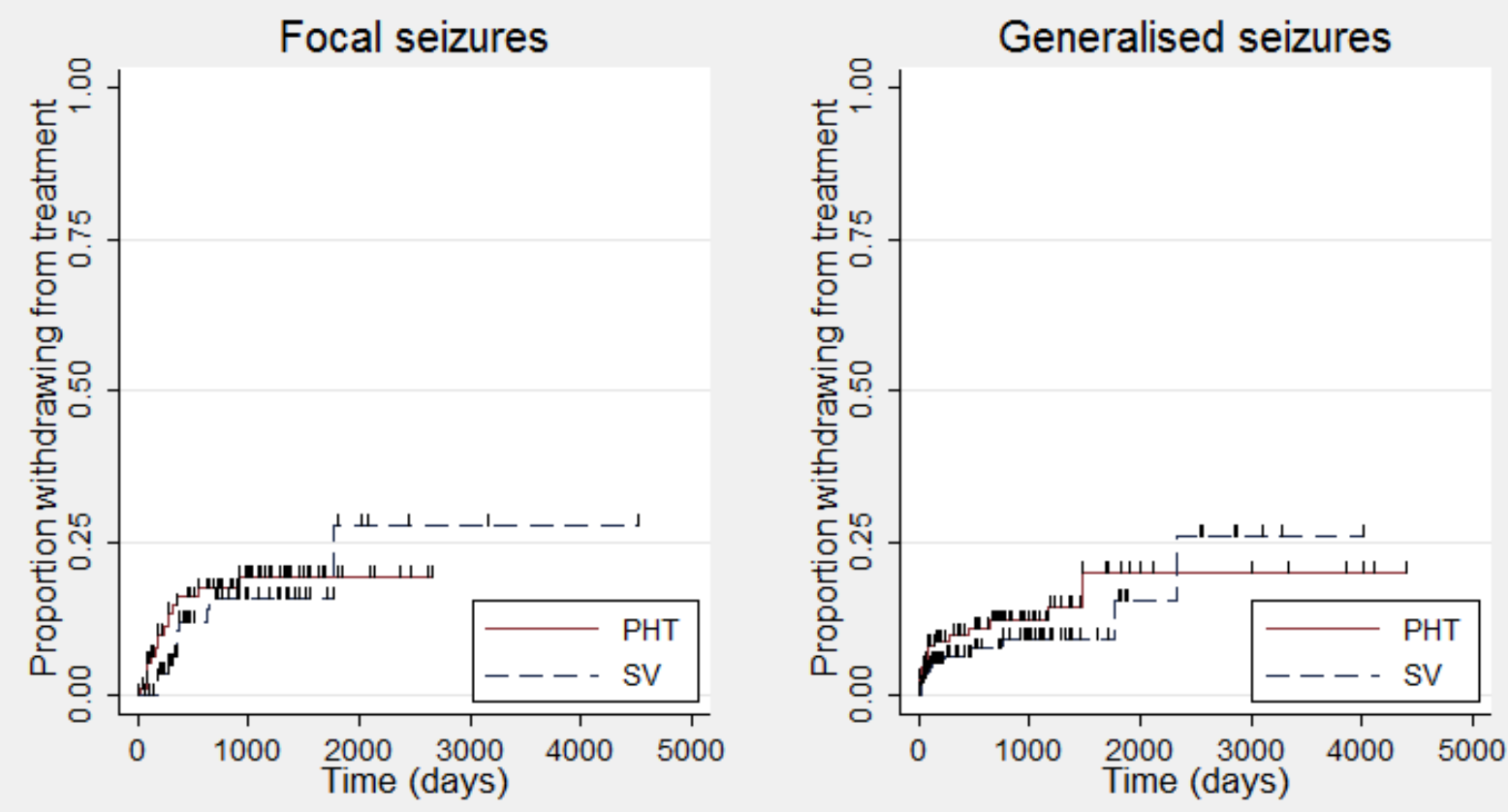

Number

At Risk

$\begin{array}{llllll}\text { PHT } 97 & 38 & 6 & 0 & 0 & 0 \\ \text { SV } 90 & 27 & 5 & 2 & 1 & 0\end{array}$

Number

At Risk

SV $90 \quad 27 \quad 5 \quad 2 \quad 2 \quad 1 \quad 0$

PHT151

SV 180

50

43

7
8

6

3

0

0 
Figure 8. Time to treatment failure due to lack of efficacy (PHT: phenytoin; SV: sodium valproate)

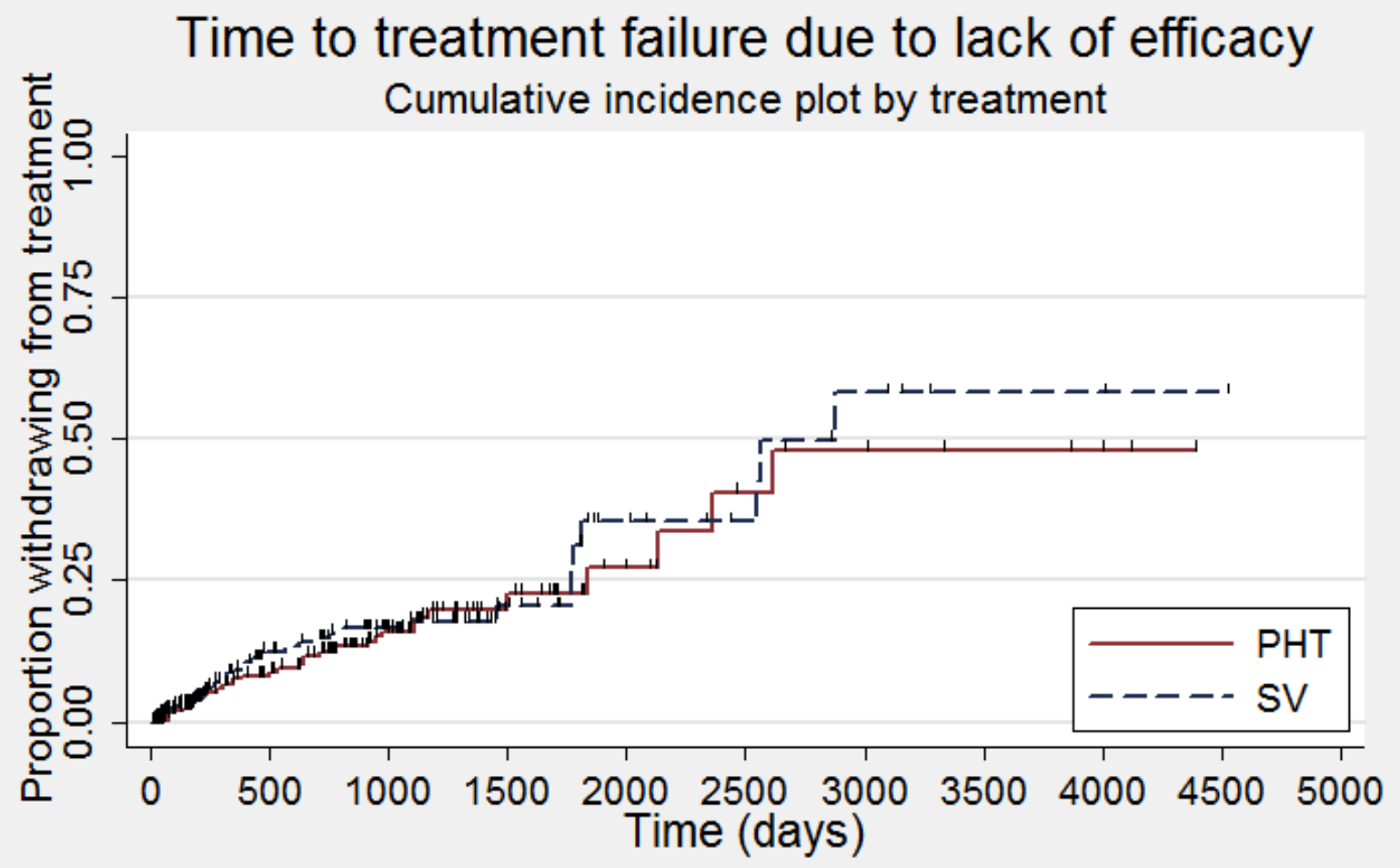

Number

At Risk

$\begin{array}{rlllllllllll}\text { PHT } & 268 & 144 & 88 & 26 & 13 & 8 & 6 & 4 & 3 & 0 & 0 \\ \text { SV } & 291 & 131 & 70 & 27 & 13 & 9 & 5 & 2 & 2 & 1 & 0\end{array}$


Figure 9. Time to treatment failure due to lack of efficacy, by epilepsy type (PHT: phenytoin; SV: sodium valproate)

\section{Time to treatment failure due to lack of efficacy Cumulative incidence plot by treatment}
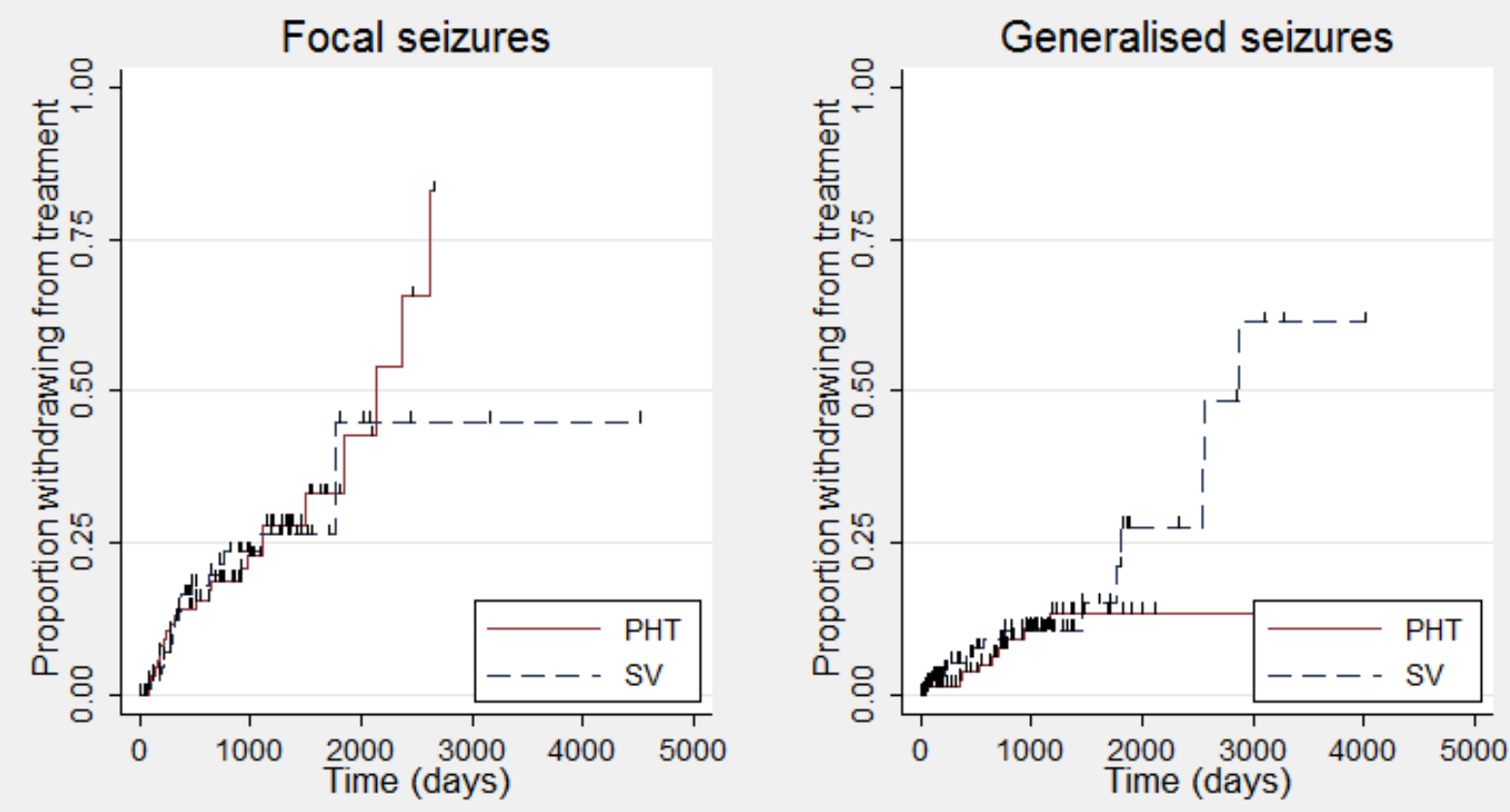

Number

At Risk

PHT 97

SV 90

38
27

$\begin{array}{ll}6 & 0 \\ 5 & 2\end{array}$

$\begin{array}{ll}0 & 0 \\ 1 & 0\end{array}$

At Risk

PHT 151

SV180

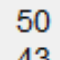

50
43

7

6

3

0

(1) 
Figure 10. Time to first seizure (PHT: phenytoin; SV: sodium valproate)

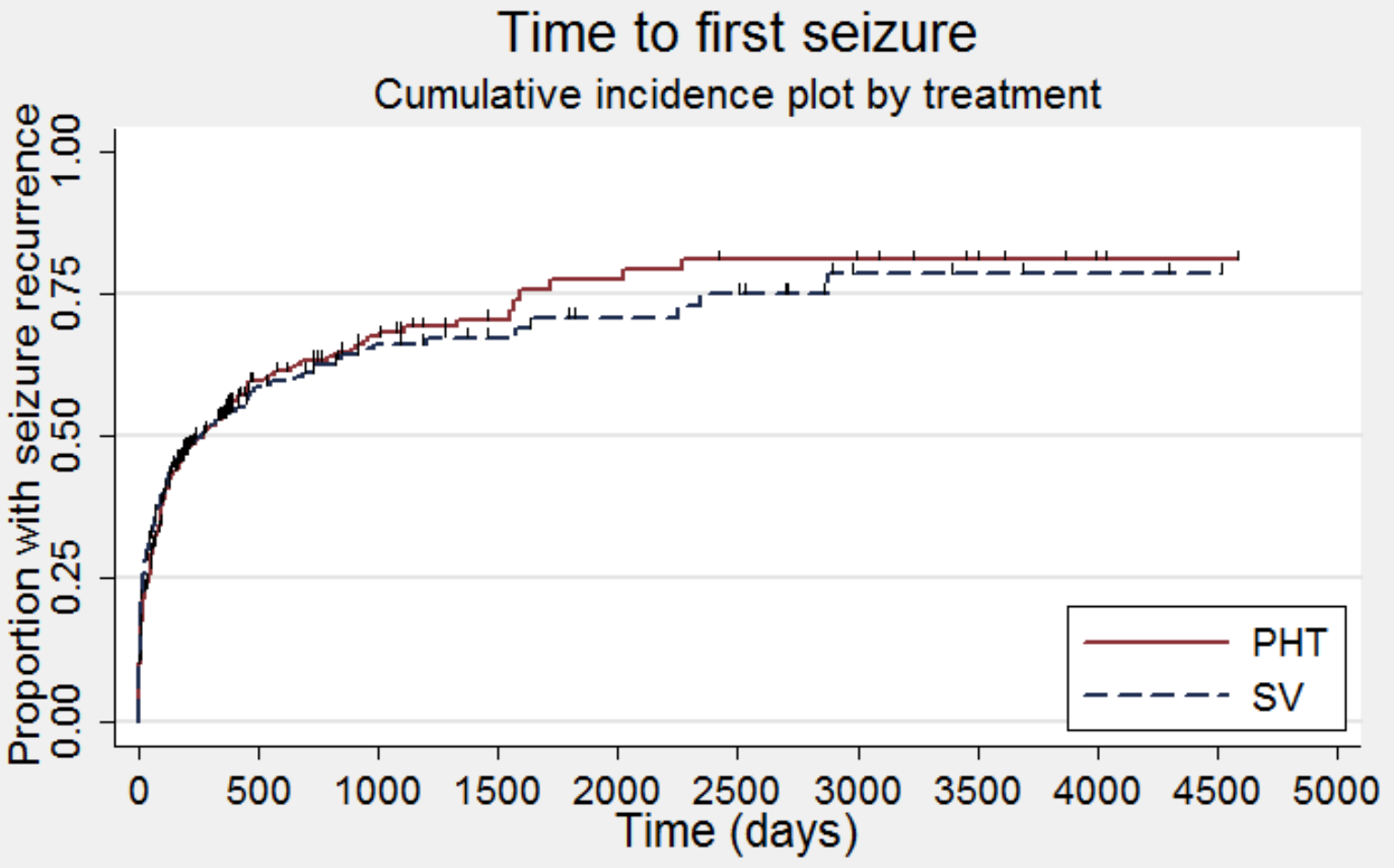

Number

At Risk

$\begin{array}{rlllllllllll}\text { PHT } & 306 & 65 & 44 & 17 & 13 & 10 & 9 & 6 & 2 & 1 & 0 \\ \text { SV } & 333 & 63 & 35 & 19 & 14 & 12 & 4 & 3 & 2 & 1 & 0\end{array}$


Figure 11. Time to first seizure - by epilepsy type. (PHT: phenytoin; SV: sodium valproate)

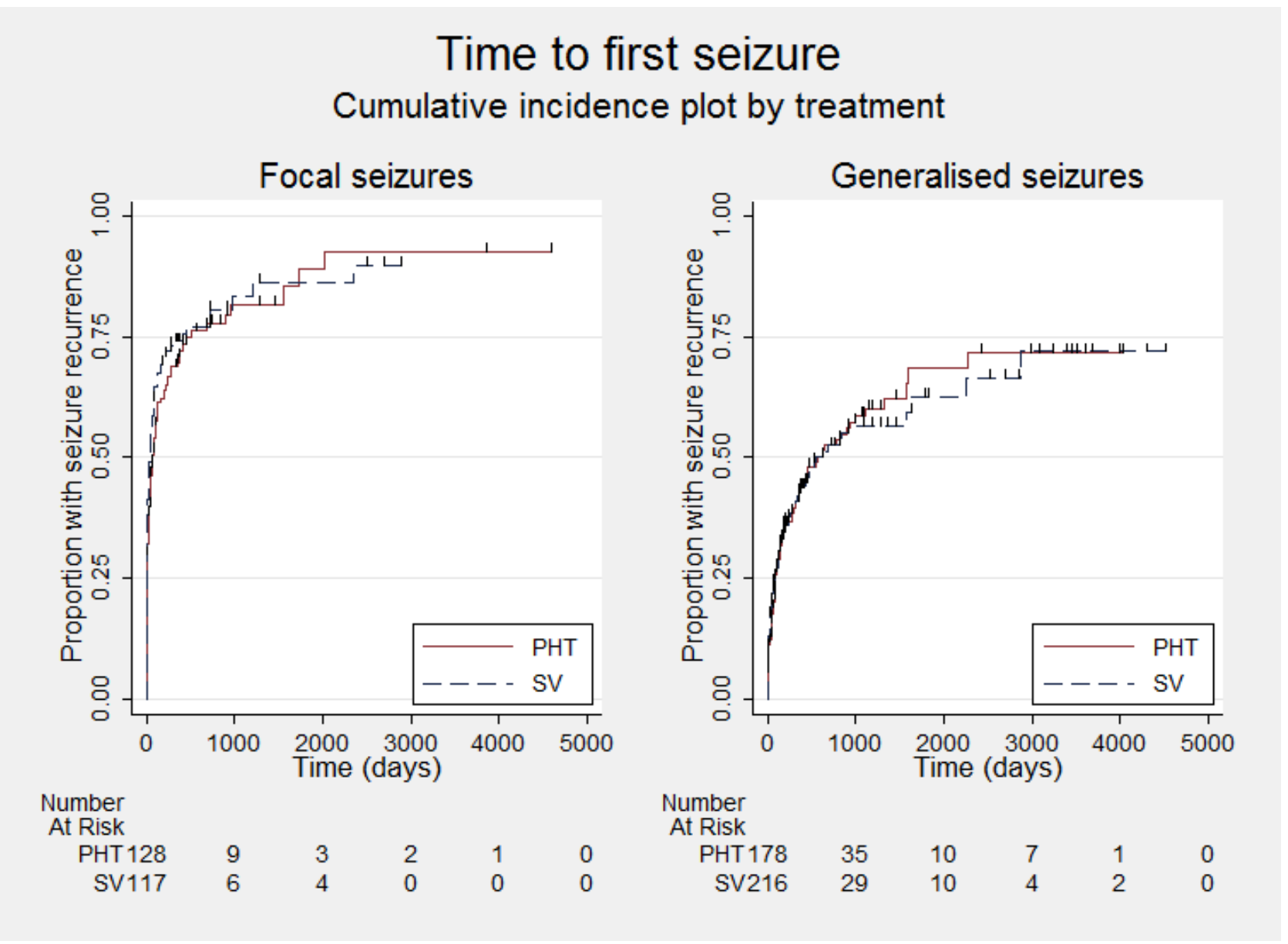


Figure 12. Time to achieve 12-month remission (PHT: phenytoin; SV: sodium valproate)

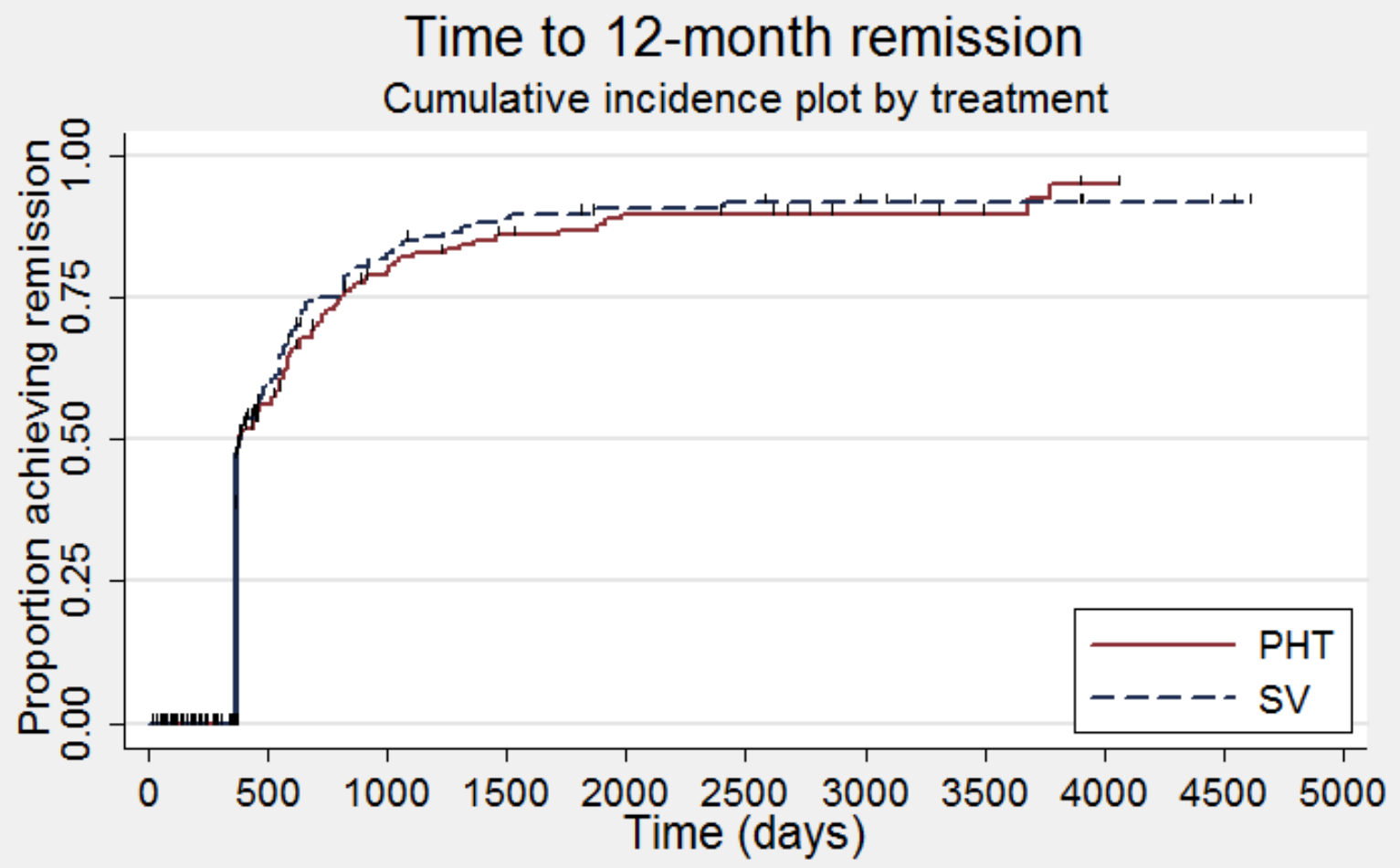

Number

At Risk

$\begin{array}{rrrrrrrrrrrr}\text { PHT } & 258 & 70 & 27 & 17 & 11 & 10 & 6 & 4 & 1 & 0 & 0 \\ \text { SV } & 256 & 58 & 24 & 14 & 10 & 9 & 7 & 5 & 3 & 2 & 0\end{array}$


Figure 13. Time to achieve 12-month remission - by epilepsy type. (PHT: phenytoin; SV: sodium valproate)

\section{Time to 12 month remission \\ Cumulative incidence plot by treatment}
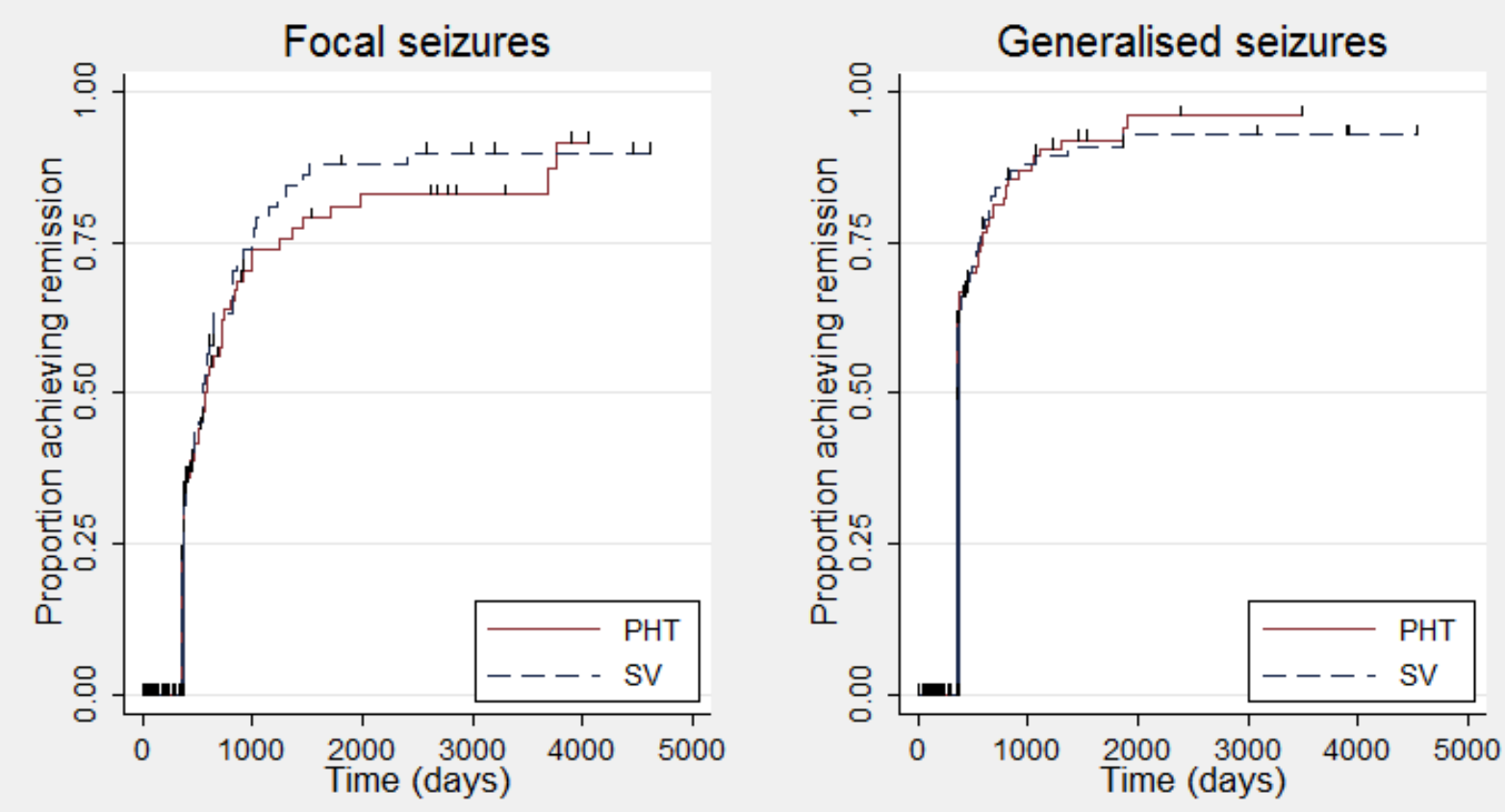

Number

At Risk

$\begin{array}{llllll}\text { PHT 128 } & 16 & 9 & 5 & 1 & 0\end{array}$

Number

At Risk

$\begin{array}{llllll}\text { SV } 117 & 15 & 6 & 3 & 2 & 0\end{array}$

PHT130

SV 139

11

2

$1 \quad 0$

0

0 
Figure 14. Time to achieve six-month remission (PHT: phenytoin; SV: sodium valproate)

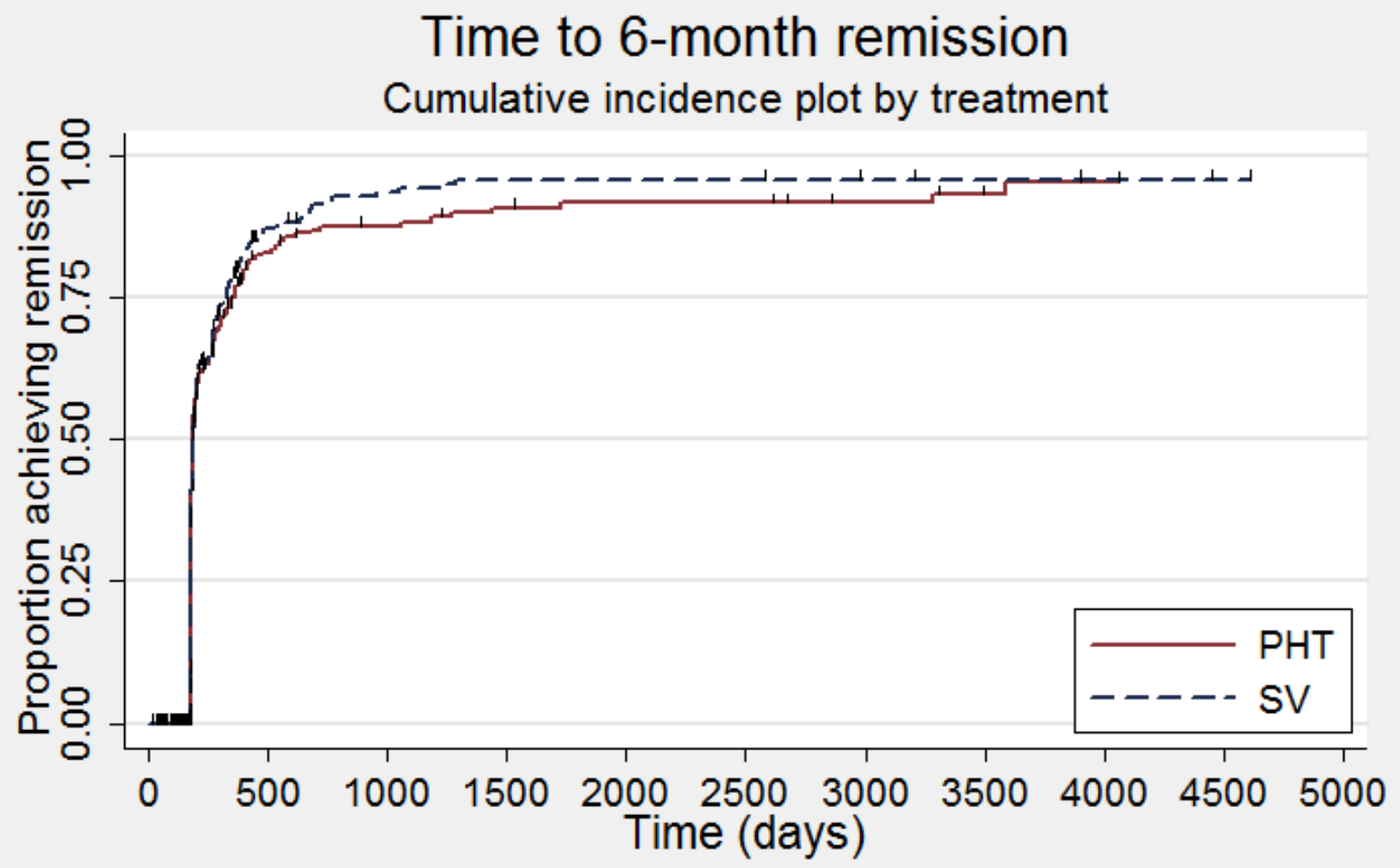

Number

At Risk

$\begin{array}{rccccccccccc}\text { PHT } & 306 & 27 & 17 & 12 & 9 & 9 & 6 & 3 & 1 & 0 & 0 \\ \text { SV } & 333 & 20 & 9 & 6 & 6 & 6 & 4 & 3 & 2 & 1 & 0\end{array}$


Figure 15. Time to achieve six-month remission (PHT: phenytoin; SV: sodium valproate)

\section{Time to six month remission \\ Cumulative incidence plot by treatment}

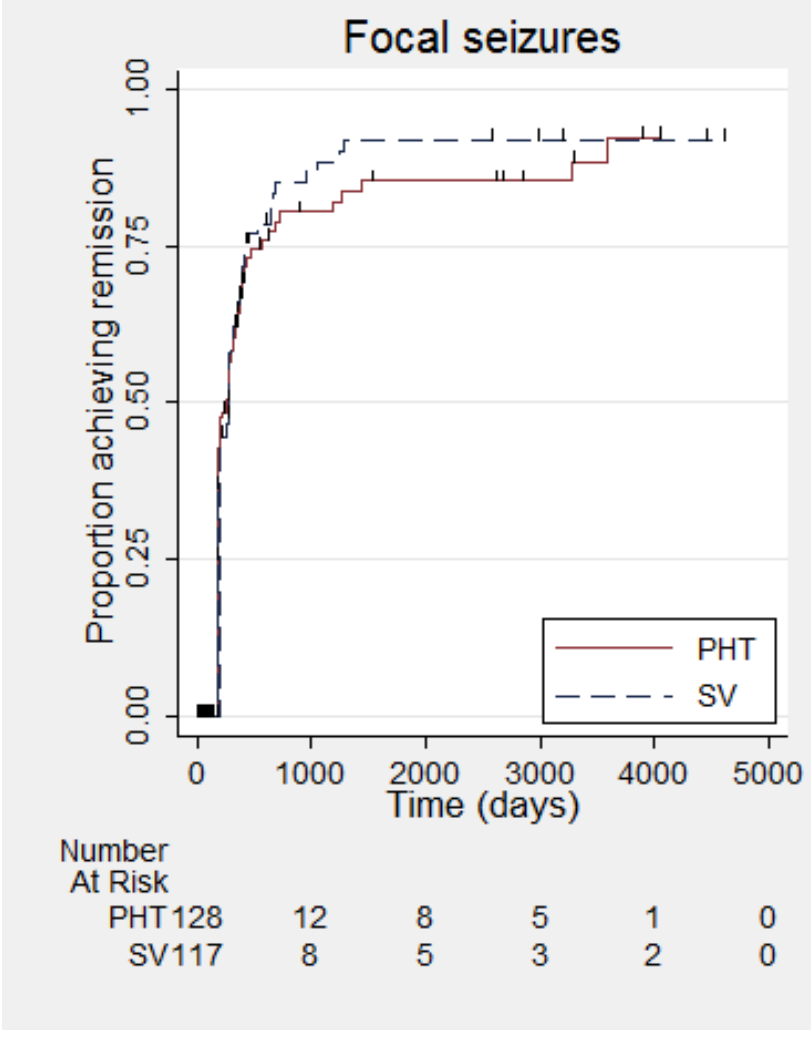

We note that participants with event times of zero (i.e. those who experienced treatment failure or experienced seizure recurrence on the day of randomisation) are not included in the 'numbers at risk' on the graphs and that data is not stratified by trial within these survival curve plots. All figures are intended to provide a visual representation of outcomes, extent of follow-up and visual differences between seizure types. These graphs are not intended to show statistical significance and numerical values may vary compared to the text due to differences in methodology.

We calculated all HRs presented below by generic inverse variance fixed-effect meta-analysis unless otherwise stated. All analyses met the assumption of proportional hazards (the addition of a timevarying covariate into the model was non-significant).

\section{Primary outcome}

\section{Time to treatment failure (retention time)}

For this outcome, a HR less than one indicates a clinical advantage for valproate.

Time to treatment failure and reason for treatment withdrawal or treatment failure were available for 495 individuals from four trials (De Silva 1996; Heller 1995; Ramsay 1992; Turnbull 1985); $74 \%$ of individuals from five trials providing IPD (44\% of all 1119 eligible individuals). Treatment failure data were not available for the fifth trial (Craig 1994). Sufficient IPD were available in the trial

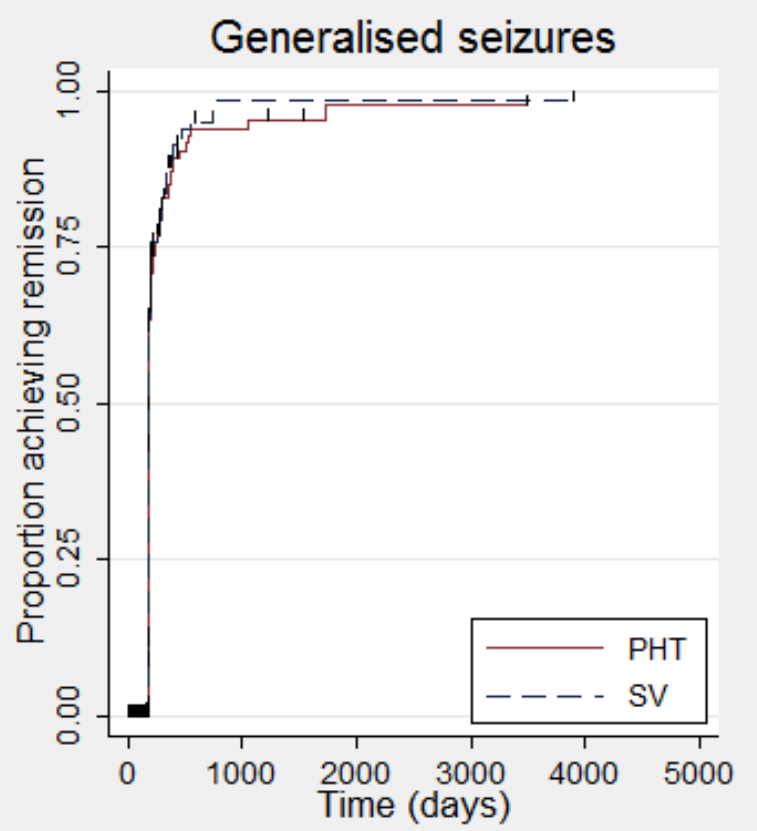

Number

At Risk

$\begin{array}{llllll}\text { PHT178 } & 5 & 1 & 1 & 0 & 0\end{array}$


of total treatment failures) on valproate and 26 (21\% of total treatment failures) on phenytoin.

We classed the other 105 reasons (53 on valproate and 52 on phenytoin), which were mostly withdrawal from treatment due to seizure remission ( $64 \%$ of other withdrawals), to be not related to the treatment and censored these participants in the analysis, in addition to the 328 participants (178 on valproate and 150 on carbamazepine) who completed the trial without withdrawing or failing treatment.

Considering time to treatment failure for any reason related to the treatment, the overall pooled $\mathrm{HR}$ (for 569 participants providing IPD from 6 trials) was 0.94 (95\% confidence interval $(\mathrm{Cl}) 0.67$ to $1.32, \mathrm{P}=$ 0.17 ; moderate-quality evidence) indicating no clear advantage for either drug (Analysis 1.1). No important heterogeneity was present between trials $(12=15 \%)$.

Considering time to treatment failure due to adverse events (all other reasons for treatment failure or treatment withdrawal censored in analysis), 495 participants provided IPD from four trials; no participants withdrew from one or both of the drugs due to lack of efficacy in two of the trials (Forsythe 1991; Shakir 1981, see Table 5). The overall pooled HR was $0.68(95 \% \mathrm{Cl} 0.40$ to $1.17, \mathrm{P}=$ 0.16 ; moderate-quality evidence) which suggests a slight advantage towards valproate (i.e. a suggestion that treatment failures due to adverse events may occur later on valproate than on phenytoin), but this is not statistically significant (Analysis 1.2). A substantial amount of heterogeneity was present between trials $(12=67 \%)$ and when analysis is repeated with random-effects, the $\mathrm{Cls}$ of the pooled HR are substantially wider $0.75(95 \% \mathrm{Cl} 0.28$ to 1.98$)$. This heterogeneity is investigated further in subgroup analysis by epilepsy type below.

Considering time to treatment failure due to lack of efficacy (all other reasons for treatment failure or treatment withdrawal censored in analysis), the overall pooled HR (for 569 participants providing IPD from 6 trials) was $1.23(95 \% \mathrm{Cl} 0.77$ to 1.97 , $P=0.38$; moderate-quality evidence) which suggests a slight advantage towards phenytoin (i.e. a suggestion that treatment failures due to lack of efficacy may occur later on phenytoin than on valproate), but this is not statistically significant (Analysis 1.3). No heterogeneity was present between trials $(12=0 \%)$.

\section{Subgroup analyses: epilepsy type (focal versus generalised onset)}

Treatment failure data for 41 participants extracted from Forsythe 1991 did not distinguish between epilepsy type (focal onset or generalised onset) and therefore could not be included in the metaanalysis stratified by epilepsy type.

Considering time to treatment failure for any reason related to the treatment, the overall pooled HR (adjusted by epilepsy type for 528 participants from 5 trials) was $0.88(95 \% \mathrm{Cl} 0.61$ to $1.27, \mathrm{P}=0.51$, $\mathrm{I}=$ 29\%; moderate-quality evidence; Analysis 1.4). This result is similar to the unadjusted pooled HR (Analysis 1.1), and conclusions remain unchanged following the exclusion of 41 individuals in the stratified analysis (Forsythe 1991).

For individuals with generalised onset seizures (341 participants from 5 trials), the pooled HR was $0.94(95 \% \mathrm{Cl} 0.55$ to $1.61, \mathrm{P}=$ $0.82, \mathrm{I}^{2}=59 \%$; (ow-quality evidence), indicating no clear advantage for either drug. For individuals with focal onset seizures (187 participants from 4 trials), the pooled $\mathrm{HR}$ was $0.83(95 \% \mathrm{Cl} 0.50$ to $1.38, P=0.48, I^{2}=0 \%$; moderate-quality evidence), suggesting a slight advantage for valproate which is not statistically significant. There was no evidence of an interaction between epilepsy type (focal onset versus generalised onset) and treatment effect $\left(\mathrm{Chi}^{2}=\right.$ $0.10, \mathrm{df}=1, \mathrm{P}=0.75, \mathrm{I}^{2}=0 \%$; Analysis 1.4).

A large amount of heterogeneity was present between trials within the generalised onset seizure subgroup $\left(I^{2}=59 \%\right)$ and when analysis is repeated with random-effects, the $\mathrm{Cls}$ of the pooled $\mathrm{HR}$ become much wider: 0.93 (95\% $\mathrm{Cl} 0.37$ to 231 ). On visual inspection of the forest plot (see Analysis 1.4), one trial appears to be the source of this variability (Heller 1995), as this trial shows a large statistically significant treatment effect in favour of phenytoin, while the other four trials show general non-significant results, mostly in favour of valproate (De Silva 1996; Ramsay 1992; Shakir 1981; Turnbull 1985). Additionally, this heterogeneity may be due to misclassification of epilepsy type (specifically where generalised onset seizures have been incorrectly classified); this is investigated further in sensitivity analysis below.

Considering time to treatment failure due to adverse events, no individuals withdrew from either drug due to adverse events in Shakir 1981 so this trial is not included in this analysis and no individuals with generalised onset seizures withdrew from valproate due to adverse events in Turnbull 1985 so this epilepsy type subgroup was not included in this analysis. The overall pooled HR (adjusted by epilepsy type for 418 participants from 4 trials) was $0.77(95 \% \mathrm{Cl} 0.44$ to $1.37, \mathrm{P}=0.38, \mathrm{l} 2=37 \%$; moderate-quality evidence; Analysis 1.5). This result is similar to the unadjusted pooled HR (Analysis 1.2), and conclusions remain unchanged following the exclusion of participants from Shakir 1981 and Turnbull 1985.

For individuals with generalised onset seizures (250 participants from 3 trials), the pooled $\mathrm{HR}$ was $0.75(95 \% \mathrm{Cl} 0.35$ to $1.60, \mathrm{P}=$ $0.46, I^{2}=71 \%$; low-quality evidence), suggesting a slight advantage for valproate which is not statistically significant. For individuals with focal onset seizures (168 participants from 3 trials), the pooled HR was $0.81\left(95 \% \mathrm{Cl} 0.34\right.$ to $1.90, \mathrm{P}=0.62, \mathrm{I}^{2}=0 \%$; moderatequality evidence), again suggesting a slight advantage for valproate which is not statistically significant. There was no evidence of an interaction between epilepsy type (focal onset versus generalised onset) and treatment effect $\left(\mathrm{Chi}^{2}=0.02, \mathrm{df}=1, \mathrm{P}=0.90, \mathrm{I}^{2}=0 \%\right.$; Analysis 1.5).

Again, a large amount of heterogeneity was present between trials within the generalised onset seizure subgroup $\left(I^{2}=71 \%\right)$, and when analysis is repeated with random-effects, the $\mathrm{Cls}$ of the pooled HR are substantially wider 1.15 ( $95 \% \mathrm{Cl} 0.21$ to 6.23$)$. This variability may also originate from fairly small numbers of individuals with generalised seizures failing treatment due to adverse events (see Table 5), or similarly to the analysis of 'time to treatment failure' for any reason related to treatment, this may be due to potential misclassification of epilepsy type; this is investigated further in sensitivity analysis below.

Considering time to treatment failure due to lack of efficacy, no individuals with generalised onset seizures withdrew from either drug due to lack of efficacy in Turnbull 1985 so this epilepsy type subgroup was not included in this analysis. The overall pooled HR (adjusted by epilepsy type for 451 participants from 5 trials) was $1.16(95 \% \mathrm{Cl} 0.71$ to $1.89, \mathrm{P}=0.55, \mathrm{l} 2=0 \%$; moderate-quality 
evidence; Analysis 1.6). This result is similar to the unadjusted pooled HR (Analysis 1.3), and conclusions remain unchanged following the exclusion of participants from Turnbull 1985.

For individuals with generalised onset seizures (264 participants from 4 trials), the pooled $\mathrm{HR}$ was $1.51(95 \% \mathrm{Cl} 0.66$ to $3.45, \mathrm{P}=0.33$, $1^{2}=23 \%$; (ow-quality evidence), suggesting a slight advantage for phenytoin which is not statistically significant. For individuals with focal onset seizures (187 participants from 4 trials), the pooled HR was $1.01\left(95 \% \mathrm{Cl} 0.55\right.$ to $1.85, \mathrm{P}=0.98, \mathrm{I}^{2}=0 \%$; moderate-quality evidence), indicating no clear advantage for either drug. There was no evidence of an interaction between epilepsy type (focal onset versus generalised onset) and treatment effect $\left(\mathrm{Chi}^{2}=0.60, \mathrm{df}=\right.$ $1, \mathrm{P}=0.44, \mathrm{I}^{2}=0 \%$; Analysis 1.6$)$. No important heterogeneity was present in overall analysis or within epilepsy type subgroups $\left(1^{2}<\right.$ $25 \%$ for all analyses).

\section{Sensitivity analysis}

Sensitivity analyses were conducted to investigate misclassification of seizure type, reclassifying up to 100 individuals from four trials (Heller 1995; Ramsay 1992; Shakir 1981; Turnbull 1985) aged 30 or older with new onset generalised seizures to focal onset seizures or an uncertain seizure type. The results of the two sensitivity analyses are shown in Table 6.

For all three treatment failure outcomes: time to treatment failure for any reason related to treatment; due to adverse events; and due to lack of efficacy, sensitivity analyses in which individuals classified as experiencing generalised onset seizures and age at onset $>30$ years reclassified as experiencing focal onset seizures, show numerically similar results and conclusions remain unchanged. There was no evidence of an association between epilepsy type and treatment effect following reclassification for any of the treatment failure outcomes

Sensitivity analysis in which individuals classified as experiencing generalised onset seizures and age at onset $>30$ years were reclassified as experiencing uncertain seizure type was performed only for time to treatment failure for any reason related to treatment.

In the sensitivity analysis of 'time to treatment failure for any reason related to treatment' in which individuals classified as experiencing generalised onset seizures and age at onset $>30$ years were reclassified as uncertain seizure type, a large, but non-significant advantage for phenytoin was shown in the uncertain seizure type group: (pooled HR 6.83, 0.82 to 57.16 ), which was substantially different in the direction of effect from estimates for the 'focal onset seizures' subgroup (pooled HR $0.83,95 \% \mathrm{Cl} 0.50$ to 1.38 ), and 'generalised onset seizures' groups (pooled HR $0.77,95 \% \mathrm{Cl} 0.42$ to 1.41), both indicating a non-significant advantage for valproate. There was, however, still no evidence of an association between epilepsy type and treatment effect in this analysis $\left(\mathrm{Chi}^{2}=3.80, \mathrm{df}=\right.$ $\left.2 ;(P=0.15), I^{2}=47.3 \%\right)$ and the result within the uncertain seizure type group should be interpreted with caution due to relatively small numbers of individuals with uncertain seizure types failing treatment in each trial.

The sensitivity analysis could not be performed for 'time to treatment failure due to adverse events' or 'due to lack of efficacy' due to very small numbers of participants failing treatment for these reasons in the uncertain epilepsy type groups in each trial.
Heterogeneity present within analyses for individuals with generalised onset seizures (see Analysis 1.4 and Analysis 1.5), does not seem to be explained by the potential misclassification of seizure type; therefore results for individuals with generalised onset seizures should be interpreted with caution due to this unexplained inconsistency in results.

\section{Secondary outcomes}

\section{Time to first seizure post-randomisation}

For this outcome, a HR less than one indicates a clinical advantage for valproate.

Data for 639 individuals ( $96 \%$ of those providing IPD) from five trials were available for the analysis of this outcome. Seizure recurrence occurred in 371 out of 639 participants (58\%), 189 out of $333(57 \%)$ on valproate and 181 out of 306 (59\%) on phenytoin.

The overall pooled HR (for 639 participants) was 1.04 (95\% $\mathrm{Cl} 0.85$ to $1.28, \mathrm{P}=0.70$; low-quality evidence) indicating no clear advantage for either drug. There was no important statistical heterogeneity between trials $\left(I^{2}=5 \%\right.$; Analysis 1.7$)$.

\section{Subgroup analyses: epilepsy type (focal versus generalised onset)}

For individuals with generalised seizures (395 participants from 5 trials), the pooled HR was $0.97(95 \% \mathrm{Cl} 0.72$ to $1.30, \mathrm{P}=0.82$; low-quality evidence), indicating no clear advantage for either drug. For individuals with focal onset seizures (244 participants from 4 trials), the pooled HR was $1.20(95 \% \mathrm{Cl} 0.90$ to $1.60, \mathrm{P}=$ 0.22; low-quality evidence), suggesting an advantage for phenytoin (i.e. that first seizure recurrence may occur later on phenytoin compared to valproate), but this advantage is not statistically significant. Overall, the pooled HR (adjusted for seizure type for 639 participants) was 1.08 ( $95 \% \mathrm{Cl} 0.88$ to $1.33, \mathrm{P}=0.47$; low-quality evidence), suggesting a slight advantage for phenytoin which is not statistically significant. There was no evidence of an interaction between epilepsy type (focal onset versus generalised onset) and treatment effect $\left(\mathrm{Chi}^{2}=1.06, \mathrm{df}=1(\mathrm{P}=0.30), \mathrm{I}^{2}=5.6 \%\right)$ and no heterogeneity was present in any analysis $\left(I^{2}=0 \%\right.$; Analysis 1.8$)$.

\section{Sensitivity analysis}

A sensitivity analysis including generalised seizures of all types during follow-up (only recorded in Ramsay 1992), produced the following results: for individuals with generalised seizures, the pooled HR was $0.95(95 \% \mathrm{Cl} 0.71$ to $1.27, \mathrm{P}=0.74)$, indicating no clear advantage for either drug. For individuals with focal onset seizures, the pooled HR was unchanged: $1.20(95 \% \mathrm{Cl} 0.90$ to $1.60, P=0.22)$, suggesting an advantage for phenytoin which is not statistically significant. Overall, the pooled HR (adjusted for seizure type) was $1.08(95 \% \mathrm{Cl} 0.86$ to $1.32, \mathrm{P}=0.49)$, suggesting an advantage for phenytoin which is not statistically significant. Numerical results are very similar to those presented in Analysis 1.7 and Analysis 1.8 and overall conclusions are unchanged, therefore, results for time to first seizure (post-randomisation) seem robust to the exclusion of other generalised seizure types (other than generalised tonic-clonic seizures) in Ramsay 1992.

Sensitivity analyses were conducted to investigate misclassification of seizure type, reclassifying 171 individuals from four trials (Craig 1994; Heller 1995; Ramsay 1992; Turnbull 1985) aged 30 or older with new onset generalised seizures to focal 
onset seizures or an uncertain seizure type. The results of the two sensitivity analyses are shown in Table 6.

Within both of the sensitivity analyses, following reclassification, an association between epilepsy type and treatment effect is suggested. For generalised seizures, and age of onset $>30$ years reclassified as 'focal onset seizures', the result of the test for subgroup differences is statistically significant: $\mathrm{Chi}^{2}=5.46, \mathrm{df}=1$ $(P=0.02), I^{2}=81.7 \%$ (Analysis 1.9). Within the focal onset seizure group, a non-significant advantage to phenytoin is suggested: $1.23(9 \% \mathrm{Cl}(0.96$ to $1.57, \mathrm{P}=0.09)$, while in the generalised onset seizure group, a non-significant advantage to valproate is suggested: pooled HR 0.72 ( $95 \% \mathrm{Cl} 0.50$ to $1.05, \mathrm{P}=0.09$ ); although neither result is statistically significant, the observed directions of effect within this sensitivity analysis was anticipated a priori (see How the intervention might work and Subgroup analysis and investigation of heterogeneity).

For generalised seizures, and age of onset $>30$ years reclassified as 'uncertain seizure type', the result of the test for subgroup differences is not statistically significant, but subgroup analysis does suggest some potential differences between the epilepsy type subgroups: Chi $^{2}=5.79, d f=2(P=0.06), I^{2}=65.5 \%$ (Analysis 1.10).

The direction of effect for the 'uncertain seizure type' subgroup (pooled HR 1.35, $95 \% \mathrm{Cl} 0.85$ to $2.14 ; \mathrm{P}=0.22$ ) is similar to that of the 'focal onset' subgroup (pooled HR $1.20,95 \% \mathrm{Cl} 0.90$ to 1.60 ; $\mathrm{P}$ $=0.22$ ), both indicating a non-significant advantage for phenytoin and also suggesting that these individuals with 'uncertain' seizure types (who were originally classified as experiencing generalised onset seizures) are actually experiencing focal onset seizures. Furthermore, valproate now appears more effective in generalised onset seizures (pooled HR $0.72,95 \% \mathrm{Cl} 0.50$ to $1.05 ; \mathrm{P}=0.09$ ) when compared to the original analysis (Analysis 1.8; Analysis 1.10). Again, although neither result is statistically significant, the observed directions of effect within this sensitivity analysis were anticipated a priori (see How the intervention might work and Subgroup analysis and investigation of heterogeneity).

Therefore, due to the potential impact of any misclassification of epilepsy type on the numerical results and conclusions for the outcome, 'time to first seizure', results of Analysis 1.7, Analysis 1.8, Analysis 1.9 and Analysis 1.10 should be interpreted with caution.

\section{Time to achieve 12-month remission (seizure-free period)}

For this outcome, a HR less than one indicates a clinical advantage for phenytoin.

Data for 514 individuals (77\% of those providing IPD) from four trials were available for the analysis of this outcome (Craig 1994; De Silva 1996; Heller 1995; Turnbull 1985; see Table 4). Individuals were only followed up for six months in the fifth trial (Ramsay 1992), which could not contribute data to this outcome. Twelvemonth remission was achieved by 302 out of 514 participants (59\%); 147 out of $256(57 \%)$ on valproate and 155 out of $258(60 \%)$ on phenytoin. The overall pooled HR (for 514 participants) was 1.03 (95\% $\mathrm{Cl} 0.82$ to $1.29, \mathrm{P}=0.80$; moderate-quality evidence), indicating no clear advantage to either drug. There is no evidence of statistical heterogeneity between trials $\left(I^{2}=0 \%\right.$; Analysis 1.11$)$.

\section{Subgroup analyses: epilepsy type (focal versus generalised onset)}

For individuals with generalised seizures (270 participants from 4 trials), the pooled $\mathrm{HR}$ was $0.96(95 \% \mathrm{Cl} 0.71$ to $1.29, \mathrm{P}=$ 0.79 ; moderate-quality evidence), indicating no clear advantage for either drug. For individuals with focal onset seizures (244 participants from 4 trials), the pooled HR was 1.11 (95\% Cl 0.78 to $1.60, \mathrm{P}=0.56$; moderate-quality evidence), indicating a slight advantage for valproate ((i.e. that 12 -month remission may occur slightly earlier on valproate than phenytoin), but this advantage is not statistically significant. Overall, the pooled HR (adjusted for epilepsy type for 514 participants) was $1.02(95 \% \mathrm{Cl} 0.81$ to 1.28 , $\mathrm{P}=0.87$; moderate-quality evidence), suggesting no clear clinical advantage for either drug. There was no evidence of an interaction between epilepsy type (focal onset versus generalised onset) and treatment $\left(\mathrm{Chi}^{2}=0.39, \mathrm{df}=1, \mathrm{P}=0.53, \mathrm{I}^{2}=0 \%\right)$ and no heterogeneity was present in any analysis $\left(\mathrm{I}^{2}=0 \%\right.$; Analysis 1.12$)$.

\section{Sensitivity analysis}

Sensitivity analyses were conducted to investigate misclassification of seizure type, reclassifying 145 individuals from three (Craig 1994; Heller 1995; Turnbull 1985) aged 30 or older with new onset generalised seizures to focal onset seizures or an uncertain seizure type. The results of the two sensitivity analyses are shown in Table 6.

Results are numerically similar for individuals with focal onset seizures, individuals with generalised onset seizures and overall for all participants; conclusions are unchanged and there is no evidence of an association between epilepsy type and treatment effect following reclassification.

\section{Time to achieve six-month remission (seizure-free period)}

For this outcome, a HR less than one indicates a clinical advantage for phenytoin.

Data for 639 individuals (96\% of those providing IPD) from five trials were available for the analysis of this outcome (see Table 4). Six-month remission was achieved by 434 out of 639 participants (68\%); 228 out of 333 (68\%) on valproate and 206 out of $306(67 \%)$ on phenytoin. The overall pooled HR (for 639 participants) was 1.08 (95\% $\mathrm{Cl} 0.89$ to $1.30, \mathrm{P}=0.44$; moderate-quality evidence), suggesting a slight advantage to valproate (i.e. that six-month remission may occur slightly earlier on valproate than phenytoin), but this advantage is not statistically significant. There is no evidence of statistical heterogeneity between trials $\left(\mathrm{I}^{2}=0 \%\right.$; see Analysis 1.13).

\section{Subgroup analyses: epilepsy type (focal versus generalised onset)}

For individuals with generalised seizures (395 participants from 5 trials), the pooled HR was $1.08(95 \% \mathrm{Cl} 0.84$ to $1.38, \mathrm{P}=0.54$; moderate-quality evidence), suggesting an advantage for valproate which is not statistically significant. For individuals with focal onset seizures (244 participants from 4 trials), the pooled HR was 1.00 (95\% Cl 0.73 to $1.35, \mathrm{P}=0.98$; moderate-quality evidence), indicating no clear advantage for either drug. Overall, the pooled HR (adjusted for epilepsy type for 639 participants) was 1.05 (95\% $\mathrm{Cl} 0.86$ to $1.27, \mathrm{P}=0.64$; moderate-quality evidence), suggesting no clear advantage for either drug. There was no evidence of an interaction between epilepsy type (focal onset versus generalised onset) and treatment $\left(\mathrm{Chi}^{2}=0.16, \mathrm{df}=1, \mathrm{P}=0.69, \mathrm{I}^{2}=0 \%\right)$ and no heterogeneity was present in any analysis $\left(I^{2}=0 \%\right.$; Analysis 1.14). 


\section{Sensitivity analyses}

A sensitivity analysis including generalised seizures of all types during follow-up (only recorded in Ramsay 1992) produced the following results: for individuals with generalised seizures $(395$ participants from 5 trials), the pooled HR was 1.19 (95\% Cl 0.88 to $1.61, P=0.26$ ), suggesting an advantage for valproate, which is not statistically significant. For individuals with focal onset seizures (244 participants from 4 trials), the pooled $\mathrm{HR}$ was unchanged: 1.00 (95\% $\mathrm{Cl} 0.73$ to $1.35, \mathrm{P}=0.98)$, indicating no clear advantage for either drug. Overall, the pooled HR (adjusted for epilepsy type) was $1.09(95 \% \mathrm{Cl} 0.88$ to $1.37, \mathrm{P}=0.40)$, suggesting an advantage for valproate, which is not statistically significant.

By including information on other generalised seizure types in the trial by Ramsay 1992, a very slightly greater advantage for valproate emerges. However, as numerical results are similar to those presented in Analysis 1.13 and Analysis 1.14 and overall conclusions are unchanged, results for time to six-month remission seem robust to the exclusion of other generalised seizure types (other than generalised tonic-clonic seizures) in Ramsay 1992.

Sensitivity analyses were conducted to investigate misclassification of seizure type, reclassifying 171 individuals from four trials (Craig 1994; Heller 1995; Ramsay 1992; Turnbull 1985) aged 30 or older with new onset generalised seizures to focal onset seizures or an uncertain seizure type. The results of the two sensitivity analyses are shown in Table 6.

Results are numerically similar for individuals with focal onset seizures, individuals with generalised onset seizures and overall for all participants; conclusions are unchanged and there is no evidence of an association between epilepsy type and treatment effect following reclassification.

\section{Incidence of adverse events}

See Table 7 for details of all adverse event data provided in the studies included in this review. It is difficult to summarise the 'most common' adverse events overall across the 11 studies due to the differences in methods and differences in the levels of detail in the reporting of adverse event data across the studies. In summary, the adverse events reported by two or more studies in this review are the following.

For valproate:

- drowsiness/somnolence/sedation (reported by Callaghan 1985; Craig 1994; De Silva 1996; Ramsay 1992; Rastogi 1991);

- weight gain (reported by Callaghan 1985; Craig 1994; Rastogi 1991; Shakir 1981);

- tremor (reported by Craig 1994; De Silva 1996; Ramsay 1992; Turnbull 1985);

- alopecia/hair loss (reported by Craig 1994; Shakir 1981; Turnbull 1985);

- dizziness/unsteadiness (reported by Craig 1994; Heller 1995; Ramsay 1992);

- skin allergy/rash (reported by Ramsay 1992; Thilothammal 1996); and

- gastrointestinal problems (reported by Rastogi 1991; Shakir 1981).

For phenytoin:
- gingival (gum) hypertrophy/hyperplasia (reported by Callaghan 1985; Rastogi 1991; Thilothammal 1996);

- rash (reported by Callaghan 1985; Craig 1994; De Silva 1996; Ramsay 1992);

- ataxia (reported by Callaghan 1985; Rastogi 1991; Shakir 1981; Thilothammal 1996; Turnbull 1985);

- nausea (reported by Ramsay 1992; Thilothammal 1996);

- dizziness/unsteadiness (reported by Craig 1994; Ramsay 1992);

- nystagmus (reported by Craig 1994; Rastogi 1991; Thilothammal 1996; Turnbull 1985);

- drowsiness/somnolence/sedation (reported by Craig 1994; De Silva 1996; Ramsay 1992; Rastogi 1991; Thilothammal 1996); and

- tremor (reported by Ramsay 1992; Turnbull 1985).

\section{ISC U S S I O N}

\section{Summary of main results}

The results of this review do not demonstrate a statistically significant effect in favour of either valproate or phenytoin for the primary global outcome 'time to treatment failure for any reason related to the treatment (retention time)'. This outcome is influenced by both the relative efficacy of the two drugs, and differences in tolerability and safety.

As a difference in efficacy in one direction may be confounded by a difference in tolerability in the other, it may not be surprising that any estimated differences are small, yet when considering specific reasons for treatment failure (adverse events or lack of efficacy), still no statistically significant differences were found between the two drugs. The confidence intervals for the treatment failure outcomes are relatively wide; too wide to confirm equivalence and clinically important differences have not been excluded, particularly when results for generalised and focal onset seizure subgroups are examined. Furthermore, as at least three of the trials contributing individual participant data (IPD) to this outcome were open-label, clinical preconceptions about the two treatments, such as that valproate is more effective in generalised seizures, while phenytoin is more effective in focal onset seizures, and lack of masking, may have influenced the treatment failure rates of the two treatments.

Similarly for the secondary outcomes 'time to achieve 12month remission (seizure-free period)', 'time to achieve sixmonth remission (seizure-free period)', and 'time to first seizure', although no statistically significant differences were found between valproate and phenytoin, the confidence intervals are too wide to confirm equivalence.

\section{Overall completeness and applicability of evidence}

We have gratefully received IPD for 669 individuals $(60 \%$ of individuals from all eligible trials) from the authors of five trials, which included a comparison of phenytoin with valproate for the treatment of epilepsy (Craig 1994; De Silva 1996; Heller 1995; Ramsay 1992; Turnbull 1985). However, 376 individuals (34\%) from four relevant trials could not be included in any analysis, as IPD were not available and outcomes of interest were not reported in the published reports (Callaghan 1985; Czapinski 1997a; Rastogi 1991; Thilothammal 1996). Sufficient data for 74 individuals (6\%) were published in two trials to contribute to analysis for the primary outcome 'time to treatment failure' (Forsythe 1991; 
Shakir 1981), but insufficient data were available to include these individuals in the analyses of other outcomes. Having to exclude data for one-third of eligible participants due to lack of IPD and insufficient reporting in study publications is likely to impact on the applicability of the evidence, however it is difficult to quantify exactly how large this impact could be.

We did not find evidence of an interaction between treatment and seizure type in any analysis using the epileptic seizure types that participants were classified with in the original analysis. This result is surprising, given the strong clinical impression that valproate is more effective in generalised onset seizures while phenytoin is more effective in focal onset seizures.

It may well be that an interaction does not exist. Alternatively, it may be that an interaction does exist but that our meta-analysis may not have the statistical power needed to detect an interaction; it must be understood that the confidence intervals around the estimates are wide, and that these results do not exclude the possibility of important differences existing. Additionally, subgroup analyses by epilepsy type show some inconsistent results, such as for our primary outcome 'time to treatment failure for any reason related to the treatment', treatment effect estimates indicate a potentially important advantage for valproate for focal onset seizures, with no clear advantage for either drug for generalised tonic-clonic seizures, which goes against current practice and belief. Furthermore, a substantial amount of statistical heterogeneity was present in some analyses of 'time to treatment failure,' particularly within analyses of individuals with generalised onset seizures, which could not be explained by sensitivity analyses.

The impression that valproate is better for generalised seizures may derive from its effects on generalised seizures other than tonic-clonic, but important differences could exist for absence and myoclonus seizure types. However, were this the case, we might have expected to see a treatment-seizure type interaction for the outcome 'time to treatment failure', if treatment had failed or a further drug added to combat other seizure types. We were unable to investigate these seizure types in detail in this review as most of the trials providing IPD did not record post-randomisation generalised seizure types other than tonic-clonic occurring postrandomisation.

The results of the original trials, and hence this meta-analysis, may have been confounded by classification bias, i.e. individuals with generalised seizures may have been misclassified as having focal onset seizures and vice versa. There is good evidence from our three reviews in our series of pair-wise reviews for monotherapy in epilepsy comparing carbamazepine to phenobarbitone, phenytoin and valproate that misclassification is indeed an important issue in epilepsy trials (Marson 2000; Nolan 2016c; Nevitt 2017b). Within our review, the most striking indication that misclassification may be a problem is the classification of subjects in Craig 1994. In this trial, 95 out of $166(56 \%)$ of the recruited individuals were classified as having a generalised epilepsy, which seems unlikely given that the individuals were newly diagnosed and over the age of 60 (Malafosse 1994). It is also interesting to note that Ramsay 1992 is the only trial in this review that attempted to recruit only individuals with generalised tonic-clonic seizures, However, this trial recruited too few individuals to have the power to detect a difference between valproate and phenytoin. In this trial, for a subgroup of individuals with definite electroencephalographic
(EEG) changes to support a diagnosis of an idiopathic generalised epilepsy, there appeared to be a greater (but not significant) advantage for valproate, compared to the trial population overall. This could again be interpreted as supporting the potential for misclassification, which in turn could confound an interaction between treatment and seizure type. We were unable to test for the effects of EEG changes on the interaction between treatment and seizure type due to EEG data not being collected for all trials, and even where it was available, it was not done in a uniform way. It is likely that these trials were initiated before the publication of the International League Against Epilepsy Classification of Epileptic Syndromes in 1989 (Commission 1989), but they did use the International League Against Epilepsy Classification of Epileptic Seizures that was published in 1981 (Commission 1981), which does allow individuals to be classified as those with focal onset or generalised seizures. The age of onset distribution of individuals classified as having generalised seizures indicates misclassification is likely to have occurred in up to 188 out of $384(49 \%)$ individuals classified as having generalised onset seizures. Our results, based on reclassifying the 188 individuals, indicate that classification bias is a potentially important confounder of the results of this review, particularly the outcome 'time to first seizure'.

Finally, it should be mentioned that the preparation of valproate used in the included trials may have influenced the results. The trials conducted in the UK all used valproate (Epilim) (Craig 1994; De Silva 1996; Heller 1995; Turnbull 1985). Ramsay 1992, conducted in the USA, used valproic acid (Depakene) which is thought to cause more gastrointestinal side effects than preparations containing either a mixture of valproate and valproic acid, or valproate alone. There is no evidence from RCTs to support this, but there are some data from observational studies (Brasfield 1999; Cranor 1997; Wilder 1983a). Given that this meta-analysis, and a similar metaanalysis comparing valproate and carbamazepine have failed to find convincing evidence of differences in effect between different drugs (Marson 2000), it seems unlikely that differing preparations of the same drug are likely to have a major effect.

\section{Quality of the evidence}

The five trials for which IPD were made available were of generally good quality, with all five trials describing adequate methods of randomisation, and Craig 1994, De Silva 1996 and Heller 1995 also describing adequate methods of allocation concealment. However, none of the five trials described a method of blinding of participants and personnel, and only one trial stated that cognitive outcome assessors were blinded to treatment allocation, raising the possibility of performance and detection bias (Craig 1994). Three trials were designed as open-label for "practical and ethical reasons" (De Silva 1996; Heller 1995; Ramsay 1992); for example, Ramsay 1992 stated that the side effects of the respective drugs would "quickly unblind" the trial anyway. A further difference between the five trials was the population recruited; two trials recruited adults of all ages (Heller 1995; Turnbull 1985), one recruited children only (De Silva 1996), one recruited adults and children (Ramsay 1992), and one recruited adults over the age of 60 only (Craig 1994).

As explained within Overall completeness and applicability of evidence, misclassification of seizure type (classification bias) is likely to have impacted upon the results of the outcome 'time to first seizure' and for treatment failure outcomes, unexplained 
heterogeneity was present in analysis, following subgroup analysis and sensitivity analysis (including reclassification of seizure type).

For the reasons outlined in this section, we judged the quality of the evidence to be moderate to low for 'time to treatment failure' due to risk of detection bias and unexplained heterogeneity (Summary of findings for the main comparison), and low/moderate for the outcomes of 'time to first seizure' and 'time to 12-month remission' respectively, due to risk of detection bias and classification bias (see Summary of findings 2).

\section{Potential biases in the review process}

We were able to include IPD up to 743 out of 1119 eligible participants (66\%) from seven out of 11 trials in this review in the analysis of at least one outcome. Such an approach has many advantages, such as allowing the standardisation of definitions of outcomes across trials, and attrition and reporting biases are reduced as we can perform additional analyses and calculate additional outcomes from unpublished data. For the outcomes we used in this review that are of a time-to-event nature, an IPD approach is considered to be the 'gold standard' approach to analysis (Parmar 1998).

For reasons outside of our control, we were unable to obtain or extract any IPD for 376 participants (34\%) from four trials for inclusion in any outcomes of this review; it is difficult to quantify whether the exclusion of at least 34\% of eligible participants from analyses is likely to have impacted on the conclusions of this review.

Finally, we made some assumptions in the statistical methodology used in this review. Firstly, when we received only follow-up dates and seizure frequencies, we used linear interpolation to estimate. We are aware that an individual's seizure patterns may be non-linear; therefore for this reason, in addition to the reasons outlined in Overall completeness and applicability of evidence, we recommend caution when interpreting the numerical results of the seizure-related outcomes.

\section{Agreements and disagreements with other studies or reviews}

No single trial has found convincing differences between valproate and phenytoin with respect to seizure control or seizure type (Callaghan 1985; Craig 1994; Czapinski 1997a; De Silva 1996; Forsythe 1991; Heller 1995; Ramsay 1992; Rastogi 1991; Shakir 1981; Thilothammal 1996; Turnbull 1985). However, confidence intervals around estimates have been wide and equivalence cannot be inferred. Furthermore, this systematic review and meta-analysis has not found any statistically significant differences between valproate and phenytoin for any of the outcomes measures. To our knowledge, this is the only systematic review and metaanalysis which compares valproate and phenytoin monotherapy for focal onset seizures and generalised onset tonic-clonic seizures. A network meta-analysis has been published (Nevitt 2017a), comparing all direct and indirect evidence from phenytoin, valproate and other standard and new antiepileptic drugs licensed for monotherapy, and it also found no differences between valproate and phenytoin for the outcomes specified in this review.

\section{AUTHORS' CONCLUSIONS}

\section{Implications for practice}

The results of this systematic review do not provide any conclusive evidence for or against the current practice of using valproate as a first-line treatment for individuals with generalised onset tonicclonic seizures, and phenytoin as monotherapy for individuals with focal onset seizures. Guidelines currently recommend lamotrigine and carbamazepine as a first-line treatment for focal onset seizures (NICE 2012); the results of this review do not inform current treatment policy.

\section{Implications for research}

Finding overall differences between these standard antiepileptic drugs has proved elusive. If overall differences do exist across heterogeneous populations of individuals, such as those studied here, those differences are likely to be small, and in order to be clinically useful, future comparative antiepileptic drug trials will need to be powered accordingly. It has been argued that future comparative antiepileptic drug trials be powered to establish equivalence (Jones 1996), and therefore be capable of detecting what is considered to be the smallest important clinical difference.

This review highlights the need for future antiepileptic drug monotherapy trials that recruit individuals with specific epilepsy syndromes, to be designed and powered to detect a difference between particular antiepileptic drugs. An approach likely to reflect and inform clinical practice, as well as being statistically powerful, would be to recruit heterogeneous populations for whom epilepsy syndromes have been adequately defined, with testing for interaction between treatment and epilepsy syndrome. In view of potential problems of misclassification, syndromes will have to be well defined, with adequate checking mechanisms to ensure that classifications are accurate, and with a system to recognise uncertainty surrounding epilepsy syndromes in individuals within trials.

Clinical uncertainty about seizure and syndrome classification is often present at the time of diagnosis and initial treatment of epilepsy, and significant numbers of individuals with newly diagnosed epilepsy cannot be classified (Bodensteiner 1988; Ottman 1993). Seizures may have been few and unwitnessed, and investigations are commonly unhelpful, but there is nevertheless no doubt that seizures have occurred and should be treated. This most commonly applies to tonic-clonic seizures that may be generalised at onset, or which may be secondarily generalised. In any trial, such unclassified individuals need to be clearly identified, because if they are not they may confound interpretation of results for well classified individuals. We need to know how to manage those whose classification we find more difficult.

The choice of outcomes at the design stage of a trial and the presentation of the results of outcomes, particularly of a time-toevent nature, require very careful consideration. While the majority of trials of a monotherapy design record an outcome measuring efficacy (seizure control) and an outcome measuring tolerability (adverse events), there is little uniformity between the definition of the outcomes and the reporting of the summary statistics related to the outcomes (Nolan 2013a), making an aggregate data approach to meta-analysis in reviews of monotherapy trials impossible. Where trial authors cannot or will not make IPD available for 
analysis, we are left with no choice but to exclude a proportion of relevant evidence from the review, which may impact upon the interpretation of the results of the review and the applicability of the evidence and conclusions. The International League Against Epilepsy recommends that trials of a monotherapy design should adopt a primary effectiveness outcome of time to treatment failure (i.e. retention time) and should be of a duration of at least 48 weeks to allow for assessment of longer-term outcomes, such as remission (ILAE 1998; ILAE 2006). If trials followed these recommendations, an aggregate data approach to meta-analysis may be feasible, reducing the resources and time required from an IPD approach.

\section{ACKN OWLEDGEMENTS}

This review update was supported by the National Institute for Health Research (NIHR), via Cochrane Infrastructure funding to the Epilepsy Group. The views and opinions expressed therein are those of the authors and do not necessarily reflect those of the Systematic Reviews Programme, NIHR, National Health Service (NHS) of the Department of Health.

We are greatly indebted to all of the trialists who have provided individual participant data (IPD) and input and review, Kenneth Sommerville and Roger Deaton at Abbott Laboratories. They have shown great patience in the way our data queries were handled.

We acknowledge Paula Williamson for contributions to the original review. 


\section{R E F E R E N C E S}

\section{References to studies included in this review}

Callaghan 1985 \{published data only\}

Callaghan N, Kenny RA, O'Neill B, Crowley M, Goggin T. A prospective study between carbamazepine, phenytoin and sodium valproate as monotherapy in previously untreated and recently diagnosed patients with epilepsy. Journal of Neurology, Neurosurgery and Psychiatry 1985;48:639-44.

\section{Craig 1994 \{published data only\}}

Craig I, Tallis R. Impact of valproate and phenytoin on cognitive function in elderly patients: results of a single-blind randomized comparative study. Epilepsia 1994;35(2):381-90.

\section{Czapinski 1997a \{unpublished data only\}}

Czapinski P, Terczynski A, Czapinska E. Randomised 36-month comparative study of valproic acid, phenytoin, phenobarbital and carbamazepine efficacy in patients with newly diagnosed epilepsy with partial complex seizures. Epilepsia 1997;38(Suppl 3):42.

\section{De Silva 1996 \{published data only\}}

De Silva M, MacArdle B, McGowan M, Hughes E, Stewart J, Neville BGR, et al. Randomised comparative monotherapy trial of phenobarbitone, phenytoin, carbamazepine, or sodium valproate for newly diagnosed childhood epilepsy. Lancet 1996;347:709-13.

\section{Forsythe 1991 \{published data only\}}

Forsythe I, Butler R, Berg I, McGuire R. Cognitive impairment in new cases of epilepsy randomly assigned to carbamazepine, phenytoin and sodium valproate. Developmental Medicine and Child Neurology 1991;33:524-34.

\section{Heller 1995 \{published data only\}}

Heller AJ, Chesterman P, Elwes RD, Crawford P, Chadwick DW, Johnson AL, et al. Phenobarbitone, phenytoin, carbamazepine, or sodium valproate for newly diagnosed adult epilepsy: a randomised comparative monotherapy trial. Journal of Neurology, Neurosurgery, and Psychiatry 1995;58:44-50.

\section{Ramsay 1992 \{published data only\}}

Ramsay RE, Wilder BJ, Murphy JV, Holmes GL, Uthman B, Slater J, et al. Efficacy and safety of valproic acid versus phenytoin as sole therapy for newly diagnosed primary generalized tonic-clonic seizures. Journal of Epilepsy 1992;5(1):55-60.

\section{Rastogi 1991 \{published data only\}}

Rastogi P, Mehrotra TN, Agarwala RK, Singh VS. Comparison of sodium valproate and phenytoin as single drug treatment in generalised and partial epilepsy. Journal of the Association of Physicians of India 1991;39(8):606-8

\section{Shakir 1981 \{published data only\}}

Shakir RA, Johnson RH, Lambie DG, Melville ID, Nanda RN. Comparison of sodium valproate and phenytoin as single drug treatment in epilepsy. Epilepsia 1981;22:27-33.
Thilothammal 1996 \{published data only\}

Thilothammal N, Banu K, Ratnam RS. Comparison of phenobarbitone, phenytoin with sodium valproate: randomized, double-blind study. Indian Pediatrics 1996;33:549-55.

\section{Turnbull 1985 \{published data only\}}

Turnbull DM, Howel D, Rawlins MD, Chadwick DW. Which drug for the adult epileptic patient: phenytoin or valproate?. BMJ 1985;290:815-9.

\section{References to studies excluded from this review}

Berg 1993 \{published data only\}

Berg I, Butler A, Ellis M, Foster J. Psychiatric aspects of epilepsy in childhood treated with carbamazepine, phenytoin or sodium valproate: a random trial. Developmental Medicine and Child Neurology 1993;35:149-57.

\section{Callaghan 1981 \{published data only\}}

Callaghan N, O'Neill B, Kenny RA. A comparison between carbamazepine, phenytoin and sodium valproate as single drug treatment in epilepsy [abstract]. Irish Journal of Medical Science 1981;150(6):194.

\section{Callaghan 1983 \{published data only\}}

Callaghan N, Kenny RA, O'Neill B, Crowley M, Goggin T. A comparative study between carbamazepine, phenytoin and sodium valproate as monotherapy in previously untreated and recently diagnosed patients with epilepsy: a preliminary communication. British Journal of Clinical Practice 1983;27:7-9.

\section{Callaghan 1984 \{published data only\}}

Callaghan N, Kenny RA, O'Neill B, Crowley M, Goggin T. A comparative study of carbamazepine, sodium valproate and phenytoin as monotherapy in epilepsy: an updated report [abstract]. Irish Journal of Medical Science 1984;153(4):154.

\section{Craig 1993 \{published data only\}}

Craig IR, Tallis RC. The impact of sodium valproate and phenytoin on cognitive function in elderly patients: results of a single-blind comparative study. Age and Ageing 1993;22(Suppl 2):10.

\section{Czapinski 1997b \{published data only\}}

Czapinski P, Terczynski A, Czapinska E. Comparative study of valproic acid (VPA), phenytoin (PHT), phenobarbital (PB) and carbamazepine (CBZ) in patients with newly diagnosed epilepsy with partial complex seizures [abstract]. Journal of Neurology 1997;244(Suppl 3):S95-6.

\section{Czapinski 1997c \{published data only\}}

Czapinski P, Terczynski A, Czapinska E. Randomized 36month comparative study of valproic acid (VPA), phenytoin $(\mathrm{PHT})$, phenobarbital (PB) and carbamazepine (CBZ) efficacy in patients with newly diagnosed epilepsy with partial complex seizures. Journal of the Neurological Sciences 1997;150(Suppl):S162-3. 
Goggin 1984 \{published data only\}

Goggin T. A re-appraisal by control and seizure type of serum levels in previously untreated patients taking part in a prospective study comparing sodium valproate, phenytoin and carbamazepine as mono-therapy in epilepsy [abstract]. Irish Journal of Medical Science 1984;153(4):154.

\section{Goggin 1986 \{published data only\}}

Goggin T, Casey C, Callaghan N. Serum levels of sodium valproate, phenytoin and carbamazepine and seizure control in epilepsy. Irish Medical Journal 1986;79(6):150-6.

\section{Jannuzzi 2000 \{published data only\}}

Jannuzzi G, Cian P, Fattore C, Gatti G, Bartoli A, Monaco F, et al. A multicenter randomized controlled trial on the clinical impact of therapeutic drug monitoring in patients with newly diagnosed epilepsy. The Italian TDM Study Group in Epilepsy. Epilepsia 2000;41(2):222-30.

\section{Kaminow 2003 \{published data only\}}

Kaminow L, Schimschock JR, Hammer AE, Vuong A. Lamotrigine monotherapy compared with carbamazepine, phenytoin, or valproate monotherapy in patients with epilepsy. Epilepsy and Behaviour 2003;4(6):659-66.

\section{Sabers 1995 \{published data only\}}

Sabers A, Møller A, Dam M, Smed A, Arlien-Søborg P, Buchman J, et al. Cognitive function and anticonvulsant therapy: effect of monotherapy in epilepsy. Acta Neurologica Scandinavica 1995;92(1):19-27.

\section{Schmidt 2007 \{published data only\}}

Schmidt $D$. How reliable is early treatment response in predicting long-term seizure outcome?. Epilepsy and Behaviour 2007;10(4):588-94.

\section{Shakir 1980 \{published data only\}}

Shakir RA. Sodium valproate, phenytoin and carbamazepine as sole anticonvulsants. Royal Society of Medicine International Congress and Symposium 1980;30:7-16.

Tallis 1994a \{published data only\}

Tallis R, Craig I, Easter D. Multicentre comparative trial of sodium valproate and phenytoin in elderly patients with newly diagnosed epilepsy. Age and Ageing 1994;23:S5.

\section{Tallis 1994b \{published data only\}}

Tallis R, Easter D. Multicenter comparative trial of valproate and phenytoin. Epilepsia 1994;35(Suppl 7):62.

\section{Turnbull 1982 \{published data only\}}

Turnbull DM, Rawlins MD, Weightman D, Chadwick DW. A comparison of phenytoin and valproate in previously untreated adult epileptic patients. Journal of Neurology, Neurosurgery and Psychiatry 1982;45(1):55-9.

\section{Wilder 1983 \{published data only\}}

Wilder BJ, Ramsay RE, Murphy JV, Karas BJ, Marquardt K, Hammond EJ. Comparison of valproic acid and phenytoin in newly diagnosed tonic-clonic seizures. Neurology 1983;33(11):1474-6.
Zeng 2010 \{published and unpublished data\}

Zeng K, Wang X, Xi Z, Yan Y. Adverse effects of carbamazepine, phenytoin, valproate and lamotrigine monotherapy in epileptic adult Chinese patients. Clinical Neurology and Neurosurgery 2010;112:291-5.

\section{Additional references}

\section{Annegers 1999}

Annegers JF, Dubinsky S, Coan SP, Newmark ME, Roht L. The incidence of epilepsy and unprovoked seizures in multiethnic, urban health maintenance organizations. Epilepsia 1999;40(4):502-6.

\section{Bodensteiner 1988}

Bodensteiner JB, Brownsworth RD, Knapik JR, Kanter MC, Cowan LD, Leviton A. Interobserver variability in the ILAE classification of seizures in childhood. Epilepsia 1988;29(2):123-8.

\section{Bourgeois 1987}

Bourgeois B, Beaumanoir A, Blajev B, Cruz ND, Despland PA, Egli $\mathrm{M}$, et al. Monotherapy with valproate in primary generalized epilepsies. Epilepsia 1987;28(Suppl 2):S8-11.

\section{Brasfield 1999}

Brasfield KH. Pilot study of divalproex sodium valproate versus valproic acid: drug acquisition costs versus all related costs. Current Therapeutic Research 1999;60(3):138-44.

\section{Bromley 2013}

Bromley RL, Mawer GE, Briggs M, Cheyne C, Clayton-Smith J, García-Fiñana M, et al. The prevalence of neurodevelopmental disorders in children prenatally exposed to antiepileptic drugs. Journal of Neurology, Neurosurgery and Psychiatry 2013;84(6):637-43. [DOI: 10.1136/jnnp-2012-304270]

\section{Bromley 2014}

Bromley R, Weston J, Adab N, Greenhalgh J, Sanniti A, McKay AJ, et al. Treatment for epilepsy in pregnancy: neurodevelopmental outcomes in the child. Cochrane Database of Systematic Reviews 2014, Issue 10. [DOI: 10.1002/14651858.CD010236.pub2]

\section{Canger 1999}

Canger R, Battino D, Canevini MP, Fumarola C, Guidolin L, Vignoli A, et al. Malformations in offspring of women with epilepsy: A prospective study. Epilepsia 1999;40(9):1231-6.

\section{Carl 1992}

Carl GF, Smith ML. Phenytoin-folate interactions: differing effects of the sodium salt and the free acid of phenytoin. Epilepsia 1992;33(2):372-5.

\section{Chadwick 1994}

Chadwick DW. Valproate in the treatment of partial epilepsies. Epilepsia 1994;35(5):S96-8. 


\section{Cockerell 1995}

Cockerell OC, Johnson AL, Sander JW, Hart YM, Shorvon SD. Remission of epilepsy: results from the National General Practice Study of Epilepsy. Lancet 1995;346(8968):140-4.

\section{Commission 1981}

Commission on Classification and Terminology of the International League Against Epilepsy. Proposal for revised clinical and electroencephalographic classification of epileptic seizures. Epilepsia 1981;22(4):489-501.

\section{Commission 1989}

Commission on Classification and Terminology of the International League Against Epilepsy. Proposal for revised classification of epilepsies and epileptic syndromes. Epilepsia 1989;30(4):389-99.

\section{Cranor 1997}

Cranor CW, Sawyer WT, Carson SW, Early JJ. Clinical and economic impact of replacing divalproex sodium with valproic acid. American Journal of Health-System Pharmacy 1997;54:1716-22.

\section{Delgado-Escueta 1984}

Delgado-Escueta AV, Enrile-Bascal F. Juvenile myoclonic epilepsy of Janz. Neurology 1984;34(3):285-94.

\section{Dinesen 1984}

Dinesen H, Gram L, Andersen T, Dam M. Weight gain during treatment with valproate. Acta Neurologica Scandinavica 1984;69:65-9.

\section{Easter 1997}

Easter D, O'Bryan-Tear CG, Verity C. Weight gain with valproate or carbamazepine-a reappraisal. Seizure 1997;6(2):121-5.

\section{Egger 1981}

Egger J, Brett EM. Effects of sodium valproate in 100 children with special reference to weight. BMJ 1981;283(6291):577-81.

\section{Gladstone 1992}

Gladstone DJ, Bologa M, Maguire C, Pastuszak A, Koren G. Course of pregnancy and fetal outcome following maternal exposure to carbamazepine and phenytoin: a prospective study. Reproductive Toxicology 1992;6(3):257-61.

\section{Hauser 1993}

Hauser WA, Annegers JF, Kurland LT. Incidence of epilepsy and unprovoked seizures in Rochester, Minnesota 1935 - 1984. Epilepsia 1993;34:453-68.

\section{Higgins 2003}

Higgins JP, Thompson SG, Deeks JJ, Altman DG. Measuring inconsistency in meta-analyses. BMJ 2003;327:557-60.

\section{Higgins 2011}

Higgins JP, Altman DG, Sterne JAC, editor(s). Chapter 8: Assessing risk of bias in included studies. In: Higgins JP, Green S, editor(s). Cochrane Handbook for Systematic Reviews of Interventions Version 5.1.0 (updated March 2011). The Cochrane
Collaboration, 2011. Available from handbook.cochrane.org. The Cochrane Collaboration.

\section{Hirtz 2007}

Hirtz D, Thurman DJ, Gwinn-Hardy K, Mohamed M, Chaudhuri AR, Zalutsky R. How common are the "common" neurologic disorders?. Neurology 2007;68:326-37.

\section{ILAE 1998}

ILAE Commission on Antiepileptic Drugs. Considerations on designing clinical trials to evaluate the place of new antiepileptic drugs in the treatment of newly diagnosed and chronic patients with epilepsy. Epilepsia 1998;39(7):799-803.

\section{ILAE 2006}

Glauser T, Ben-Menachem E, Bourgeois B, Cnaan A, Chadwick D, Guerreiro $C$, et al. ILAE treatment guidelines: Evidence based analysis of antiepileptic drug efficacy and effectiveness as initial monotherapy for epileptic seizures and syndromes. Epilepsia 2006;47(7):1094-120.

\section{Jeavons 1977}

Jeavons PM. Choice of drug therapy in epilepsy. Practitioner 1977;219:542-56.

\section{Jones 1996}

Jones B, Jarvis P, Lewis JA, Ebbutt AF. Trials to assess equivalence: the importance of rigorous methods. $B M J$ 1996;313(7048):36-9.

\section{Juul Jenson 1983}

Juul-Jenson P, Foldspang A. Natural history of epileptic seizures. Epilepsia 1983;24:297-312.

\section{Kirkham 2010}

Kirkham JJ, Dwan KM, Altman DG, Gamble C, Dodd S, Smyth R, et al. The impact of outcome reporting bias in randomised controlled trials on a cohort of systematic reviews. BMJ 2010;340:c365.

\section{Kwan 2000}

Kwan P, Brodie MJ. Early identification of refractory epilepsy. New England Journal of Medicine 2000;342:314-9.

\section{Lefebvre 2011}

Lefebvre C, Manheimer E, Glanville J. Chapter 6: Searching for studies. In: Higgins JP, Green S, editor(s). Cochrane Handbook for Systematic Reviews of Interventions Version 5.1.0 (updated March 2011). The Cochrane Collaboration, 2011. Available from handbook.cochrane.org.

\section{Liporace 1994}

Liporace JD, Sperling MR, Dichter MA. Absence seizures and carbamazepine in adults. Epilepsia 1994;35(5):1026-8.

\section{MacDonald 2000}

MacDonald BK, Johnson AL, Goodridge DM, Cockerell OC, Sander JWA, Shorvon SD. Factors predicting prognosis of epilepsy after presentation with seizures. Annals of Neurology 2000;48:833-41. 


\section{Malafosse 1994}

Malafosse A, Genton P, Hirsch E, Marescaux C, Broglin D, Bernasconi R, editor(s), et al. Idiopathic Generalised Epilepsies: Clinical, Experimental and Genetic Aspects. Eastleigh: John Libbey and Company, 1994. [0861964365]

\section{Marson 2000}

Marson AG, Williamson PR, Hutton JL, Clough HE, Chadwick DW. Carbamazepine versus valproate monotherapy for epilepsy. Cochrane Database of Systematic Reviews 2000, Issue 3. [DOI: 10.1002/14651858.CD001030]

\section{Mattson 1985}

Mattson RH, Cramer JA, Collins JF, Smith DB, DelgadoEscueta AV, Browne TR, et al. Comparison of carbamazepine, phenobarbital, phenytoin, and primidone in partial and secondarily generalized tonic-clonic seizures. New England Journal of Medicine 1985;313(3):145-51.

\section{Meador 2008}

Meador K, Reynolds M, Crean S, Fahrbach K, Probst C . Pregnancy outcomes in women with epilepsy: A systematic review and meta-analysis of published pregnancy registries and cohorts. Epilepsy Research 2008;81:1-13.

\section{Morrow 2006}

Morrow J, Russel A, Guthrie E, Parsons L, Robertson I, Waddell R, et al. Pregnancy outcomes in women with epilepsy: A systematic review and meta-analysis of published pregnancy registries and cohorts. Journal of Neurology, Neurosurgery and Neuropsychiatry 2006;77(2):193-8.

\section{Murray 1994}

Murray CJL, Lopez AD, World Health Organization. Global comparative assessments in the health sector: disease burden, expenditures and intervention packages. apps.who.int/iris/ handle/10665/41177 (accessed 0108 2018).

\section{Nevitt 2017a}

Nevitt SJ, Sudell M, Weston J, Tudur Smith C, Marson A. Antiepileptic drug monotherapy for epilepsy: a network meta-analysis of individual participant data. Cochrane Database of Systematic Reviews 2017, Issue 12. [DOI: 10.1002/14651858.CD011412.pub3]

\section{Nevitt 2017b}

Nevitt SJ, Marson AG, Weston J, Tudur-Smith C. Carbamazepine versus phenytoin monotherapy for epilepsy: an individual participant data review. Cochrane Database of Systematic Reviews 2017, Issue 2. [DOI: 10.1002/14651858.CD001911.pub3]

\section{Nevitt 2018}

Nevitt SJ, Tudur Smith C, Weston J, Marson AG. Lamotrigine versus carbamazepine monotherapy for epilepsy: an individual participant data review. Cochrane Database of Systematic Reviews 2018, Issue 6. [DOI: 10.1002/14651858.CD001031.pub4]

\section{Ngugi 2010}

Ngugi AK, Bottomley C, Kleinschmidt I, Sander JW, Newton CR. Estimation of the burden of active and life-time epilepsy: a meta-analytic approach. Epilepsia 2010;51:883-90.

\section{NICE 2012}

National Institute for Health and Care Excellence. The epilepsies: the diagnosis and management of the epilepsies in adults and children in primary and secondary care. www.nice.org.uk/guidance/cg137 (accessed 0108 2018).

\section{Nolan 2013b}

Nolan SJ, Muller M, Tudur Smith C, Marson AG. Oxcarbazepine versus phenytoin monotherapy for epilepsy. Cochrane Database of Systematic Reviews 2013, Issue 5. [DOI: 10.1002/14651858.CD003615.pub3]

\section{Nolan 2013c}

Nolan SJ, Tudur Smith C, Pulman J, Marson AG. Phenobarbitone versus phenytoin monotherapy for partial onset seizures and generalised onset tonic-clonic seizures. Cochrane Database of Systematic Reviews 2013, Issue 1. [DOI: 10.1002/14651858.CD002217.pub2]

\section{Nolan 2013d}

Nolan SJ, Sutton L, Marson A, Tudur Smith C. Consistency of outcome and statistical reporting of time-to-event data: the impact on Cochrane Reviews and meta-analyses in epilepsy. 21st Cochrane Colloquium: Better Knowledge for Better Health, Quebec City. 2013:114-5.

\section{Nolan 2016b}

Nolan SJ, Sudell M, Tudur Smith C, Marson A. Topiramate versus carbamazepine monotherapy for epilepsy: an individual participant data review. Cochrane Database of Systematic Reviews 2016, Issue 12. [DOI: 10.1002/14651858.CD012065.pub2]

\section{Nolan 2016c}

Nolan SJ, Marson AG, Weston J, Tudur Smith C. Carbamazepine versus phenobarbitone monotherapy for epilepsy: an individual participant data review. Cochrane Database of Systematic Reviews 2016, Issue 12. [DOI: 10.1002/14651858.CD001904.pub2]

\section{Novak 1999}

Novak GP, Maytal J, Alshansky A, Eviatar L, Sy-Kho R, Siddique $\mathrm{Q}$. Risk of excessive weight gain in epileptic children treated with valproate. Journal of Child Neurology 1999;14(8):490-5

\section{Nulman 1997}

Nulman I, Scolnik D, Chitayat D, Farkas LD, Koren G. Findings in children exposed in utero to phenytoin and carbamazepine monotherapy: independent effects of epilepsy and medications. American Journal of Medical Genetics 1997;68(1):18-24.

\section{Olafsson 2005}

Olafsson E, Ludvigsson P, Gudmundsson G, Hesdorfer D, Kjartansson $\mathrm{O}$, Hauser WA. Incidence of unprovoked seizures and epilepsy in Iceland and assessment of the epilepsy syndrome classification: a prospective study. Lancet Neurology 2005;4:627-34. 


\section{Ornoy 2009}

Ornoy A. Valproic acid in pregnancy: How much are we endangering the embryo and fetus?. Reproductive Toxicology 2009;28(1):1-10.

\section{Ottman 1993}

Ottman R, Lee JH, Hauser WA, Hong S, Hesdorffer D, Schupf N, et al. Reliability of seizure classification using a semistructured interview. Neurology 1993;43(12):2526-30.

\section{Parmar 1998}

Parmar MKB, Torri V, Stewart L. Extracting summary statistics to perform meta-analysis of the published literature for survival endpoints. Statistics in Medicine 1998;17:2815-34.

\section{Penry 1989}

Penry JK, Dean JC, Riela AR. Juvenile myoclonic epilepsy: long term response to therapy. Epilepsia 1989;30(Suppl 4):S19-23.

\section{Sander 1996}

Sander JW, Shorvon SD. Epidemiology of the epilepsies. Journal of Neurology, Neurosurgery, and Psychiatry 1996;61(5):433-43.

\section{Sander 2004}

Sander JW. The use of anti-epileptic drugs - principles and practice. Epilepsia 2004;45(6):28-34.

\section{Scheffer 2017}

Scheffer IE, Berkovic S, Capovilla G, Connolly MB, French J, et al. ILAE classification of the epilepsies: Position paper of the ILAE Commission for Classification and Terminology. Epilepsia 2017;58(4):512-21.

\section{Scheinfeld 2003}

Scheinfeld N. Phenytoin in cutaneous medicine: Its uses, mechanisms and side effects. Dermatology Online Journal 2003;9(3):6

\section{Schünemann 2013}

Schünemann H, Brożek J, Guyatt G, Oxman A, editor(s). Handbook for grading the quality of evidence and the strength of recommendations using the GRADE approach (updated October 2013). Available from gdt.guidelinedevelopment.org/ app/handbook/handbook.html. GRADE Working Group, 2013.

\section{Stata 2015 [Computer program]}

StataCorp. Stata Statistical Software: Release 14. College Station, TX: StataCorp LP, 2015.

\section{Tomson 2011}

Tomson T, Battino D, Bonizzoni E, Craig J, Lindhout D, Sabers A, et al. Dose-dependent risk of malformation with antiepileptic drugs: An analysis of data from the EURAP epilepsy and pregnancy registry. Lancet Neurology 2011;10(7):609-17.

\section{Troupin 1975}

Troupin AS, Ojemann LM. Paradoxical intoxication - a complication of anticonvulsant administration. Epilepsia 1975;16:753-8.

\section{Tudur Smith 2007}

Tudur Smith C, Marson AG, Chadwick DW, Williamson PR. Multiple treatment comparisons in epilepsy monotherapy trials. Trials 2007;5(8):34

\section{Vallarta 1974}

Vallarta JM, Bell DB, Reichert A. Progressive encephalopathy due to chronic hydantoin intoxication. American Journal of Diseases of Children 1974;128:27-34.

\section{Wallace 1997}

Wallace H, Shorvon SD, Hopkins A, O'Donoghue M. National Society of Epilepsy Guidelines. London: Royal College of Physicians 1997.

\section{Weston 2017}

Weston J, Bromley R, Jackson CF, Adab N, Clayton-Smith J, Greenhalgh J, et al. Monotherapy treatment of epilepsy in pregnancy: congenital malformation outcomes in the child. Cochrane Database of Systematic Reviews 2017, Issue 4. [DOI: 10.1002/14651858.CD010224.pub2]

\section{Wilder 1983a}

Wilder BJ, Karas BJ, Penry JK, Asconape J. Gastrointestinal tolerance of divalproex sodium. Neurology 1983;33:808-11.

\section{Wilder 1995}

Wilder BJ. Phenytoin: clinical use. Antiepileptic Drugs. New York: Raven Press, 1995:339-44.

\section{Williamson 2000}

Williamson PR, Marson AG, Tudur C, Hutton JL, Chadwick DW. Individual patient data meta-analysis of randomized antiepileptic drug monotherapy trials. Journal of Evaluation in Clinical Practice 2000;6(2):205-14.

\section{Williamson 2002}

Williamson PR, Tudur Smith C, Hutton JL, Marson AG. Aggregate data meta-analysis with time-to-event outcomes. Statistics in Medicine 2002;21(11):3337-51.

\section{References to other published versions of this review Nolan 2013a}

Nolan SJ, Marson AG, Pulman J, Tudur Smith C. Phenytoin versus valproate monotherapy for partial onset seizures and generalised onset tonic-clonic seizures. Cochrane Database of Systematic Reviews 2013, Issue 8. [DOI: 10.1002/14651858.CD001769.pub2]

\section{Nolan 2016a}

Nolan SJ, Marson AG, Weston J, Tudur Smith C. Phenytoin versus valproate monotherapy for partial onset seizures and generalised onset tonic-clonic seizures: an individual participant data review. Cochrane Database of Systematic Reviews 2016, Issue 4. [DOI: 10.1002/14651858.CD001769.pub3]

\section{Tudur 1999}

Tudur C, Ramaratnam S, Marson AG, Williamson PR, Hutton JL, Chadwick DW. Phenytoin vs sodium valproate monotherapy for 
epilepsy. Cochrane Database of Systematic Reviews 1999, Issue 3. [DOI: 10.1002/14651858.CD001769]

\section{Tudur Smith 2001}

Tudur Smith C, Marson AG, Williamson PR. Phenytoin versus valproate monotherapy for partial onset seizures

\section{CHARACTERISTICS OF STUDIES}

Characteristics of included studies [ordered by study ID]

\section{Callaghan 1985}

Parallel study design, outpatient setting
Study conducted in Eire (Republic of Ireland)
Randomisation based on two Latin squares and the preference of drug for the participant
An independent person selected "drug of first preference" from randomisation list

\begin{tabular}{ll}
\hline Participants & $\begin{array}{l}\text { Adults and children with a minimum of } 2 \text { untreated generalised or focal seizures in the } 6 \text { months pre- } \\
\text { ceding the trial }\end{array}$ \\
& Number randomised: PHT = 58; SV = 64 \\
& 48 participants (39\%) with focal epilepsy. $67(55 \%)$ men \\
& Age range: $5-71$. Duration of treatment (range in months):3-48 \\
\hline Interventions & Monotherapy with PHT or SV \\
& Mean daily dose achieved: PHT: $5.4 \mathrm{mg} / \mathrm{kg} ; \mathrm{SV}: 15.6 \mathrm{mg} / \mathrm{kg}$ \\
\hline Outcomes & $\begin{array}{l}\text { Seizure control: } \\
\text { excellent (complete freedom of seizures) } \\
\text { good }(>50 \% \text { reduction in seizure frequency) } \\
\text { poor (<50\% reduction in seizure frequency) }\end{array}$ \\
\hline Outcomes chosen for this review were not reported. IPD not available
\end{tabular}
ceding the trial

Number randomised: $\mathrm{PHT}=58 ; \mathrm{SV}=64$

48 participants (39\%) with focal epilepsy. 67 (55\%) men

Age range: 5-71. Duration of treatment (range in months):3-48

\begin{tabular}{ll}
\hline Participants & $\begin{array}{l}\text { Adults and children with a minimum of } 2 \text { untreated generalised or focal seizures in the } 6 \text { months pre- } \\
\text { ceding the trial }\end{array}$ \\
& Number randomised: PHT = 58; SV = 64 \\
& 48 participants (39\%) with focal epilepsy. $67(55 \%)$ men \\
& Age range: $5-71$. Duration of treatment (range in months):3-48 \\
\hline Interventions & Monotherapy with PHT or SV \\
& Mean daily dose achieved: PHT: $5.4 \mathrm{mg} / \mathrm{kg} ; \mathrm{SV}: 15.6 \mathrm{mg} / \mathrm{kg}$ \\
\hline Outcomes & $\begin{array}{l}\text { Seizure control: } \\
\text { excellent (complete freedom of seizures) } \\
\text { good }(>50 \% \text { reduction in seizure frequency) } \\
\text { poor (<50\% reduction in seizure frequency) }\end{array}$ \\
\hline Outcomes chosen for this review were not reported. IPD not available
\end{tabular}

Notes

Outcomes chosen for this review were not reported. IPD not available

\section{Risk of bias}

\begin{tabular}{|c|c|c|}
\hline Bias & Authors' judgement & Support for judgement \\
\hline $\begin{array}{l}\text { Random sequence genera- } \\
\text { tion (selection bias) }\end{array}$ & Unclear risk & $\begin{array}{l}\text { Randomisation based on } 2 \text { Latin Squares without stratification. The first, sec- } \\
\text { ond and third preference of drug for the participant appears to have been tak- } \\
\text { en into account in the process. Unclear if assignment was completely random }\end{array}$ \\
\hline $\begin{array}{l}\text { Allocation concealment } \\
\text { (selection bias) }\end{array}$ & High risk & $\begin{array}{l}\text { An independent person (department secretary) selected the "drug of first pref- } \\
\text { erence" from randomisation list on a sequential basis. Allocation not ade- } \\
\text { quately concealed }\end{array}$ \\
\hline $\begin{array}{l}\text { Blinding of participants } \\
\text { and personnel (perfor- } \\
\text { mance bias) } \\
\text { All outcomes }\end{array}$ & Unclear risk & No information provided \\
\hline
\end{tabular}

and generalized onset tonic-clonic seizures. Cochrane Database of Systematic Reviews 2001, Issue 4. [DOI: 10.1002/14651858.CD001769]

\begin{tabular}{|c|c|c|}
\hline $\begin{array}{l}\text { Blinding of outcome as- } \\
\text { sessment (detection bias) }\end{array}$ & Unclear risk & No information provided \\
\hline
\end{tabular}


Callaghan 1985 (Continued)

Incomplete outcome data Low risk Attirition rates reported. ITT approach taken, all randomised participants (attrition bias) analysed

All outcomes

Selective reporting (re- Low risk porting bias)

Primary outcomes (seizure control) and secondary outcomes (side effects) reported sufficiently. No protocol available, outcomes for this review not reported

\begin{tabular}{ll}
\hline Other bias $\quad$ Low risk $\quad$ No other bias detected \\
\hline
\end{tabular}

\section{Craig 1994}

Parallel study design
Study conducted in the UK
Participants randomised using computerised stratified minimisation programme by age group, sex and
seizure type
Allocation was pharmacy-controlled
The main investigator performing cognitive testing was blinded to allocation. Participants and person-
nel unblinded

\begin{tabular}{|c|c|}
\hline \multirow[t]{4}{*}{ Participants } & $\begin{array}{l}\text { Participants over } 60 \text { years of age with newly onset seizures ( } 1 \text { or more generalised tonic-clonic seizures } \\
\text { or } 2 \text { or more focal seizures) }\end{array}$ \\
\hline & Number randomised: $\mathrm{PHT}=81 ; \mathrm{SV}=85$ \\
\hline & 80 participants (48\%) with focal epilepsy, $71(44 \%)$ men \\
\hline & Mean age (range): 78 (61-95 years). Range of follow-up: 1-20 months \\
\hline
\end{tabular}

\begin{tabular}{ll} 
Interventions & Monotherapy with PHT or SV \\
& Starting doses: PHT: $200 \mathrm{mg} /$ day, SV: $400 \mathrm{mg} /$ day \\
& Median daily dose achieved: PHT $247 \mathrm{mg}$ (range 175-275); SV: $688 \mathrm{mg}$ (range 400-1000) \\
\hline Outcomes & Psychological tests (cognitive function, anxiety and depression) \\
& Adverse event frequency \\
& Seizure control \\
\hline Notes & $\begin{array}{l}\text { Trial paper reports on a subset of } 38 \text { participants. Full IPD set provided and used for this review in- } \\
\text { cludes all 166 participants randomised in the trial. IPD provided for } 3 / 4 \text { outcomes of this review ('time } \\
\text { to treatment failure' not available) }\end{array}$
\end{tabular}

\section{Risk of bias}

\begin{tabular}{lll}
\hline Bias & Authors' judgement & Support for judgement \\
\hline $\begin{array}{l}\text { Random sequence genera- } \\
\text { tion (selection bias) }\end{array}$ & Low risk & $\begin{array}{l}\text { Computerised stratified minimisation programme, stratified for age group, } \\
\text { gender and seizure type }\end{array}$ \\
\hline $\begin{array}{l}\text { Allocation concealment } \\
\text { (selection bias) }\end{array}$ & Low risk & $\begin{array}{l}\text { Pharmacy-controlled allocation, prescription disclosed to general practitioner } \\
\text { and consultant }\end{array}$ \\
\hline
\end{tabular}


Craig 1994 (Continued)
Blinding of participants
High risk
Participants and personnel unblinded and personnel (performance bias)

All outcomes

\begin{tabular}{lll}
\hline $\begin{array}{l}\text { Blinding of outcome as- } \\
\text { sessment (detection bias) } \\
\text { All outcomes }\end{array}$ & Low risk & The main investigator performing cognitive testing was blinded to allocation \\
\hline $\begin{array}{l}\text { Incomplete outcome data } \\
\begin{array}{l}\text { (attrition bias) } \\
\text { All outcomes }\end{array}\end{array}$ & Low risk & $\begin{array}{l}\text { Attrition rates reported. ITT analysis undertaken with all randomised partici- } \\
\text { pants from IPD (see footnote 2) }\end{array}$ \\
\hline $\begin{array}{l}\text { Selective reporting (re- } \\
\text { porting bias) }\end{array}$ & Low risk & $\begin{array}{l}\text { All outcome measures reported in published report or provided in IPD (see } \\
\text { footnote 2) }\end{array}$ \\
\hline \begin{tabular}{l} 
Other bias \\
\hline
\end{tabular} & Low risk & No other bias detected \\
\hline
\end{tabular}

Czapinski 1997a

\begin{tabular}{|c|c|c|}
\hline \multirow[t]{4}{*}{ Methods } & \multicolumn{2}{|c|}{ 36-month randomised comparative trial } \\
\hline & \multicolumn{2}{|l|}{ Parallel study design } \\
\hline & \multicolumn{2}{|c|}{ Study conducted in Poland } \\
\hline & \multicolumn{2}{|c|}{ Method of generation of random list and allocation concealment not stated } \\
\hline \multirow[t]{4}{*}{ Participants } & \multicolumn{2}{|c|}{ Adults with newly diagnosed epilepsy } \\
\hline & \multicolumn{2}{|c|}{ Number randomised: $\mathrm{PHT}=30 ; \mathrm{SV}=30$} \\
\hline & \multicolumn{2}{|c|}{$100 \%$ focal epilepsy, age range: 18 to 40 years } \\
\hline & \multicolumn{2}{|c|}{ Percentage men and range of follow-up not mentioned } \\
\hline \multirow[t]{2}{*}{ Interventions } & \multicolumn{2}{|c|}{ Monotherapy with PHT or SV } \\
\hline & \multicolumn{2}{|c|}{ Starting doses: РНT: 200 mg/day, SV: 600 mg/day. Dose achieved not stated } \\
\hline Outcomes & \multicolumn{2}{|c|}{$\begin{array}{l}\text { Proportion achieving 24-month remission at } 3 \text { years } \\
\text { Exclusions after randomisation due to adverse events or no efficacy }\end{array}$} \\
\hline Notes & \multicolumn{2}{|c|}{ Abstract only. Outcomes chosen for this review were not reported. IPD pledged but not received } \\
\hline \multicolumn{3}{|l|}{ Risk of bias } \\
\hline Bias & Authors' judgement & Support for judgement \\
\hline $\begin{array}{l}\text { Random sequence genera- } \\
\text { tion (selection bias) }\end{array}$ & Unclear risk & Trial "randomised" but no further information provided \\
\hline $\begin{array}{l}\text { Allocation concealment } \\
\text { (selection bias) }\end{array}$ & Unclear risk & No information provided \\
\hline
\end{tabular}




\title{
Czapinski 1997a (Continued)
}

\author{
Blinding of participants Unclear risk No information provided \\ and personnel (perfor- \\ mance bias) \\ All outcomes
}

\begin{tabular}{lll}
\hline $\begin{array}{l}\text { Blinding of outcome as- } \\
\text { sessment (detection bias) } \\
\text { All outcomes }\end{array}$ & Unclear risk & No information provided \\
\hline $\begin{array}{l}\text { Incomplete outcome data } \\
\text { (attrition bias) } \\
\text { All outcomes }\end{array}$ & Unclear risk & $\begin{array}{l}\text { "Exclusion rates" (interpreted as treatment withdrawal rates) reported for all } \\
\text { treatment groups, no further information provided }\end{array}$ \\
\hline $\begin{array}{l}\text { Selective reporting (re- } \\
\text { porting bias) }\end{array}$ & Unclear risk & $\begin{array}{l}\text { No protocol available and trial reported only in abstract form; outcomes for } \\
\text { this review not available }\end{array}$ \\
\hline Other bias & Unclear risk & Insufficient detail provided in abstract to allow judgement \\
\hline
\end{tabular}

\section{De Silva 1996}

\begin{tabular}{|c|c|c|}
\hline \multirow[t]{5}{*}{ Methods } & \multicolumn{2}{|c|}{ Parallel study design, outpatient setting } \\
\hline & \multicolumn{2}{|c|}{ Study conducted at two centres in the UK } \\
\hline & \multicolumn{2}{|c|}{ Random list generated using random permuted blocks } \\
\hline & \multicolumn{2}{|c|}{ Allocation concealed using sealed opaque envelopes } \\
\hline & \multicolumn{2}{|l|}{ Unblinded } \\
\hline \multirow[t]{4}{*}{ Participants } & \multicolumn{2}{|c|}{$\begin{array}{l}\text { Children with newly diagnosed epilepsy ( } 2 \text { or more untreated focal or generalised tonic-clonic seizures } \\
\text { in the } 12 \text { months preceding the trial) }\end{array}$} \\
\hline & \multicolumn{2}{|c|}{ Number randomised: $\mathrm{PHT}=54 ; \mathrm{SV}=49$} \\
\hline & \multicolumn{2}{|c|}{55 children (53\%) with focal epilepsy. 52 (50\%) boys } \\
\hline & \multicolumn{2}{|c|}{ Mean age (range): 10 (3-16) years. Range of follow-up (months): 3-88 } \\
\hline Interventions & \multicolumn{2}{|c|}{ Monotherapy with PHT or SV } \\
\hline & \multicolumn{2}{|c|}{ Median daily dose achieved: PHT: 175 mg/day, SV: 600 mg/day } \\
\hline Outcomes & \multicolumn{2}{|c|}{$\begin{array}{l}\text { Time to first seizure recurrence after start of therapy } \\
\text { Time to } 12 \text {-month remission from all seizures } \\
\text { Adverse events and treatment withdrawals due to adverse events }\end{array}$} \\
\hline Notes & \multicolumn{2}{|c|}{ IPD provided for all outcomes of this review } \\
\hline \multicolumn{3}{|l|}{ Risk of bias } \\
\hline Bias & Authors' judgement & Support for judgement \\
\hline $\begin{array}{l}\text { Random sequence genera- } \\
\text { tion (selection bias) }\end{array}$ & Low risk & $\begin{array}{l}\text { Randomisation list generated using permuted blocks of size } 8 \text { or } 16 \text { with strati- } \\
\text { fication for centre, seizure type and presence of neurological signs }\end{array}$ \\
\hline
\end{tabular}


De Silva 1996 (Continued)

$\begin{aligned} & \text { Allocation concealment } \\ & \text { (selection bias) }\end{aligned} \quad$ Low risk Allocation concealed via 4 batches of sealed opaque envelopes

\begin{tabular}{|c|c|c|}
\hline $\begin{array}{l}\text { Blinding of participants } \\
\text { and personnel (perfor- } \\
\text { mance bias) } \\
\text { All outcomes }\end{array}$ & High risk & $\begin{array}{l}\text { Unblinded, authors state masking of treatment would not be "practicable or } \\
\text { ethical" and would "undermine compliance" }\end{array}$ \\
\hline $\begin{array}{l}\text { Blinding of outcome as- } \\
\text { sessment (detection bias) } \\
\text { All outcomes }\end{array}$ & High risk & $\begin{array}{l}\text { Unblinded, authors state masking of treatment would not be "practicable or } \\
\text { ethical" and would "undermine compliance" }\end{array}$ \\
\hline $\begin{array}{l}\text { Incomplete outcome data } \\
\text { (attrition bias) } \\
\text { All outcomes }\end{array}$ & Low risk & $\begin{array}{l}\text { Attrition rates reported, all randomised participants analysed from IPD provid- } \\
\text { ed (see footnote } 2 \text { ) }\end{array}$ \\
\hline $\begin{array}{l}\text { Selective reporting (re- } \\
\text { porting bias) }\end{array}$ & Low risk & All outcomes reported or calculated with IPD provided (see footnote 2 ) \\
\hline Other bias & Low risk & No other bias detected \\
\hline
\end{tabular}

\section{Forsythe 1991}

\begin{tabular}{|c|c|c|}
\hline \multirow[t]{4}{*}{ Methods } & \multicolumn{2}{|c|}{ Parallel study design, outpatient setting } \\
\hline & \multicolumn{2}{|c|}{ Study conducted in the UK } \\
\hline & \multicolumn{2}{|c|}{$\begin{array}{l}\text { Patients randomly allocated using quota allocation allowing for gender, age, seizure type and current } \\
\text { treatment }\end{array}$} \\
\hline & \multicolumn{2}{|c|}{ Outcome assessors were single-blinded for cognitive testing } \\
\hline \multirow[t]{4}{*}{ Participants } & \multicolumn{2}{|c|}{ Children with at least 3 newly diagnosed generalised or focal seizures within a period of 6 months } \\
\hline & \multicolumn{2}{|c|}{ Number randomised: $\mathrm{PHT}=20 ; \mathrm{SV}=21$} \\
\hline & \multicolumn{2}{|c|}{ No information on epilepsy type, gender or range of follow-up } \\
\hline & \multicolumn{2}{|c|}{ Age range: $5-14$ years. Trial duration: 12 months } \\
\hline \multirow[t]{2}{*}{ Interventions } & \multicolumn{2}{|c|}{ Monotherapy with PHT or SV } \\
\hline & \multicolumn{2}{|c|}{ Mean dose achieved: PHT: $6.1 \mathrm{mg} /$ day, SV: $25.3 \mathrm{mg} /$ day } \\
\hline Outcomes & \multicolumn{2}{|c|}{$\begin{array}{l}\text { Cognitive assessments } \\
\text { Summary of withdrawals from randomised drug }\end{array}$} \\
\hline Notes & \multicolumn{2}{|c|}{$\begin{array}{l}\text { Outcomes chosen for this review were not reported. IPD not available, but could be constructed from } \\
\text { the publication for the outcome 'time on allocated drug' (without stratification by seizure type) }\end{array}$} \\
\hline \multicolumn{3}{|l|}{ Risk of bias } \\
\hline Bias & Authors' judgement & Support for judgement \\
\hline $\begin{array}{l}\text { Random sequence genera- } \\
\text { tion (selection bias) }\end{array}$ & High risk & $\begin{array}{l}\text { Quota allocation by gender, age, seizure type and current treatment is an inad- } \\
\text { equate randomisation method }\end{array}$ \\
\hline
\end{tabular}


Forsythe 1991 (Continued)

\begin{tabular}{l}
$\begin{array}{l}\text { Allocation concealment } \\
\text { (selection bias) }\end{array} \quad$ Unclear risk No information provided \\
\hline
\end{tabular}

\begin{tabular}{|c|c|c|}
\hline $\begin{array}{l}\text { Blinding of participants } \\
\text { and personnel (perfor- } \\
\text { mance bias) } \\
\text { All outcomes }\end{array}$ & High risk & Personnel and participants (and parents) unblinded \\
\hline $\begin{array}{l}\text { Blinding of outcome as- } \\
\text { sessment (detection bias) } \\
\text { All outcomes }\end{array}$ & Low risk & Outcome assessors single-blinded for cognitive testing \\
\hline $\begin{array}{l}\text { Incomplete outcome data } \\
\text { (attrition bias) } \\
\text { All outcomes }\end{array}$ & Low risk & $\begin{array}{l}\text { Attrition rates reported, results reported and analysed for all participants ran- } \\
\text { domised and all who completed various stages of follow-up }\end{array}$ \\
\hline $\begin{array}{l}\text { Selective reporting (re- } \\
\text { porting bias) }\end{array}$ & Unclear risk & $\begin{array}{l}\text { Cognitive outcomes described in methods section well reported in results sec- } \\
\text { tion. Adverse events reported, no seizure outcomes reported and outcomes } \\
\text { chosen for this review not reported. No protocol available so unclear if seizure } \\
\text { outcomes were planned a priori }\end{array}$ \\
\hline Other bias & Low risk & No other bias detected \\
\hline
\end{tabular}

Heller 1995

\begin{tabular}{|c|c|}
\hline \multirow[t]{5}{*}{ Methods } & Parallel study design, outpatient setting \\
\hline & Study conducted at two centres in the UK \\
\hline & Random list generated using random permuted blocks \\
\hline & Allocation concealed using sealed opaque envelopes \\
\hline & Unblinded \\
\hline
\end{tabular}

Participants

Adults with newly diagnosed epilepsy (2 or more untreated focal or generalised tonic-clonic seizures in the 12 months preceding the trial)

Number randomised: $\mathrm{PHT}=63 ; \mathrm{SV}=61$

53 participants (43\%) with focal epilepsy. $62(48 \%)$ men

Mean age (range): 33 (14-72) years

Range of follow-up (months): 1-91

\begin{tabular}{ll}
\hline Interventions & Monotherapy with PHT or SV \\
& Median daily dose achieved: $\mathrm{PHT}: 300 \mathrm{mg} / \mathrm{day}, \mathrm{SV}: 800 \mathrm{mg} / \mathrm{day}$ \\
\hline Outcomes & Time to first seizure recurrence after start of therapy \\
& Time to 12 -month remission from all seizures \\
& Adverse events and treatment withdrawal due to adverse events \\
\hline Notes & IPD provided for all outcomes of this review
\end{tabular}

\section{Risk of bias}


Heller 1995 (Continued)

\section{Bias Authors' judgement Support for judgement}

Random sequence genera- Low risk Randomisation list generated using permuted blocks of size 8 or 16 with stratition (selection bias) fication for centre, seizure type and presence of neurological signs

Allocation concealment Low risk Allocation concealed via 4 batches of concealed opaque envelopes
(selection bias)

$\begin{array}{ll}\text { Blinding of participants } \quad \text { High risk } & \text { Unblinded, authors state masking of treatment would not be "practical" and } \\ \text { and personnel (perfor- } & \text { would have "introduced bias due to a very large drop-out rate" }\end{array}$
mance bias)

All outcomes

Blinding of outcome assessment (detection bias) All outcomes
High risk

Unblinded, authors state masking of treatment would not be "practical" and would have "introduced bias due to a very large drop-out rate"

\begin{tabular}{lll}
\hline $\begin{array}{l}\text { Incomplete outcome data } \\
\text { (attrition bias) } \\
\text { All outcomes }\end{array}$ & Low risk & $\begin{array}{l}\text { Attrition rates reported, all randomised participants analyses from IPD provid- } \\
\text { ed (see footnote 2) }\end{array}$ \\
\hline $\begin{array}{l}\text { Selective reporting (re- } \\
\text { porting bias) }\end{array}$ & Low risk & All outcomes reported or calculated with IPD provided (see footnote 2) \\
\hline Other bias & Low risk & No other bias detected \\
\hline
\end{tabular}

Ramsay 1992

Methods
Study conducted at 16 centres in the USA
Participants assigned via randomisation tables within each centre in a 2:1 ratio (SV:PHT)
Method of allocation concealment not stated
Unblinded
Participants Participants with at least 2 newly diagnosed and previously untreated primary generalised tonic-clonic seizures within 14 days of starting the trial
Number randomised: $\mathrm{PHT}=50 ; \mathrm{SV}=86$
0\% participants with focal epilepsy, 73 (54\%) men
Mean age (range): 21 (3-64 years). Participants followed up for up to 6 months

\begin{tabular}{ll}
\hline Interventions & $\begin{array}{l}\text { Monotherapy with PHT or SV } \\
\text { Starting doses PHT: } 3-5 \mathrm{mg} / \mathrm{kg} / \text { day, SV: } 10-15 \\
\text { Doses achieved not stated }\end{array}$ \\
\hline Outcomes & Time to first generalised tonic-clonic seizure \\
6-month seizure recurrence rates \\
Adverse events
\end{tabular}


Ramsay 1992 (Continued)

Notes

IPD provided for 3/4 outcomes of this review (maximum follow-up 6 months, therefore trial cannot contribute to outcome 'time to achieve 12-month remission')

\section{Risk of bias}

\begin{tabular}{|c|c|c|}
\hline Bias & Authors' judgement & Support for judgement \\
\hline $\begin{array}{l}\text { Random sequence genera- } \\
\text { tion (selection bias) }\end{array}$ & Low risk & $\begin{array}{l}\text { Participants randomised on a 2:1 ratio SV:PHT using randomisation tables in } \\
\text { each centre (information provided by trial author) }\end{array}$ \\
\hline $\begin{array}{l}\text { Allocation concealment } \\
\text { (selection bias) }\end{array}$ & Unclear risk & No information provided \\
\hline $\begin{array}{l}\text { Blinding of participants } \\
\text { and personnel (perfor- } \\
\text { mance bias) } \\
\text { All outcomes }\end{array}$ & High risk & $\begin{array}{l}\text { Open-label trial; authors state that differences in adverse events of PHT and SV } \\
\text { would "quickly unblind" the trial anyway }\end{array}$ \\
\hline $\begin{array}{l}\text { Blinding of outcome as- } \\
\text { sessment (detection bias) } \\
\text { All outcomes }\end{array}$ & High risk & $\begin{array}{l}\text { Open-label trial; authors state that differences in adverse events of PHT and SV } \\
\text { would "quickly unblind" the trial anyway }\end{array}$ \\
\hline $\begin{array}{l}\text { Incomplete outcome data } \\
\text { (attrition bias) } \\
\text { All outcomes }\end{array}$ & Low risk & $\begin{array}{l}\text { Attrition rates reported, all randomised participants analysed from IPD provid- } \\
\text { ed (see footnote } 2 \text { ) }\end{array}$ \\
\hline $\begin{array}{l}\text { Selective reporting (re- } \\
\text { porting bias) }\end{array}$ & Low risk & All outcomes reported or calculated with IPD provided (see footnote 2 ) \\
\hline Other bias & Low risk & No other bias detected \\
\hline
\end{tabular}

\section{Rastogi 1991}

Methods Parallel study design, outpatient setting

Study conducted in Meerut, India

No information provided on method of generation of random list, allocation concealment or blinding

Participants with at least 2 focal or generalised tonic-clonic seizuresp
Unclear if participants were newly diagnosed
Number randomised: PHT $=45 ; \mathrm{SV}=49$
27 participants (29\%) focal epilepsy, $70(74 \%)$ men
Age range: PHT: $12-42$ years; SV: $8-52$ years
Participants were evaluated after 4, 12 and 24 weeks of treatment
No information on range of follow-up

$\begin{array}{ll}\text { Interventions } & \text { Monotherapy with PHT or SV } \\ & \text { Average daily dose achieved: PHT: } 5.6 \mathrm{mg} / \mathrm{kg} / \text { day, SV: } 18.8 \mathrm{mg} / \mathrm{kg} / \text { day }\end{array}$


Rastogi 1991 (Continued)

excellent (100\% reduction)

good $(75 \%-99 \%$ reduction)

fair $(50 \%-74 \%$ reduction)

poor ( $<50 \%$ reduction)

Adverse effects

Seizure control

Notes Outcomes chosen for this review were not reported. IPD not available

\section{Risk of bias}

Bias Authors' judgement Support for judgement

Random sequence genera- Unclear risk Participants "randomly allocated irrespective of seizure type," no further infortion (selection bias) mation provided

\begin{tabular}{lll}
\hline $\begin{array}{l}\text { Allocation concealment } \\
\text { (selection bias) }\end{array}$ & Unclear risk & No information provided \\
\hline $\begin{array}{l}\text { Blinding of participants } \\
\text { and personnel (perfor- } \\
\text { mance bias) }\end{array}$ & Unclear risk & No information provided \\
All outcomes & \\
\hline
\end{tabular}

Blinding of outcome as- Unclear risk No information provided

sessment (detection bias)

All outcomes

\begin{tabular}{|c|c|c|}
\hline $\begin{array}{l}\text { Incomplete outcome data } \\
\text { (attrition bias) } \\
\text { All outcomes }\end{array}$ & Unclear risk & $\begin{array}{l}\text { Frequency of seizures reported for all randomised participants, no information } \\
\text { provided on treatment withdrawal rates/attrition rates etc. }\end{array}$ \\
\hline
\end{tabular}

\begin{tabular}{lll}
\hline $\begin{array}{l}\text { Selective reporting (re- } \\
\text { porting bias) }\end{array}$ & Low risk & $\begin{array}{l}\text { Frequency of seizures during treatment well reported, most common adverse } \\
\text { events reported }\end{array}$ \\
& $\begin{array}{l}\text { No protocol available to compare with a priori analysis plan, outcomes for this } \\
\text { review not reported }\end{array}$ \\
\hline Other bias & Low risk & No other bias detected \\
\hline
\end{tabular}

\section{Shakir 1981}

$\begin{array}{ll}\text { Methods } & \text { Parallel study design, outpatient setting } \\ \text { Study conducted in two centres (Glasgow, Scotland and Wellington, New Zealand) } \\ \text { Participants allocated using telephone randomisation within the two centres (information provided by } \\ \text { trial author) } \\ \text { No information provided on method of allocation concealment or blinding }\end{array}$

\section{Participants}

$21(64 \%)$ participants previously untreated, 12 (36\%) participants continued to have seizures on previous drug therapies

Original treatments gradually withdrawn before PHT or SV treatment introduced

Number randomised: $\mathrm{PHT}=15 ; \mathrm{SV}=18$ 
Shakir 1981 (Continued)

19 participants (58\%) with focal epilepsy, 12 (36\%) men

Mean age (range): 23 (7-55 years). Mean follow-up (range): 30 (9-48 months)

\begin{tabular}{|c|c|c|}
\hline Interventions & \multicolumn{2}{|c|}{ Monotherapy with PHT or SV } \\
\hline & \multicolumn{2}{|c|}{ Starting doses: $\mathrm{PHT}:<12$ years $150 \mathrm{mg} /$ day, older participants: $300 \mathrm{mg} /$ day } \\
\hline & \multicolumn{2}{|c|}{ SV: $<12$ years $300-400 \mathrm{mg} /$ day, older participants: $800-1200 \mathrm{mg} /$ day. Doses achieved not stated } \\
\hline Outcomes & \multicolumn{2}{|c|}{$\begin{array}{l}\text { Seizures during treatment } \\
\text { Adverse events }\end{array}$} \\
\hline Notes & \multirow{2}{*}{\multicolumn{2}{|c|}{$\begin{array}{l}\text { Outcomes chosen for this review were not reported } \\
\text { IPD not available but could be constructed from the publication for the outcome 'time to treatment } \\
\text { failure' }\end{array}$}} \\
\hline & & \\
\hline \multicolumn{3}{|l|}{ Risk of bias } \\
\hline Bias & Authors' judgement & Support for judgement \\
\hline $\begin{array}{l}\text { Random sequence genera- } \\
\text { tion (selection bias) }\end{array}$ & Low risk & $\begin{array}{l}\text { Participants "randomly divided", using telephone randomisation (information } \\
\text { provided by trial author) }\end{array}$ \\
\hline $\begin{array}{l}\text { Allocation concealment } \\
\text { (selection bias) }\end{array}$ & Unclear risk & No information provided \\
\hline $\begin{array}{l}\text { Blinding of participants } \\
\text { and personnel (perfor- } \\
\text { mance bias) } \\
\text { All outcomes }\end{array}$ & Unclear risk & No information provided \\
\hline
\end{tabular}

\begin{tabular}{lll}
$\begin{array}{l}\text { Blinding of outcome as- } \\
\text { sessment (detection bias) } \\
\text { All outcomes }\end{array}$ & Unclear risk & No information provided \\
\hline $\begin{array}{l}\text { Incomplete outcome data } \\
\text { (attrition bias) } \\
\text { All outcomes }\end{array}$ & Low risk & $\begin{array}{l}\text { Results reported for all randomised participants, time on treatment reported } \\
\text { for all randomised participants. No losses to follow-up reported }\end{array}$ \\
\hline $\begin{array}{l}\text { Selective reporting (re- } \\
\text { porting bias) }\end{array}$ & Low risk & $\begin{array}{l}\text { No protocol available, outcomes chosen for this review not reported. Seizure } \\
\text { outcomes and adverse events well reported }\end{array}$ \\
\hline Other bias & Low risk & No other bias detected \\
\hline
\end{tabular}

Thilothammal 1996

$\begin{array}{ll}\text { Methods } & \text { Parallel study design, outpatient setting } \\ \text { Study conducted in Madras (Chennai), India } \\ \text { Random list generated using computer-generated random numbers } \\ \text { Method of concealment not mentioned } \\ \text { Double-blind achieved by providing additional placebo tablets }\end{array}$


Thilothammal 1996 (Continued)
Participants
Children with more than 1 previously untreated generalised tonic-clonic (afebrile) seizure
Number randomised: $\mathrm{PHT}=52 ; \mathrm{SV}=48$
$0 \%$ focal epilepsy. 52 (52\%) men. Age range: 4-12 years
Range of follow-up (months): 22-36

\begin{tabular}{ll}
\hline Interventions & Monotherapy with PHT or SV \\
& Starting doses: PHT: $5-8 \mathrm{mg} / \mathrm{kg} / \mathrm{day}, \mathrm{SV}: 15-50 \mathrm{mg} / \mathrm{kg} /$ day \\
& Dose achieved not stated \\
\hline Outcomes & $\begin{array}{l}\text { Proportion with recurrence of seizures } \\
\text { Adverse events }\end{array}$ \\
\hline Notes & Outcomes chosen for this review were not reported. IPD not available
\end{tabular}

\section{Risk of bias}

\begin{tabular}{|c|c|c|}
\hline Bias & Authors' judgement & Support for judgement \\
\hline $\begin{array}{l}\text { Random sequence genera- } \\
\text { tion (selection bias) }\end{array}$ & Low risk & Participants randomised via a computer-generated list of random numbers \\
\hline $\begin{array}{l}\text { Allocation concealment } \\
\text { (selection bias) }\end{array}$ & Unclear risk & No information provided \\
\hline $\begin{array}{l}\text { Blinding of participants } \\
\text { and personnel (perfor- } \\
\text { mance bias) } \\
\text { All outcomes }\end{array}$ & Unclear risk & Double-blinded using additional placebo tablets; unclear who was blinded \\
\hline $\begin{array}{l}\text { Blinding of outcome as- } \\
\text { sessment (detection bias) } \\
\text { All outcomes }\end{array}$ & Unclear risk & Double-blinded using additional placebo tablets; unclear who was blinded \\
\hline $\begin{array}{l}\text { Incomplete outcome data } \\
\text { (attrition bias) } \\
\text { All outcomes }\end{array}$ & Low risk & Attrition rates reported; all randomised participants analysed \\
\hline $\begin{array}{l}\text { Selective reporting (re- } \\
\text { porting bias) }\end{array}$ & Low risk & No protocol available; outcomes chosen for this review not reported \\
\hline Other bias & Low risk & No other bias detected \\
\hline
\end{tabular}

Turnbull 1985

\begin{tabular}{ll}
\hline Methods & Parallel study design, outpatient setting \\
Study conducted in the UK & Participants allocated to treatment stratified by age group, gender and seizure type \\
& No information provided on method of generation of random list, allocation concealment or blinding \\
\hline Participants & Participants with 2 or more focal or generalised tonic-clonic seizure in the past 3 years \\
\hline
\end{tabular}


Turnbull 1985 (Continued)

Participants were previously untreated but started on antiepileptic drug treatment within 3 months of their most recent seizure

Number randomised: $\mathrm{PHT}=70 ; \mathrm{SV}=70$

63 participants (45\%) with focal onset seizures, 73 (52\%) men

Mean age (range): 35 (14-70 years). Range of follow-up: 24-48 months

Interventions

Monotherapy with PHT or SV

Starting doses: PHT 300 mg/day, SV 600 mg/day. Dose achieved not stated

\begin{tabular}{ll}
\hline Outcomes & Time to 2-year remission \\
& Time to first seizure \\
& Adverse events \\
\hline Notes & IPD provided for all outcomes included in this review
\end{tabular}

\section{Risk of bias}

\begin{tabular}{lll}
\hline Bias & Authors' judgement & Support for judgement \\
\hline $\begin{array}{l}\text { Random sequence genera- } \\
\text { tion (selection bias) }\end{array}$ & Unclear risk & $\begin{array}{l}\text { Participants randomised with stratification for age group, gender and seizure } \\
\text { type. Method of randomisation not stated }\end{array}$ \\
\hline $\begin{array}{l}\text { Allocation concealment } \\
\text { (selection bias) }\end{array}$ & Unclear risk & No information provided \\
\hline $\begin{array}{l}\text { Blinding of participants } \\
\text { and personnel (perfor- } \\
\text { mance bias) } \\
\text { All outcomes }\end{array}$ & Unclear risk & No information provided \\
\hline
\end{tabular}

\begin{tabular}{lll}
\hline $\begin{array}{l}\text { Blinding of outcome as- } \\
\text { sessment (detection bias) } \\
\text { All outcomes }\end{array}$ & Unclear risk & No information provided \\
\hline $\begin{array}{l}\text { Incomplete outcome data } \\
\begin{array}{l}\text { (attrition bias) } \\
\text { All outcomes }\end{array}\end{array}$ & Low risk & $\begin{array}{l}\text { Attrition rates reported, ITT approach, all randomised participants analysed } \\
\text { from IPD provided (see footnote 2) }\end{array}$ \\
\hline $\begin{array}{l}\text { Selective reporting (re- } \\
\text { porting bias) }\end{array}$ & Low risk & All outcomes reported or calculated with IPD provided (see footnote 2) \\
\hline Other bias & Low risk & No other bias detected \\
\hline
\end{tabular}

\footnotetext{
1 Abbreviations:

IPD: individual participant data; ITT: intention-to-treat; PHT: phenytoin; SV: sodium valproate.

2 For studies which provided IPD, attrition and reporting bias are reduced as attrition rates and unpublished outcome data are requested

(Craig 1994; De Silva 1996; Heller 1995; Ramsay 1992; Turnbull 1985).

3 See Figure 2 and Figure 3 for 'Risk of bias' summary and graph.
}

Characteristics of excluded studies [ordered by study ID] 


\begin{tabular}{|c|c|}
\hline Study & Reason for exclusion \\
\hline Berg 1993 & $\begin{array}{l}\text { Reports the same trial as Forsythe 1991, but more relevant information given in the Forsythe publi- } \\
\text { cation }\end{array}$ \\
\hline Callaghan 1981 & Abstract only. Preliminary results of the trial reported in Callaghan 1985 \\
\hline Callaghan 1983 & Abstract only. Preliminary results of the trial reported in Callaghan 1985 \\
\hline Callaghan 1984 & Preliminary results of the trial reported in Callaghan 1985 \\
\hline Craig 1993 & Abstract only. Preliminary results of the trial reported in Craig 1994 \\
\hline Czapinski 1997b & Reports the same abstract as Czapinski 1997a \\
\hline Czapinski 1997c & Reports the same abstract as Czapinski 1997a \\
\hline Goggin 1984 & Abstract only. Preliminary results of the trial reported in Callaghan 1985 \\
\hline Goggin 1986 & $\begin{array}{l}\text { Reports the same trial as Callaghan 1985, but more relevant information given in the Callaghan } \\
\text { publication }\end{array}$ \\
\hline Jannuzzi 2000 & $\begin{array}{l}\text { No randomised comparison of valproate and phenytoin (participants randomised to a dose adjust- } \\
\text { ment method rather than to a treatment) }\end{array}$ \\
\hline Kaminow 2003 & $\begin{array}{l}\text { No randomised comparison of valproate and phenytoin (study of lamotrigine versus 'standard' } \\
\text { antiepileptic drug treatment) }\end{array}$ \\
\hline Sabers 1995 & $\begin{array}{l}\text { Not fully randomised: "The treatment was chosen at random unless the individual diagnoses re- } \\
\text { quired a specific drug" }\end{array}$ \\
\hline Schmidt 2007 & $\begin{array}{l}\text { No randomised comparison of valproate and phenytoin (post hoc analysis of } 5 \text { studies of oxcar- } \\
\text { bazepine versus another antiepileptic drug) }\end{array}$ \\
\hline Shakir 1980 & $\begin{array}{l}\text { Reports the same trial as Shakir } 1981 \text {. There are some differences between the results in the } 2 \text { pub- } \\
\text { lications. The reason for this could not be established }\end{array}$ \\
\hline Tallis 1994a & Abstract only. Reports the same trial as Craig 1994 \\
\hline Tallis 1994b & Abstract only. Reports the same trial as Craig 1994 \\
\hline Turnbull 1982 & Preliminary results of the trial reported in Turnbull 1985 \\
\hline Wilder 1983 & Preliminary results of the trial reported in Turnbull 1985 \\
\hline Zeng 2010 & Not randomised \\
\hline
\end{tabular}

\section{DATA AND ANALYSES}


Comparison 1. Sodium valproate versus phenytoin

\begin{tabular}{|c|c|c|c|c|}
\hline Outcome or subgroup title & No. of studies & $\begin{array}{l}\text { No. of partici- } \\
\text { pants }\end{array}$ & Statistical method & Effect size \\
\hline $\begin{array}{l}1 \text { Time to treatment failure (any reason } \\
\text { related to the treatment) }\end{array}$ & 6 & 569 & $\begin{array}{l}\text { Hazard Ratio (Fixed, 95\% } \\
\mathrm{Cl} \text { ) }\end{array}$ & $0.94[0.67,1.32]$ \\
\hline $\begin{array}{l}2 \text { Time to treatment failure due to ad- } \\
\text { verse events }\end{array}$ & 4 & 495 & $\begin{array}{l}\text { Hazard Ratio (Fixed, 95\% } \\
\mathrm{Cl} \text { ) }\end{array}$ & $0.68[0.40,1.17]$ \\
\hline $\begin{array}{l}3 \text { Time to treatment failure due to lack } \\
\text { of efficacy }\end{array}$ & 6 & 569 & $\begin{array}{l}\text { Hazard Ratio (Fixed, 95\% } \\
\mathrm{Cl} \text { ) }\end{array}$ & $1.23[0.77,1.97]$ \\
\hline $\begin{array}{l}4 \text { Time to treatment failure (any reason } \\
\text { related to the treatment) - by epilepsy } \\
\text { type }\end{array}$ & 5 & 528 & $\begin{array}{l}\text { Hazard Ratio (Fixed, 95\% } \\
\mathrm{Cl} \text { ) }\end{array}$ & $0.88[0.61,1.27]$ \\
\hline 4.1 Focal onset seizures & 4 & 187 & $\begin{array}{l}\text { Hazard Ratio (Fixed, 95\% } \\
\mathrm{Cl} \text { ) }\end{array}$ & $0.83[0.50,1.38]$ \\
\hline $\begin{array}{l}4.2 \text { Generalised onset seizures (ton- } \\
\text { ic-clonic only) }\end{array}$ & 5 & 341 & $\begin{array}{l}\text { Hazard Ratio (Fixed, 95\% } \\
\mathrm{Cl} \text { ) }\end{array}$ & $0.94[0.55,1.61]$ \\
\hline $\begin{array}{l}5 \text { Time to treatment failure due to ad- } \\
\text { verse events - by epilepsy type }\end{array}$ & 4 & 418 & $\begin{array}{l}\text { Hazard Ratio (Fixed, 95\% } \\
\mathrm{Cl} \text { ) }\end{array}$ & $0.77[0.44,1.37]$ \\
\hline 5.1 Focal onset seizures & 3 & 168 & $\begin{array}{l}\text { Hazard Ratio (Fixed, 95\% } \\
\mathrm{Cl} \text { ) }\end{array}$ & $0.75[0.35,1.60]$ \\
\hline $\begin{array}{l}5.2 \text { Generalised onset seizures (ton- } \\
\text { ic-clonic only) }\end{array}$ & 3 & 250 & $\begin{array}{l}\text { Hazard Ratio (Fixed, 95\% } \\
\mathrm{Cl} \text { ) }\end{array}$ & $0.81[0.34,1.90]$ \\
\hline $\begin{array}{l}6 \text { Time to treatment failure due to lack } \\
\text { of efficacy - by epilepsy type }\end{array}$ & 5 & 451 & $\begin{array}{l}\text { Hazard Ratio (Fixed, 95\% } \\
\mathrm{Cl} \text { ) }\end{array}$ & $1.16[0.71,1.89]$ \\
\hline 6.1 Focal onset seizures & 4 & 187 & $\begin{array}{l}\text { Hazard Ratio (Fixed, 95\% } \\
\mathrm{Cl} \text { ) }\end{array}$ & $1.01[0.55,1.85]$ \\
\hline $\begin{array}{l}6.2 \text { Generalised onset seizures (ton- } \\
\text { ic-clonic only) }\end{array}$ & 4 & 264 & $\begin{array}{l}\text { Hazard Ratio (Fixed, 95\% } \\
\mathrm{Cl} \text { ) }\end{array}$ & $1.51[0.66,3.45]$ \\
\hline 7 Time to first seizure & 5 & 639 & $\begin{array}{l}\text { Hazard Ratio (Fixed, 95\% } \\
\mathrm{Cl} \text { ) }\end{array}$ & $1.04[0.85,1.28]$ \\
\hline 8 Time to first seizure - by epilepsy type & 5 & 639 & $\begin{array}{l}\text { Hazard Ratio (Fixed, 95\% } \\
\mathrm{Cl} \text { ) }\end{array}$ & $1.08[0.88,1.33]$ \\
\hline 8.1 Focal onset seizures & 4 & 244 & $\begin{array}{l}\text { Hazard Ratio (Fixed, 95\% } \\
\mathrm{Cl} \text { ) }\end{array}$ & $1.20[0.90,1.60]$ \\
\hline $\begin{array}{l}8.2 \text { Generalised onset seizures (ton- } \\
\text { ic-clonic only) }\end{array}$ & 5 & 395 & $\begin{array}{l}\text { Hazard Ratio (Fixed, 95\% } \\
\mathrm{Cl} \text { ) }\end{array}$ & $0.97[0.72,1.30]$ \\
\hline $\begin{array}{l}9 \text { Time to first seizure - epilepsy type re- } \\
\text { classified to focal for generalised and } \\
\text { age of onset }>30 \text { years }\end{array}$ & 5 & 639 & $\begin{array}{l}\text { Hazard Ratio (Fixed, 95\% } \\
\mathrm{Cl} \text { ) }\end{array}$ & $1.05[0.86,1.29]$ \\
\hline
\end{tabular}




\begin{tabular}{|c|c|c|c|c|}
\hline Outcome or subgroup title & No. of studies & $\begin{array}{l}\text { No. of partici- } \\
\text { pants }\end{array}$ & Statistical method & Effect size \\
\hline 9.1 Focal onset seizures & 5 & 416 & $\begin{array}{l}\text { Hazard Ratio (Fixed, 95\% } \\
\mathrm{Cl} \text { ) }\end{array}$ & $1.23[0.96,1.57]$ \\
\hline $\begin{array}{l}9.2 \text { Generalised onset seizures (ton- } \\
\text { ic-clonic only) }\end{array}$ & 4 & 223 & $\begin{array}{l}\text { Hazard Ratio (Fixed, 95\% } \\
\mathrm{Cl} \text { ) }\end{array}$ & $0.72[0.50,1.05]$ \\
\hline $\begin{array}{l}10 \text { Time to first seizure - epilepsy type } \\
\text { reclassified to uncertain for generalised } \\
\text { and age of onset }>30 \text { years }\end{array}$ & 5 & 649 & $\begin{array}{l}\text { Hazard Ratio (Fixed, 95\% } \\
\mathrm{Cl} \text { ) }\end{array}$ & $1.06[0.86,1.30]$ \\
\hline 10.1 Focal onset seizures & 4 & 255 & $\begin{array}{l}\text { Hazard Ratio (Fixed, 95\% } \\
\mathrm{Cl} \text { ) }\end{array}$ & $1.20[0.90,1.60]$ \\
\hline $\begin{array}{l}10.2 \text { Generalised onset seizures (ton- } \\
\text { ic-clonic only) }\end{array}$ & 4 & 223 & $\begin{array}{l}\text { Hazard Ratio (Fixed, 95\% } \\
\mathrm{Cl} \text { ) }\end{array}$ & $0.72[0.50,1.05]$ \\
\hline 10.3 Uncertain seizure type & 4 & 171 & $\begin{array}{l}\text { Hazard Ratio (Fixed, 95\% } \\
\mathrm{Cl} \text { ) }\end{array}$ & $1.35[0.85,2.14]$ \\
\hline 11 Time to achieve 12 -month remission & 4 & 514 & $\begin{array}{l}\text { Hazard Ratio (Fixed, 95\% } \\
\mathrm{Cl} \text { ) }\end{array}$ & $1.03[0.82,1.29]$ \\
\hline $\begin{array}{l}12 \text { Time to achieve } 12 \text {-month remission } \\
\text { - by epilepsy type }\end{array}$ & 4 & 514 & $\begin{array}{l}\text { Hazard Ratio (Fixed, 95\% } \\
\mathrm{Cl} \text { ) }\end{array}$ & $1.02[0.81,1.28]$ \\
\hline 12.1 Focal onset seizures & 4 & 244 & $\begin{array}{l}\text { Hazard Ratio (Fixed, 95\% } \\
\mathrm{Cl} \text { ) }\end{array}$ & $1.11[0.78,1.60]$ \\
\hline $\begin{array}{l}12.2 \text { Generalised onset seizures (ton- } \\
\text { ic-clonic only) }\end{array}$ & 4 & 270 & $\begin{array}{l}\text { Hazard Ratio (Fixed, 95\% } \\
\mathrm{Cl} \text { ) }\end{array}$ & $0.96[0.71,1.29]$ \\
\hline 13 Time to achieve six-month remission & 5 & 639 & $\begin{array}{l}\text { Hazard Ratio (Fixed, 95\% } \\
\mathrm{Cl} \text { ) }\end{array}$ & $1.08[0.89,1.30]$ \\
\hline $\begin{array}{l}14 \text { Time to achieve six-month remission } \\
\text { - by epilepsy type }\end{array}$ & 5 & 639 & $\begin{array}{l}\text { Hazard Ratio (Fixed, 95\% } \\
\mathrm{Cl} \text { ) }\end{array}$ & $1.05[0.86,1.27]$ \\
\hline 14.1 Focal onset seizures & 4 & 244 & $\begin{array}{l}\text { Hazard Ratio (Fixed, 95\% } \\
\mathrm{Cl} \text { ) }\end{array}$ & $1.00[0.73,1.35]$ \\
\hline $\begin{array}{l}14.2 \text { Generalised onset seizures (ton- } \\
\text { ic-clonic only) }\end{array}$ & 5 & 395 & $\begin{array}{l}\text { Hazard Ratio (Fixed, 95\% } \\
\mathrm{Cl} \text { ) }\end{array}$ & $1.08[0.84,1.38]$ \\
\hline
\end{tabular}

Analysis 1.1. Comparison 1 Sodium valproate versus phenytoin, Outcome 1 Time to treatment failure (any reason related to the treatment).

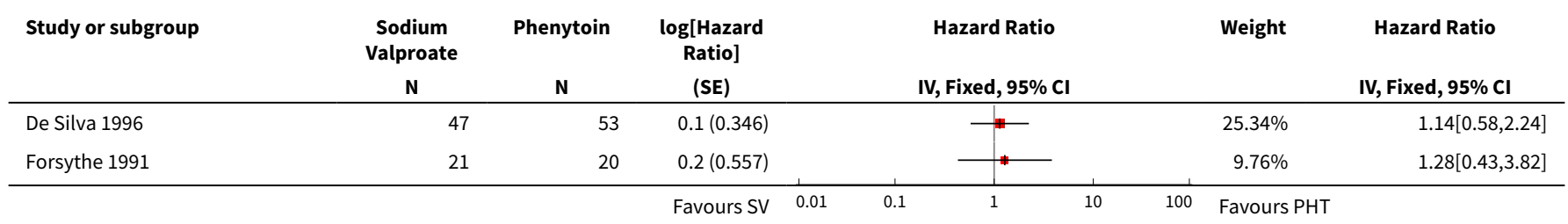




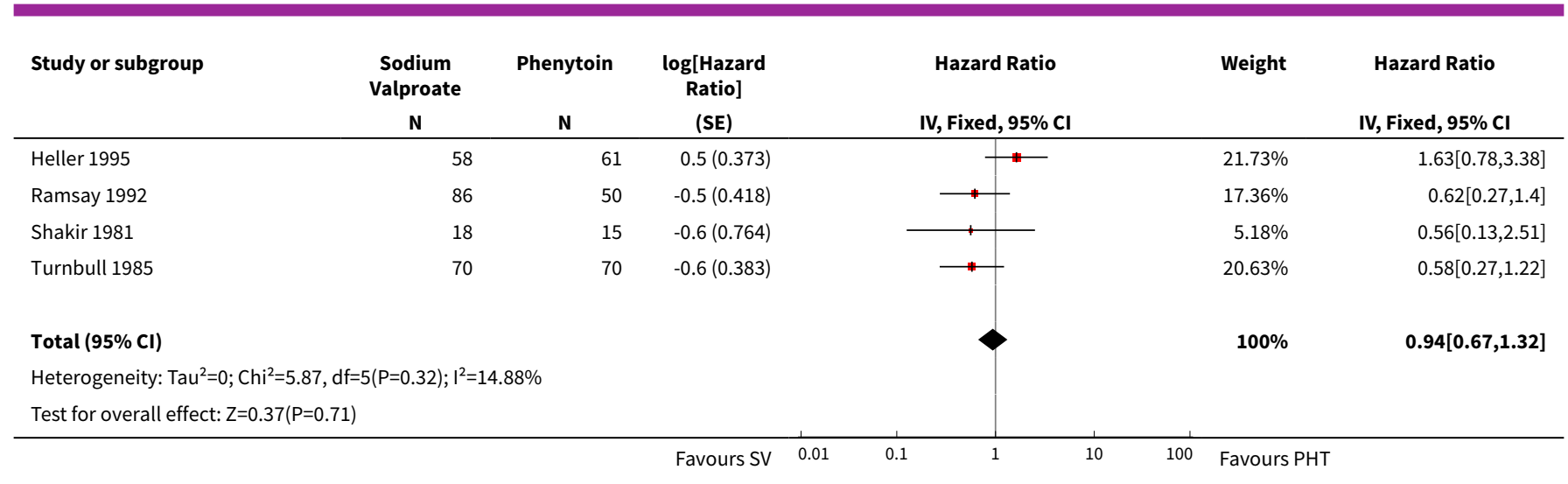

Analysis 1.2. Comparison 1 Sodium valproate versus phenytoin, Outcome 2 Time to treatment failure due to adverse events.

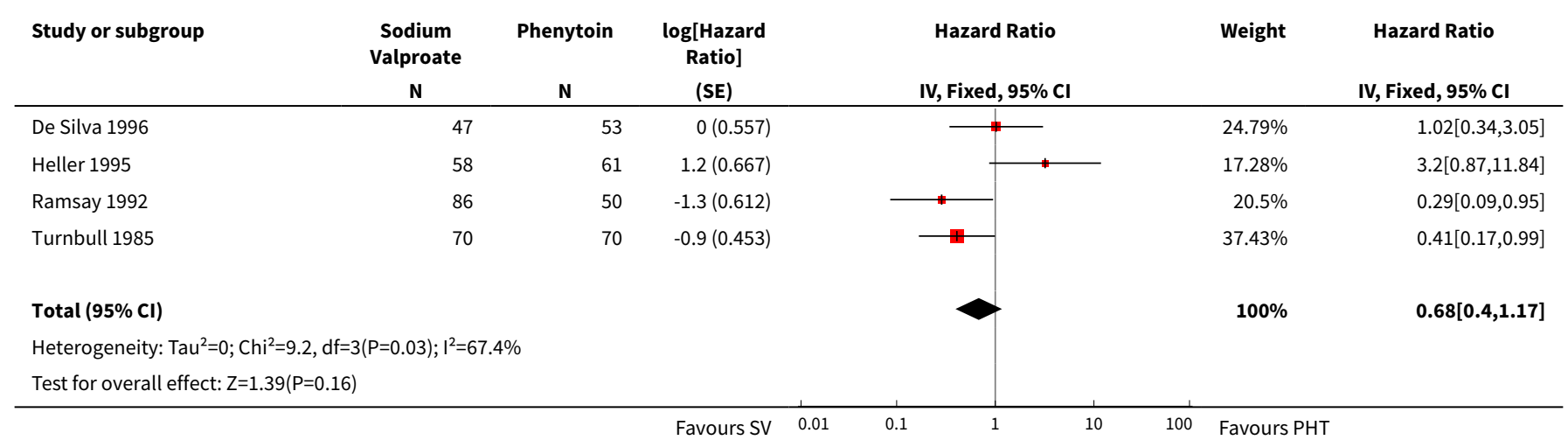

Analysis 1.3. Comparison 1 Sodium valproate versus phenytoin, Outcome 3 Time to treatment failure due to lack of efficacy.

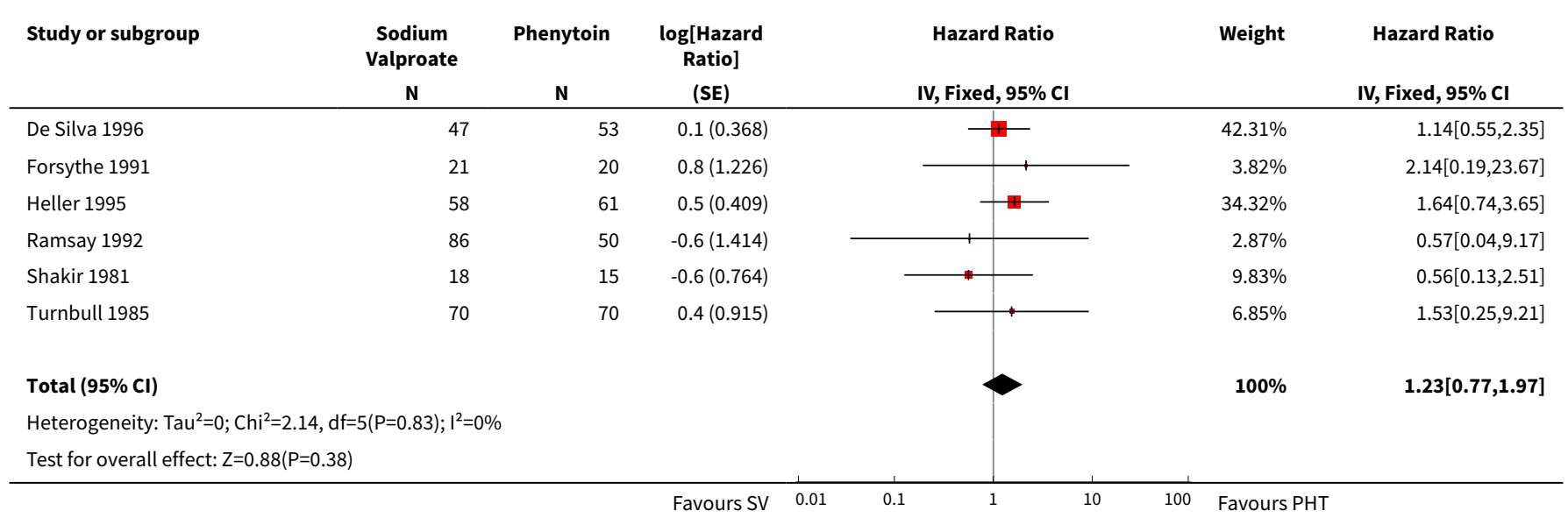


Analysis 1.4. Comparison 1 Sodium valproate versus phenytoin, Outcome 4 Time to treatment failure (any reason related to the treatment) - by epilepsy type.

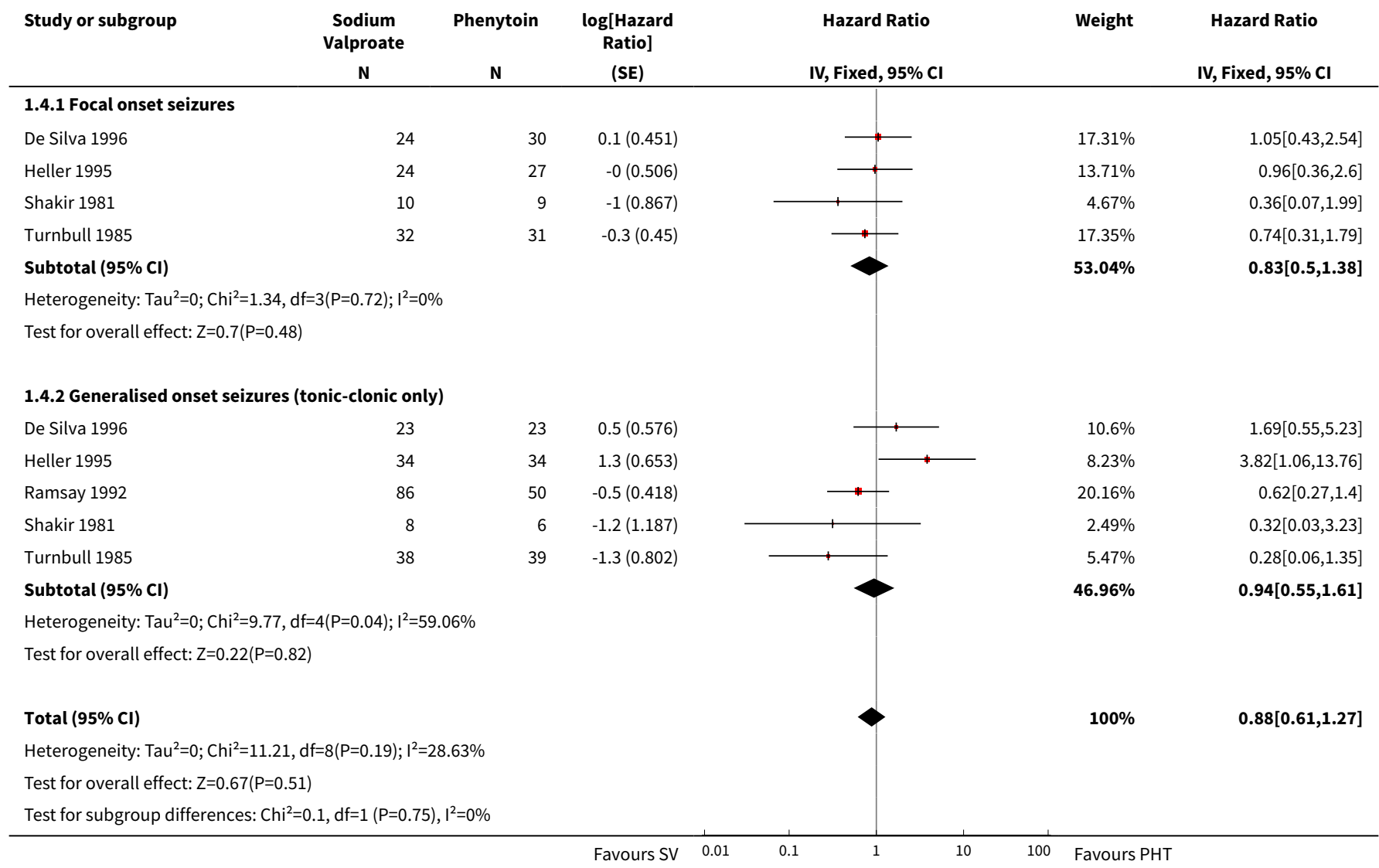

Analysis 1.5. Comparison 1 Sodium valproate versus phenytoin, Outcome 5 Time to treatment failure due to adverse events - by epilepsy type.

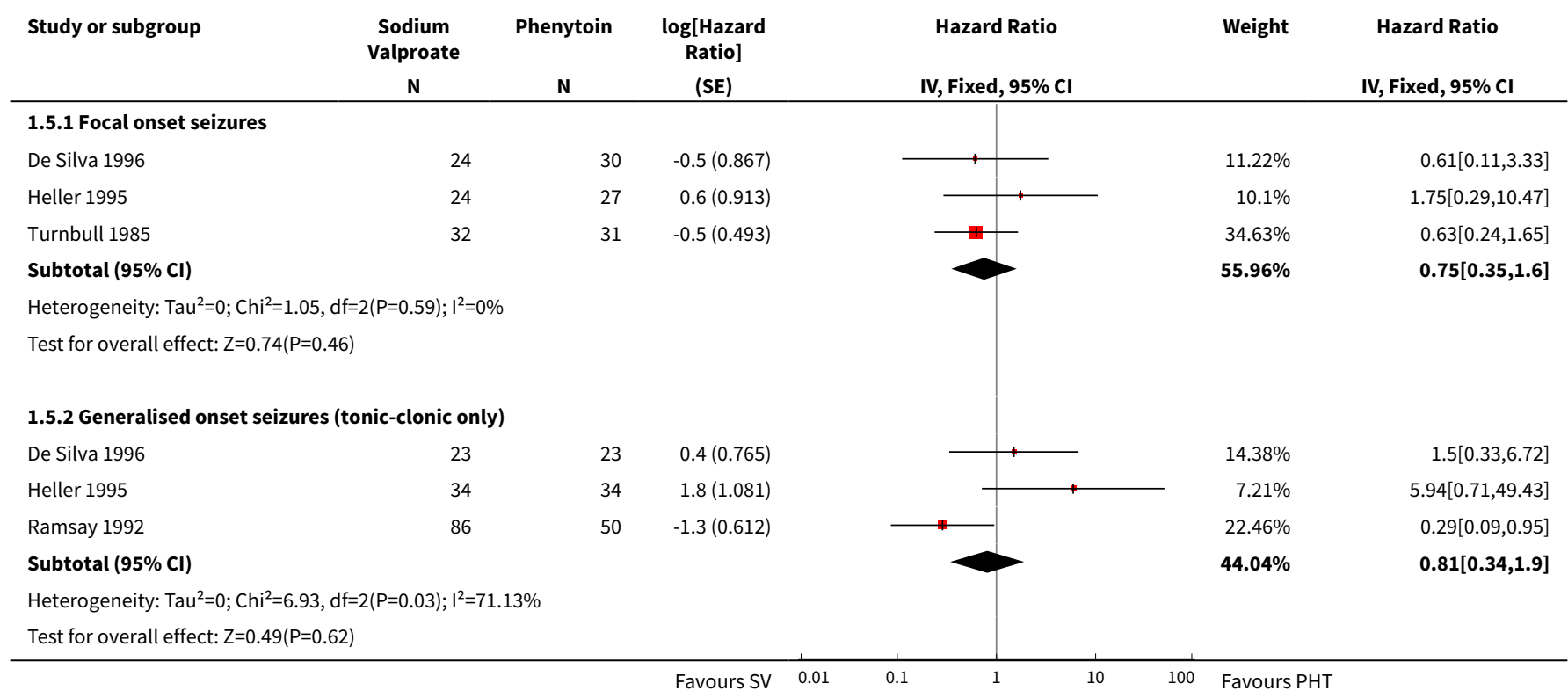




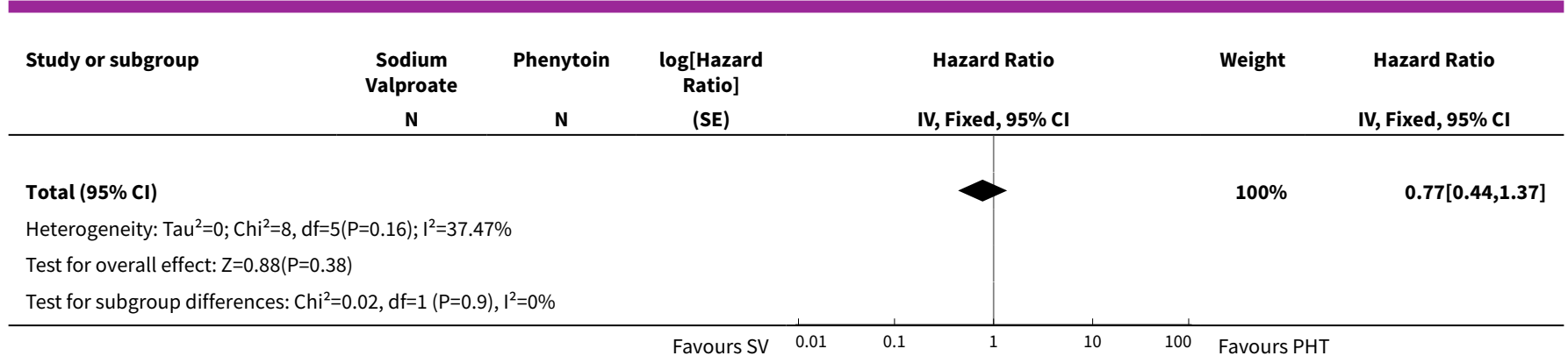

Analysis 1.6. Comparison 1 Sodium valproate versus phenytoin, Outcome 6 Time to treatment failure due to lack of efficacy - by epilepsy type.

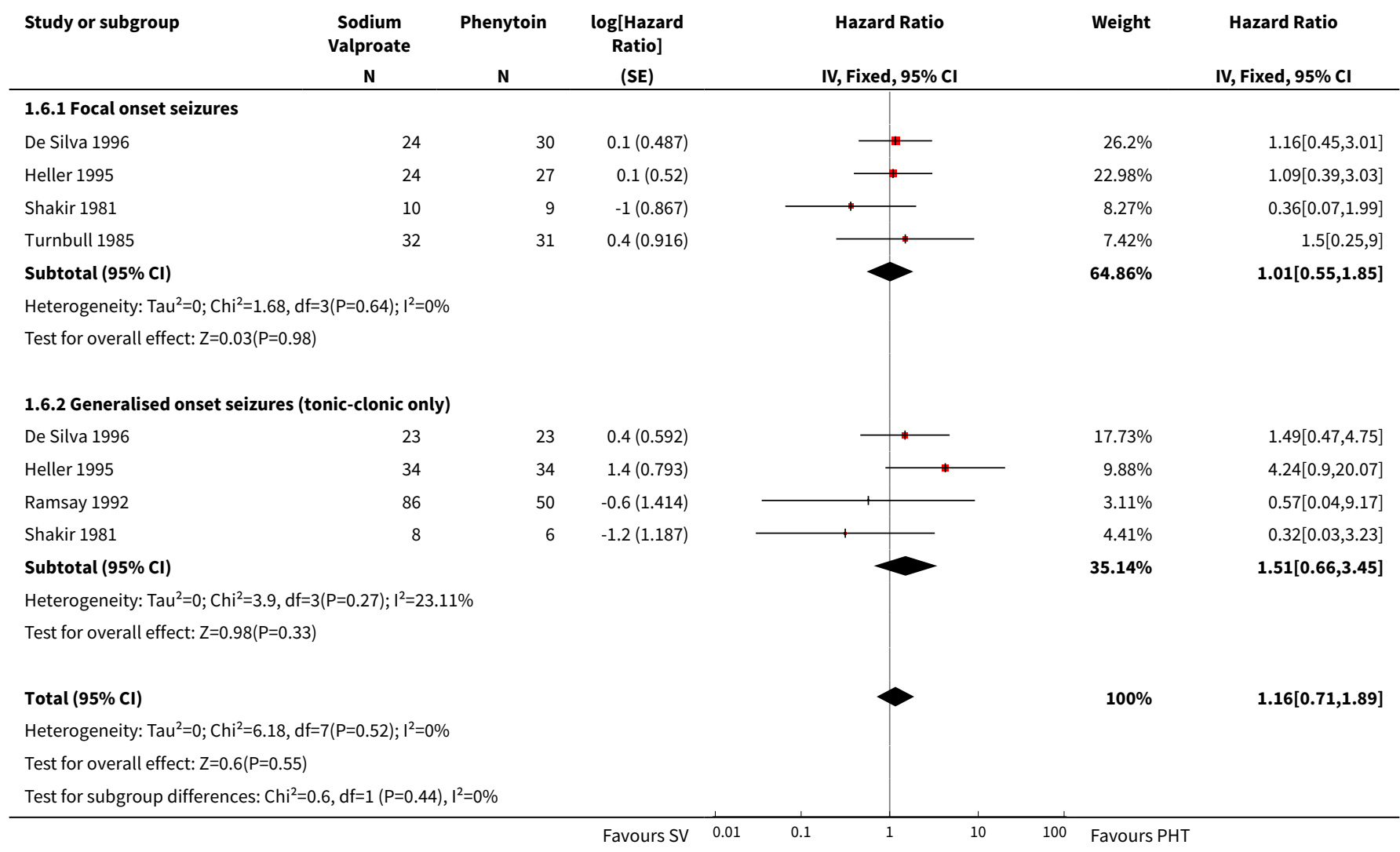

Analysis 1.7. Comparison 1 Sodium valproate versus phenytoin, Outcome 7 Time to first seizure.

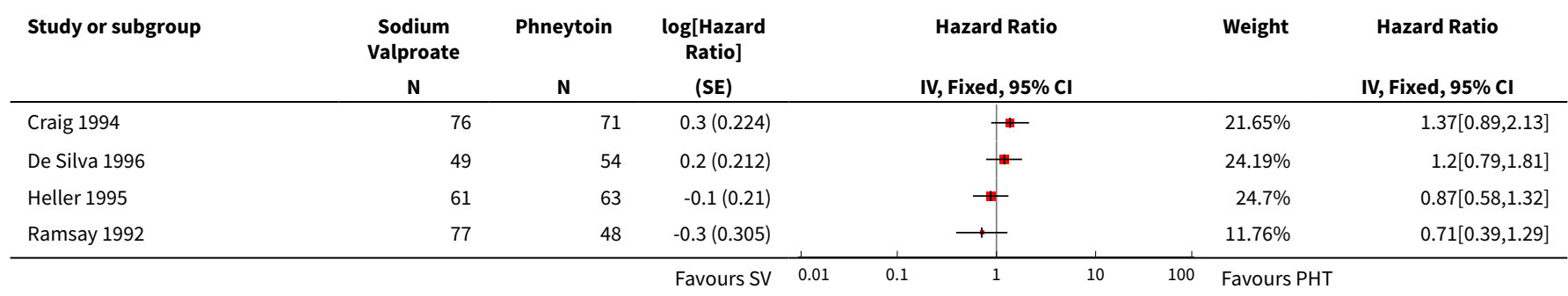




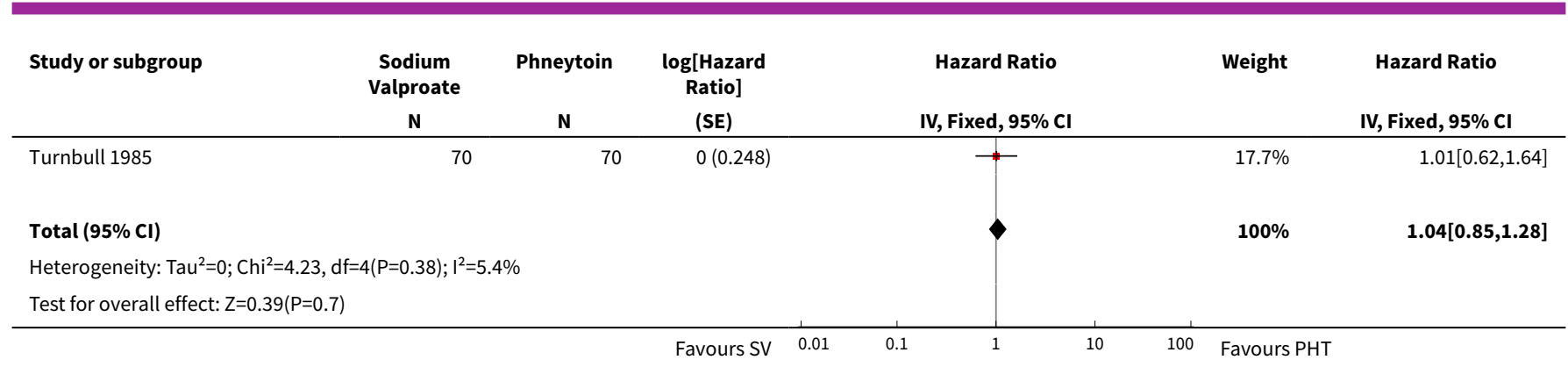

Analysis 1.8. Comparison 1 Sodium valproate versus phenytoin, Outcome 8 Time to first seizure - by epilepsy type.

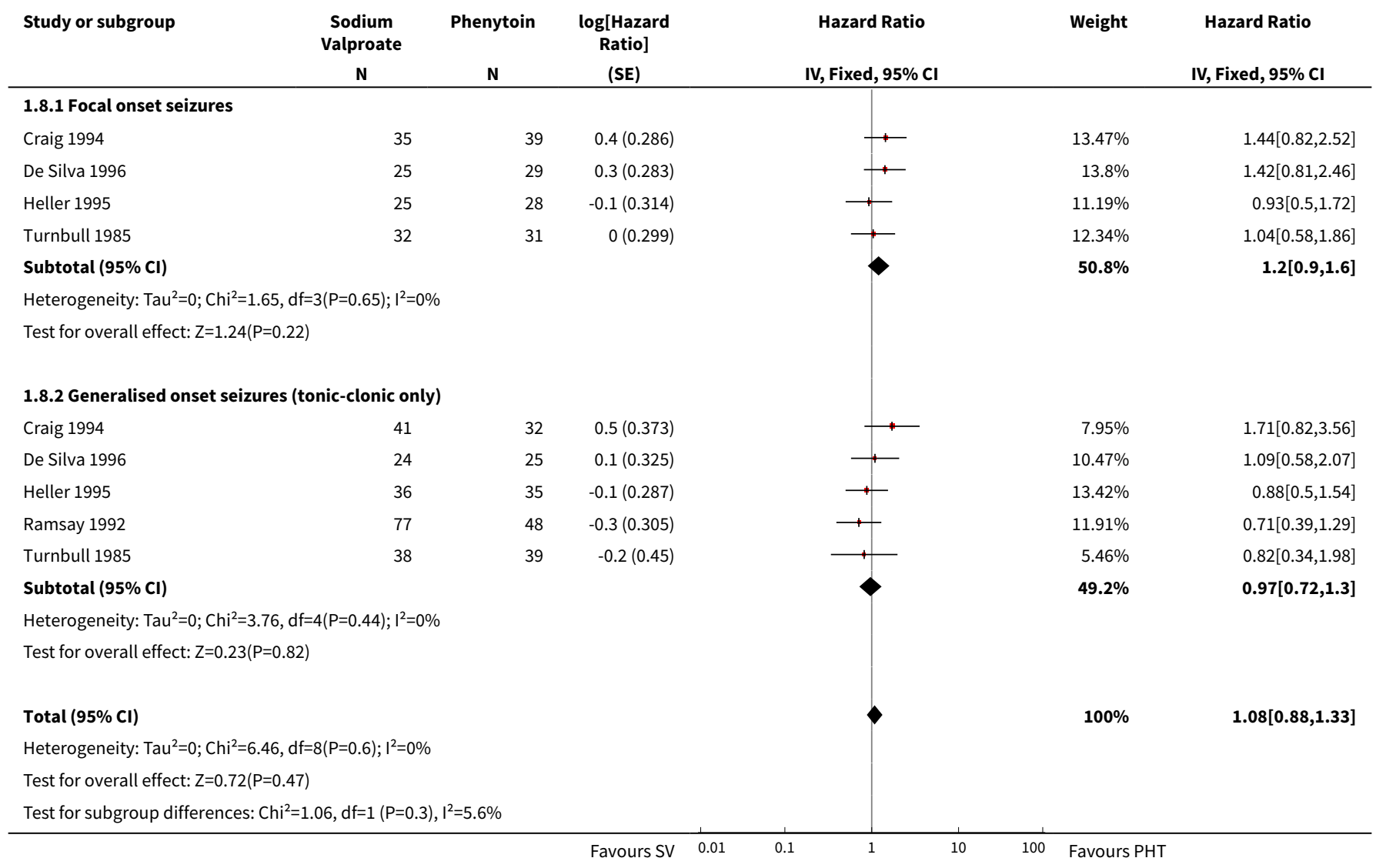

Analysis 1.9. Comparison 1 Sodium valproate versus phenytoin, Outcome 9 Time to first seizure - epilepsy type reclassified to focal for generalised and age of onset $>30$ years.

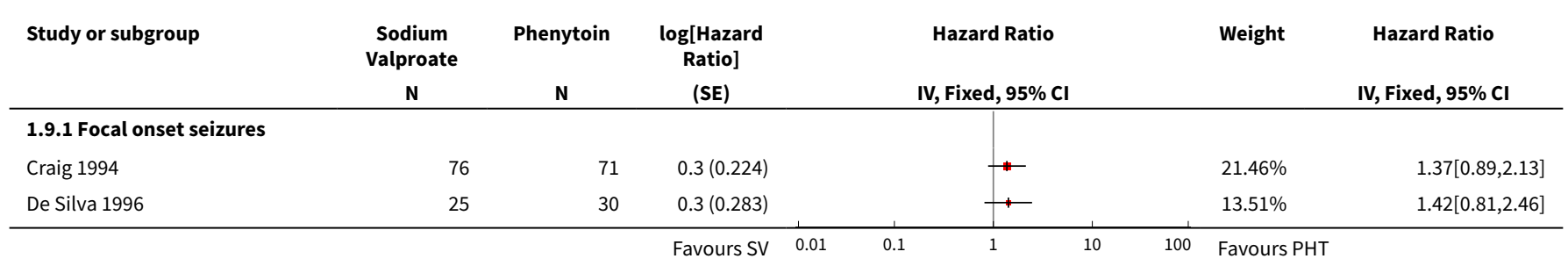




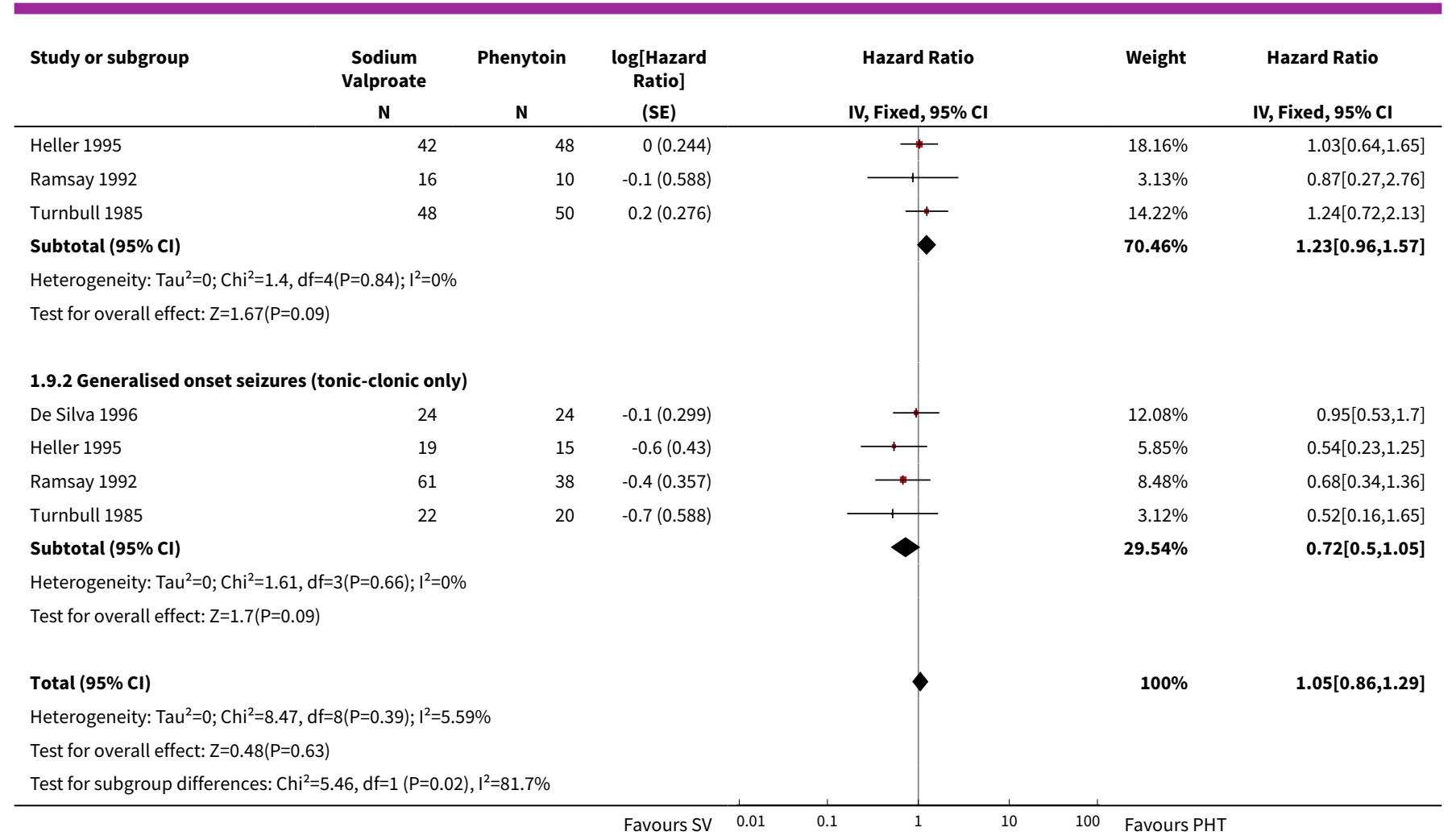

Analysis 1.10. Comparison 1 Sodium valproate versus phenytoin, Outcome 10 Time to first
seizure - epilepsy type reclassified to uncertain for generalised and age of onset $>30$ years.

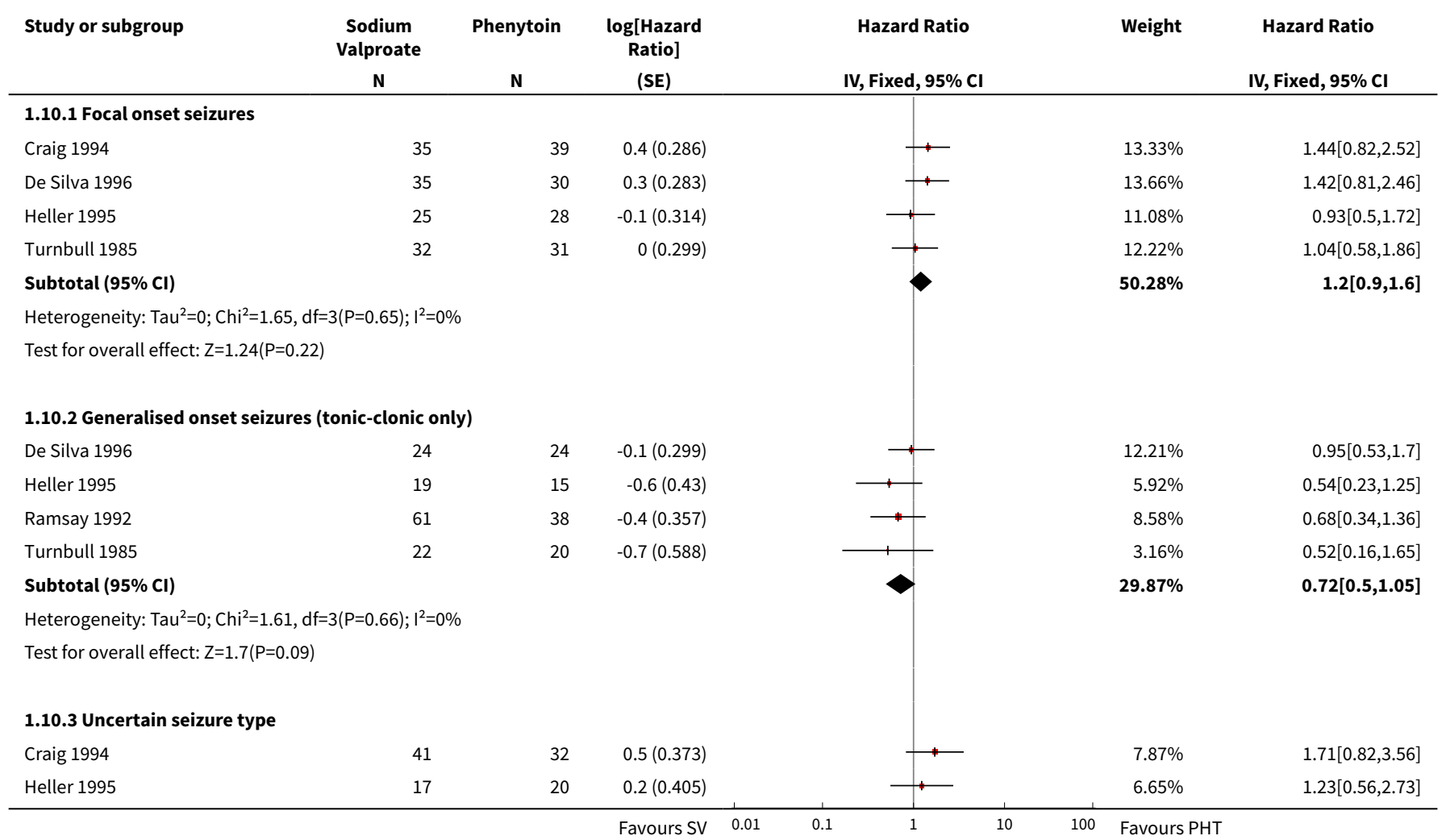




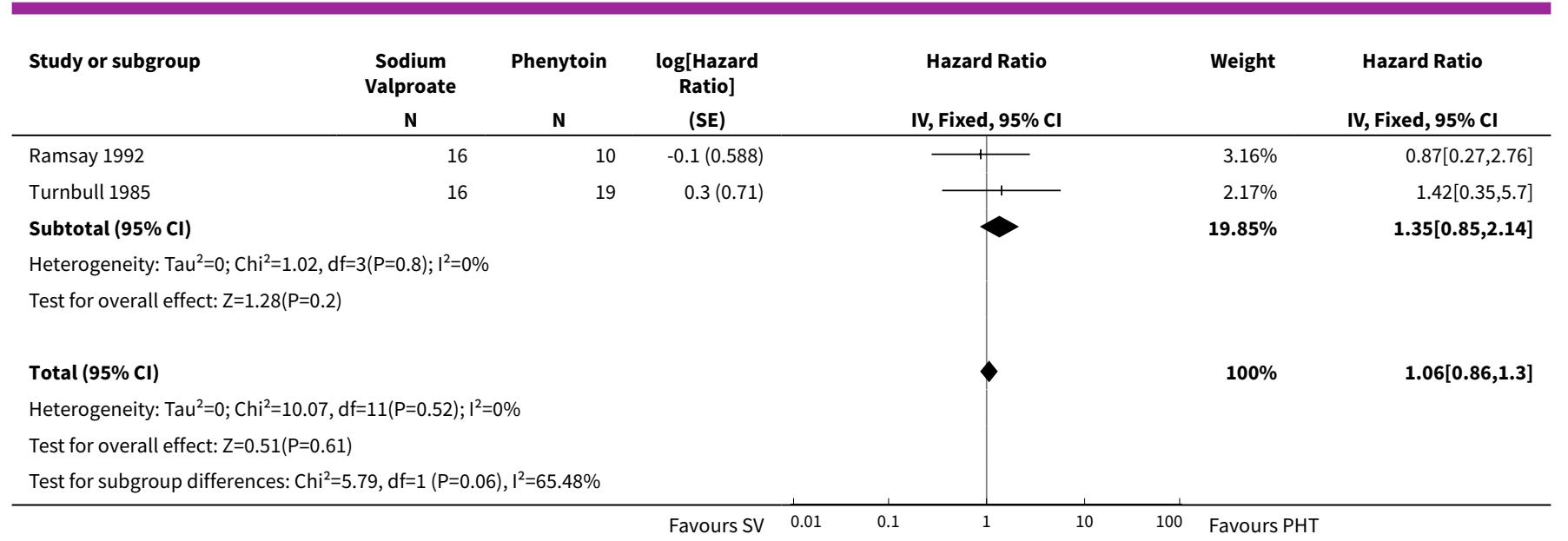

Analysis 1.11. Comparison 1 Sodium valproate versus phenytoin, Outcome 11 Time to achieve 12-month remission.

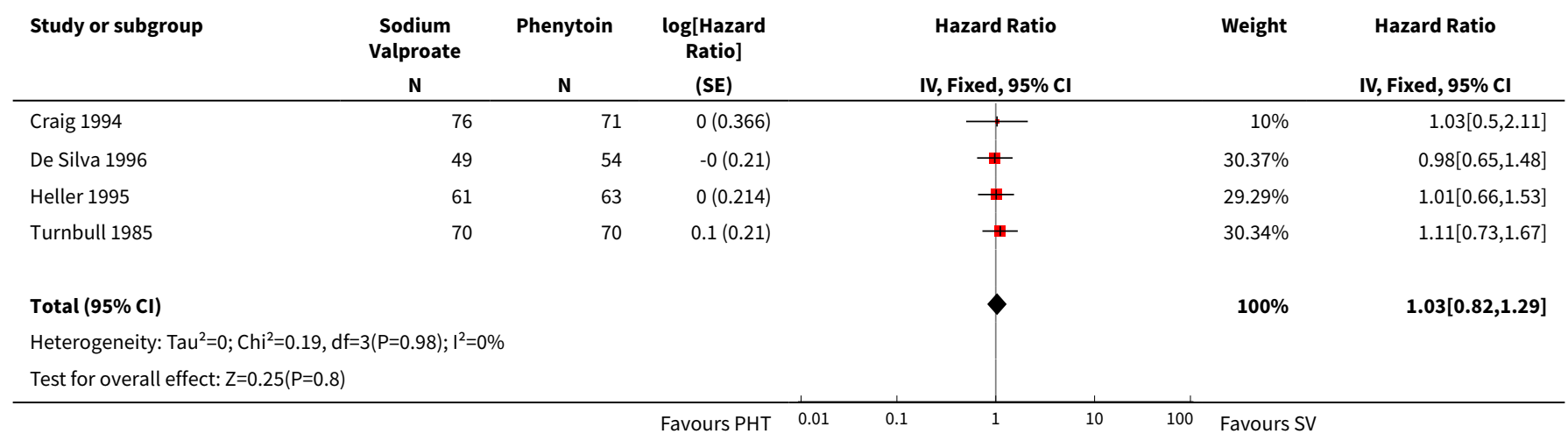

Analysis 1.12. Comparison 1 Sodium valproate versus phenytoin, Outcome 12 Time to achieve 12-month remission - by epilepsy type.

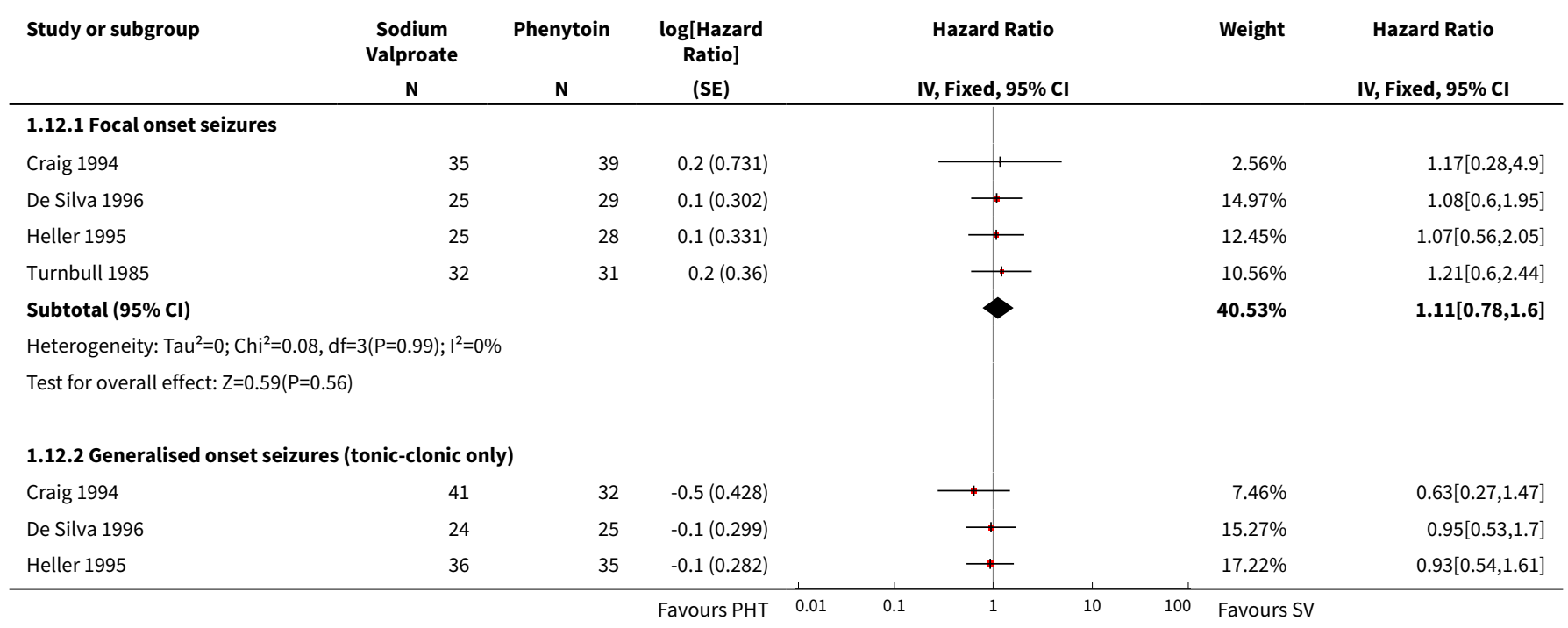




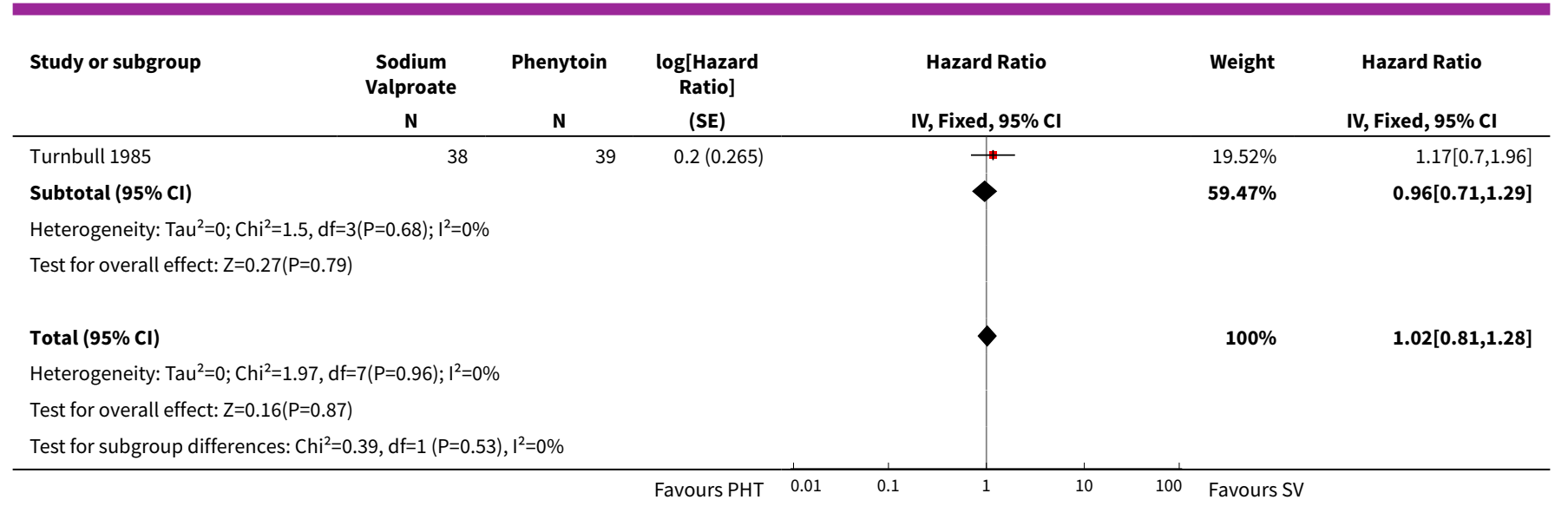

Analysis 1.13. Comparison 1 Sodium valproate versus phenytoin, Outcome 13 Time to achieve six-month remission.

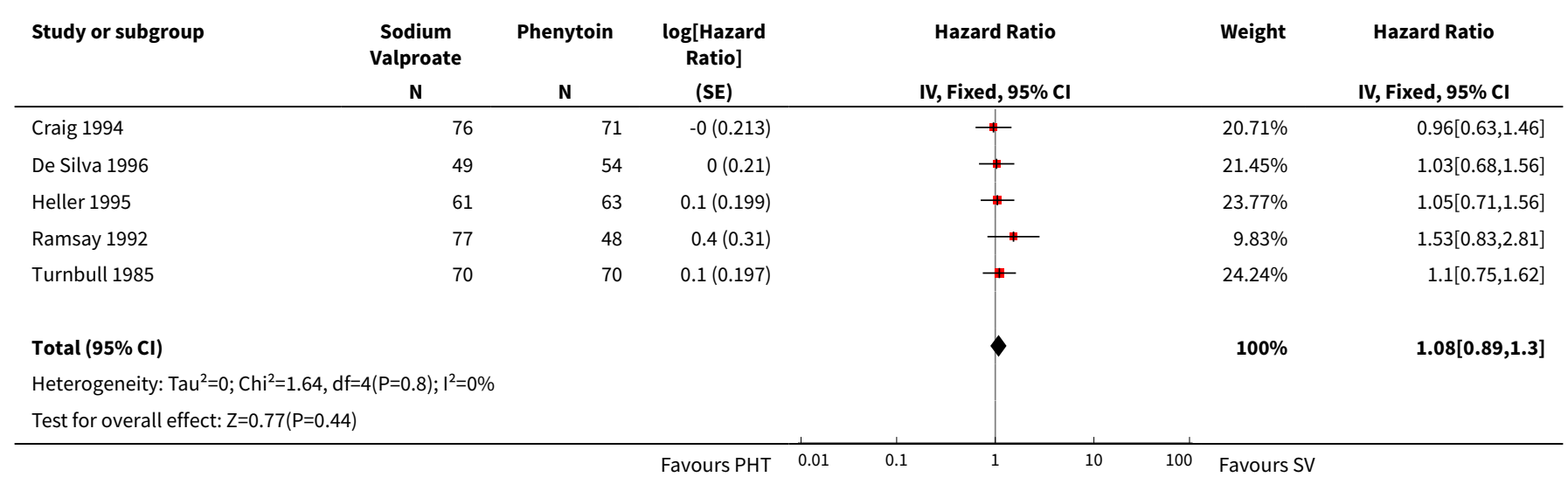

Analysis 1.14. Comparison 1 Sodium valproate versus phenytoin, Outcome 14 Time to achieve six-month remission - by epilepsy type.

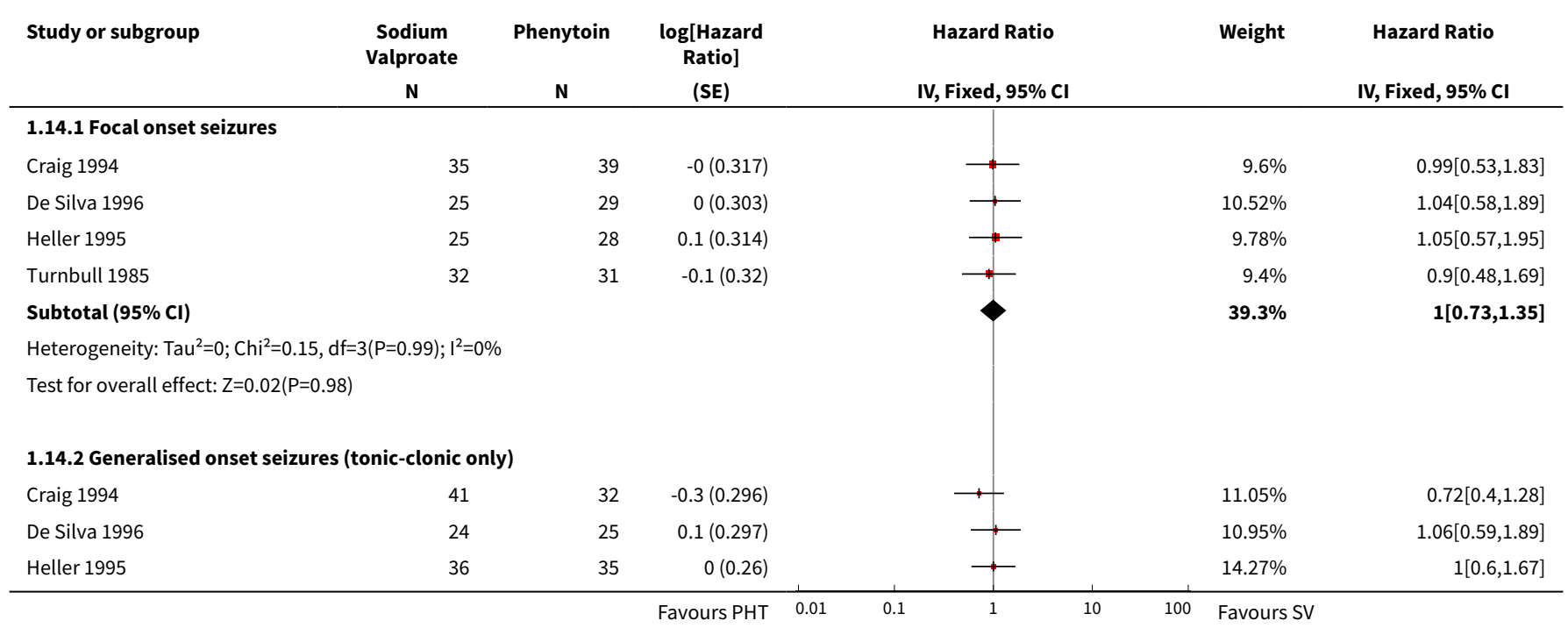




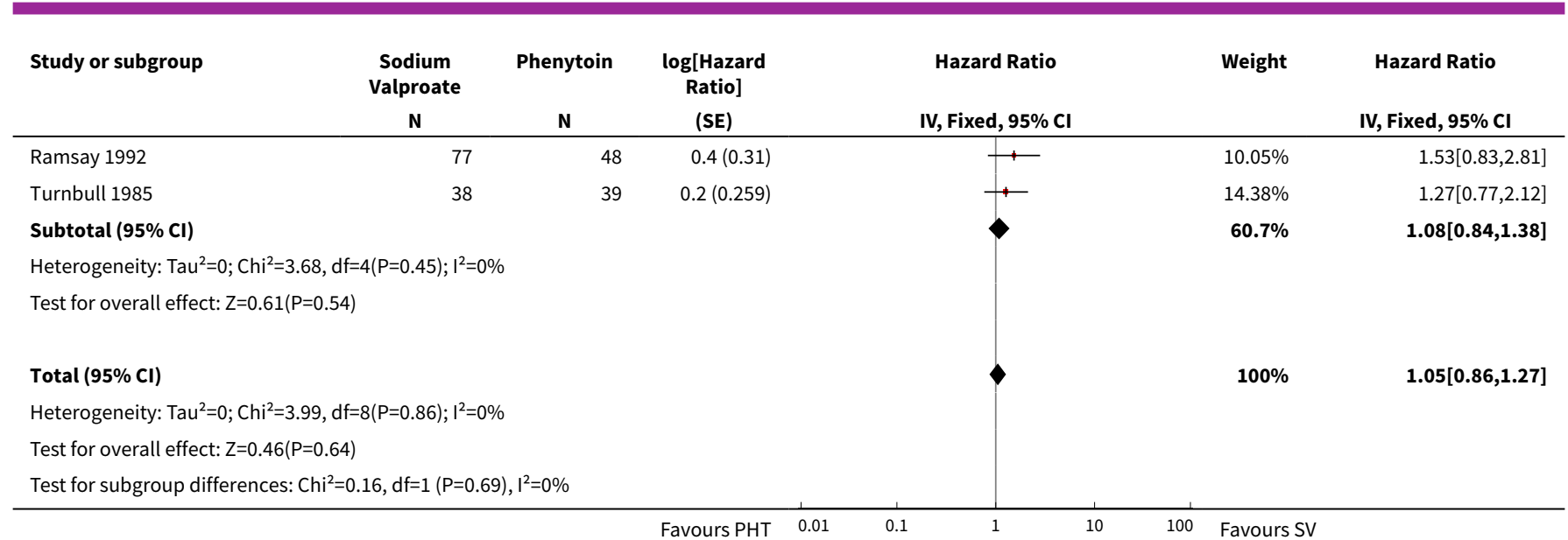




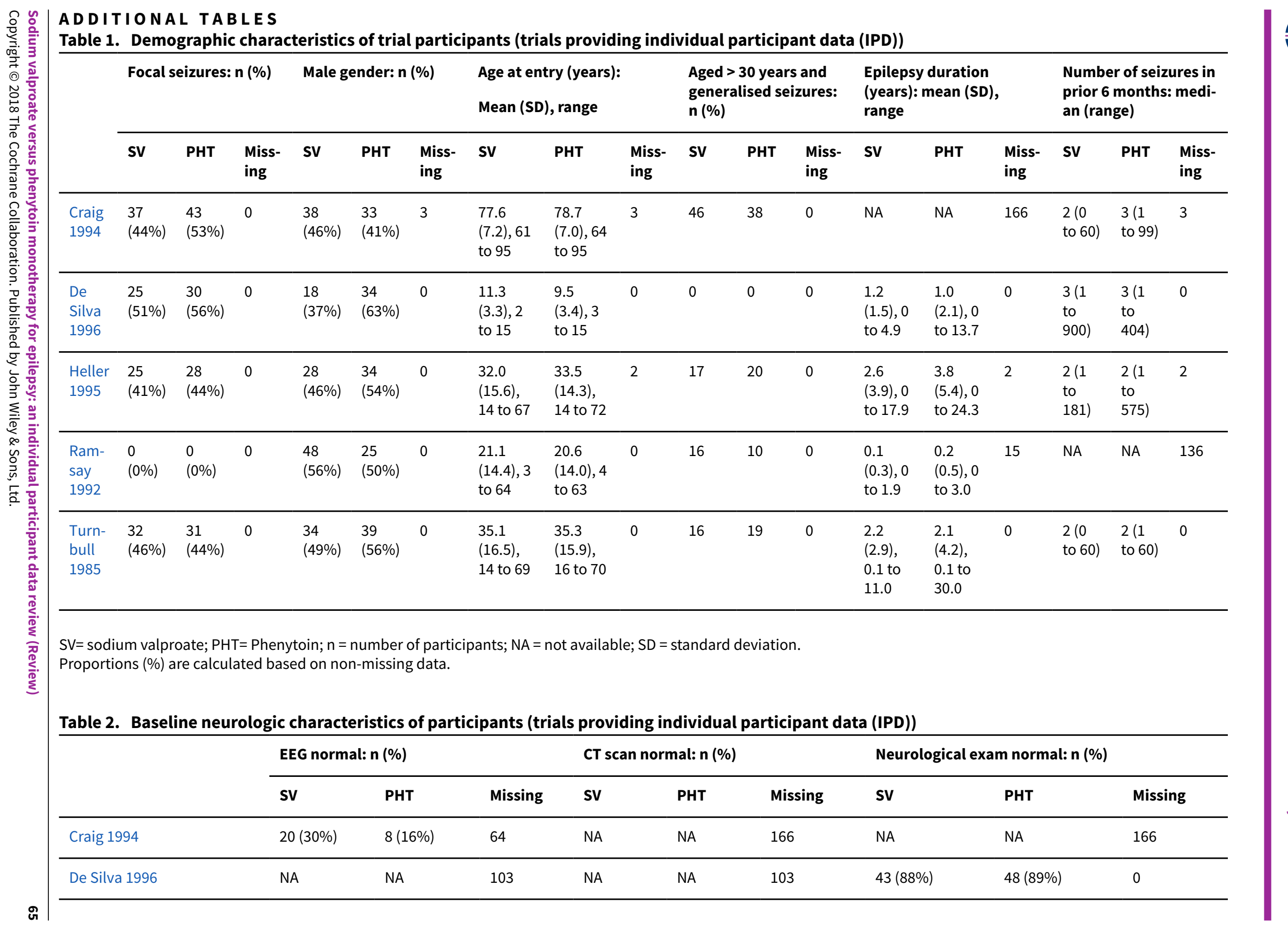




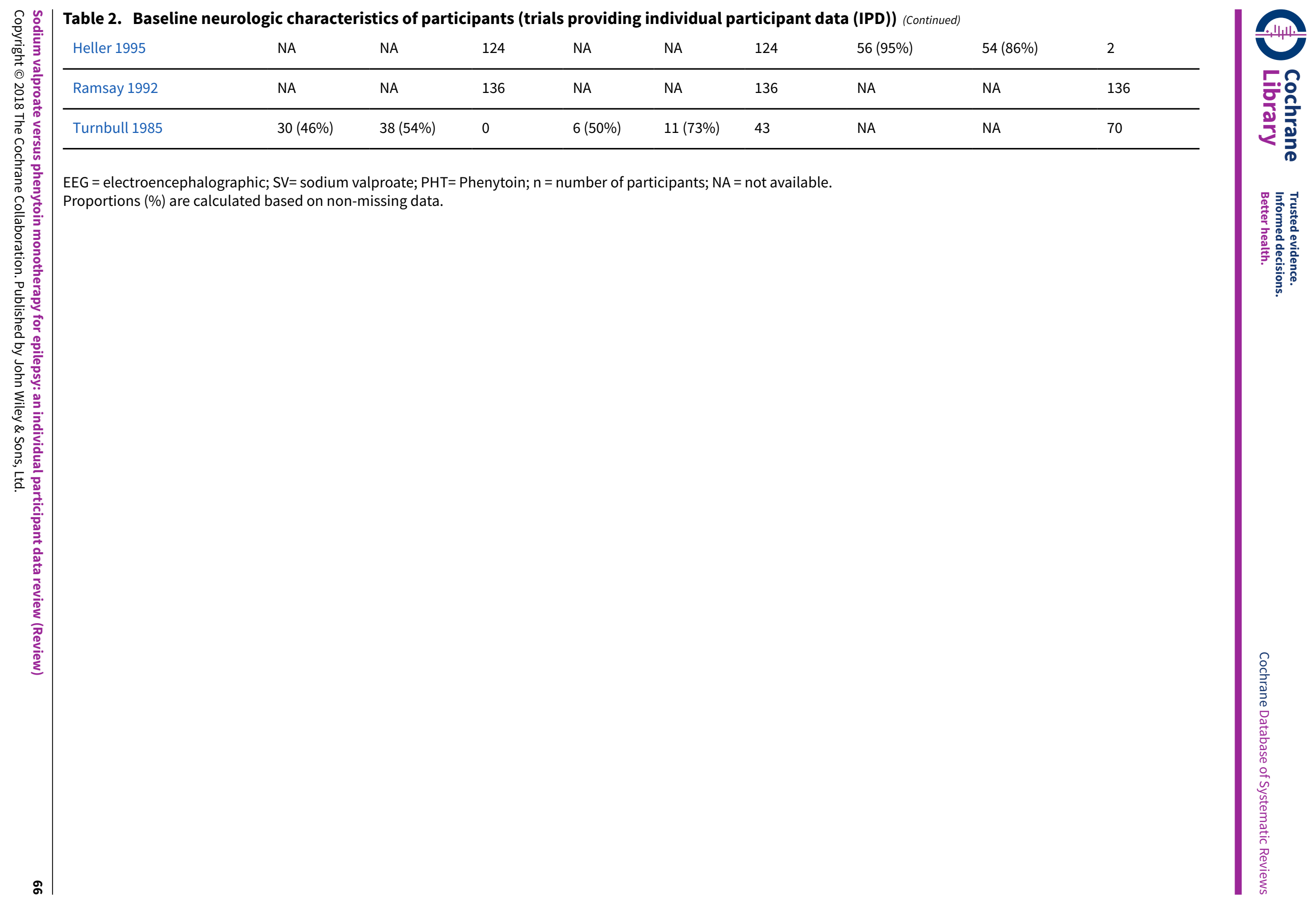


Table 3. Outcomes considered and summary of results for trials with no individual participant data (IPD)

\begin{tabular}{|c|c|c|}
\hline Trial & Outcomes reported & Summary of results \\
\hline Callaghan 1985 & $\begin{array}{l}\text { - Seizure control } \\
* \text { excellent (seizure-free) } \\
* \text { good (> } 50 \% \text { reduction) } \\
* \text { poor (<50\% reduction) } \\
\text { - Adverse events }\end{array}$ & 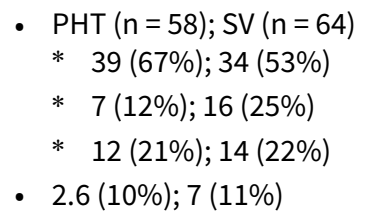 \\
\hline
\end{tabular}

Czapinski 1997a - Proportion achieving 24-month remission at 3 years (PHT: 59\%; SV: 64\%)

- Proportion excluded after randomisation due to adverse events or no efficacy (PHT: 23\%; SV: 23\%)

\begin{tabular}{ll}
\hline Forsythe $1991 \quad$ Cognitive assessments \\
- & Withdrawals from randomised drug \\
& \\
\hline Rastogi 1991 & Reduction in frequency of seizures at 24 \\
& weeks \\
& $*$ excellent $(100 \%$ reduction) \\
& $*$ fair $(50 \%-74 \%$ reduction) \\
& $*$ poor $(<50 \%$ reduction) \\
& Adverse events
\end{tabular}

- Significant difference favouring SV test of speed of information processing $(\mathrm{P}<0.01)$

No significant differences between treatment groups for any other cognitive tests

- PHT: $6 / 20(30 \%) ; \mathrm{SV}: 7 / 21(33 \%)$
PHT $(n=45) ; S V(n=49)$
* $23(51 \%) ; 24(49 \%)$
* $13(24 \%) ; 17(35 \%)$
* $8(18 \%) ; 5(10 \%)$
* $1(2 \%) ; 3(6 \%)$

- All reported adverse events were minor

* PHT: gum hyperplasia (18\%), nystagmus (13\%), gastrointestinal symptoms (4\%), drowsiness (4\%), ataxia (2\%)

* SV: gastrointestinal symptoms (12\%), drowsiness (6\%), weight gain $(2 \%)$

Shakir 1981 - Seizures during treatment
- Adverse events

- Adverse events
- Recurrence of seizures
- Adverse events
- PHT: 5 (33\%); SV: 7 (39\%)

- PHT: 1 case of ataxia, 5 cases of acne

- SV: 2 cases of gastrointestinal symptoms, 2 cases of hair loss, 4 cases of weight gain

- PHT: $14 / 52(27 \%) / \mathrm{SV}: 10 / 48(21 \%)$

- PHT: $33 / 52(63 \%) / S V: 15 / 48(31 \%)$

$\mathrm{n}=$ number of participants; PHT: phenytoin; SV: sodium valproate. 


\begin{tabular}{|c|c|c|c|c|c|c|c|c|c|c|c|c|c|c|c|c|}
\hline \multirow[t]{2}{*}{ Trial } & \multicolumn{3}{|c|}{ Number randomised } & \multicolumn{4}{|c|}{$\begin{array}{l}\text { Time to treatment failure } \\
\text { (for any reason related to } \\
\text { treatment) }\end{array}$} & \multicolumn{3}{|c|}{$\begin{array}{l}\text { Time to achieve 12- } \\
\text { month remission }\end{array}$} & \multicolumn{3}{|c|}{$\begin{array}{l}\text { Time to achieve 6- } \\
\text { month remission }\end{array}$} & \multicolumn{3}{|c|}{ Time to first seizure } \\
\hline & PHT & sv & Total & PHT & \multicolumn{2}{|l|}{ sv } & Total & PHT & SV & Total & PHT & SV & Total & PHT & SV & Total \\
\hline Craig $1994 a$ & 81 & 85 & 166 & 0 & \multicolumn{2}{|l|}{0} & 0 & 71 & 76 & 147 & 71 & 76 & 147 & 71 & 76 & 147 \\
\hline De Silva 1996 & 54 & 49 & 103 & 53 & \multicolumn{2}{|l|}{47} & 100 & 54 & 49 & 103 & 54 & 49 & 103 & 54 & 49 & 103 \\
\hline Forsythe $1991^{b}$ & 20 & 21 & 41 & 20 & \multicolumn{2}{|l|}{21} & 41 & 0 & 0 & 0 & 0 & 0 & 0 & 0 & 0 & 0 \\
\hline Heller 1995 & 63 & 61 & 124 & 61 & \multicolumn{2}{|l|}{58} & 119 & 63 & 61 & 124 & 63 & 61 & 124 & 63 & 61 & 124 \\
\hline Ramsay $1992^{c}$ & 50 & 86 & 136 & 50 & \multicolumn{2}{|l|}{86} & 136 & 0 & 0 & 0 & 48 & 77 & 125 & 48 & 77 & 125 \\
\hline Turnbull 1985 & 70 & 70 & 140 & 70 & \multicolumn{2}{|l|}{70} & 140 & 70 & 70 & 140 & 70 & 70 & 140 & 70 & 70 & 140 \\
\hline Shakir $1981^{b}$ & 15 & 18 & 33 & 15 & \multicolumn{2}{|l|}{18} & 33 & 0 & 0 & 0 & 0 & 0 & 0 & 0 & 0 & 0 \\
\hline Total & 353 & 390 & 743 & 269 & \multicolumn{2}{|c|}{300} & 569 & 258 & 256 & 514 & 306 & 333 & 639 & 306 & 333 & 639 \\
\hline \multicolumn{17}{|c|}{$\begin{array}{l}\text { aTreatment failure information not provided for Craig } 1994 \text {, so cannot contribute to } \\
\text { bData extracted from Forsythe } 1991 \text { and Shakir } 1981 \text { publications to calculate time } \\
\text { CFollow-up for Ramsay } 1992 \text { is less than } 12 \text { months so cannot contribute to 'time to } \\
\text { PHT: phenytoin; SV: sodium valproate. } \\
\text { Table 5. Reasons for premature discontinuation (treatment failure) }\end{array}$} \\
\hline \multirow{2}{*}{\multicolumn{2}{|c|}{$\begin{array}{l}\text { Reason for early termination } \\
\text { (and classification in time-to-event } \\
\text { analysis) }\end{array}$}} & \multicolumn{2}{|c|}{ De Silva $1996 \mathbf{b}$} & \multicolumn{2}{|c|}{ Heller $1995 \mathbf{b}, \mathbf{c}$} & \multicolumn{2}{|c|}{ Ramsay 1992} & \multicolumn{2}{|c|}{$\begin{array}{l}\text { Turnbull } \\
1985\end{array}$} & \multicolumn{2}{|c|}{$\begin{array}{l}\text { Forsythe } \\
1991\end{array}$} & \multicolumn{2}{|c|}{ Shakir 1981 d } & \multicolumn{2}{|c|}{ Totala } & \\
\hline & & sv & PHT & sv & PHT & sv & PHT & sv & PHT & SV & PHT & SV & PHT & sv & PHT & All \\
\hline Adverse events & & 2 & 2 & 4 & 1 & 4 & 8 & 6 & 14 & 0 & 1 & 0 & 0 & 16 & 26 & 42 \\
\hline Lack of efficacy & & 11 & 10 & 9 & 8 & 1 & 1 & 2 & 0 & 2 & 1 & 3 & 6 & 28 & 26 & 54 \\
\hline $\begin{array}{l}\text { Both adverse ev } \\
\text { (event) }\end{array}$ & cacy & 4 & 5 & 6 & 2 & 0 & 0 & 1 & 2 & 0 & 0 & 0 & 0 & 11 & 9 & 20 \\
\hline
\end{tabular}




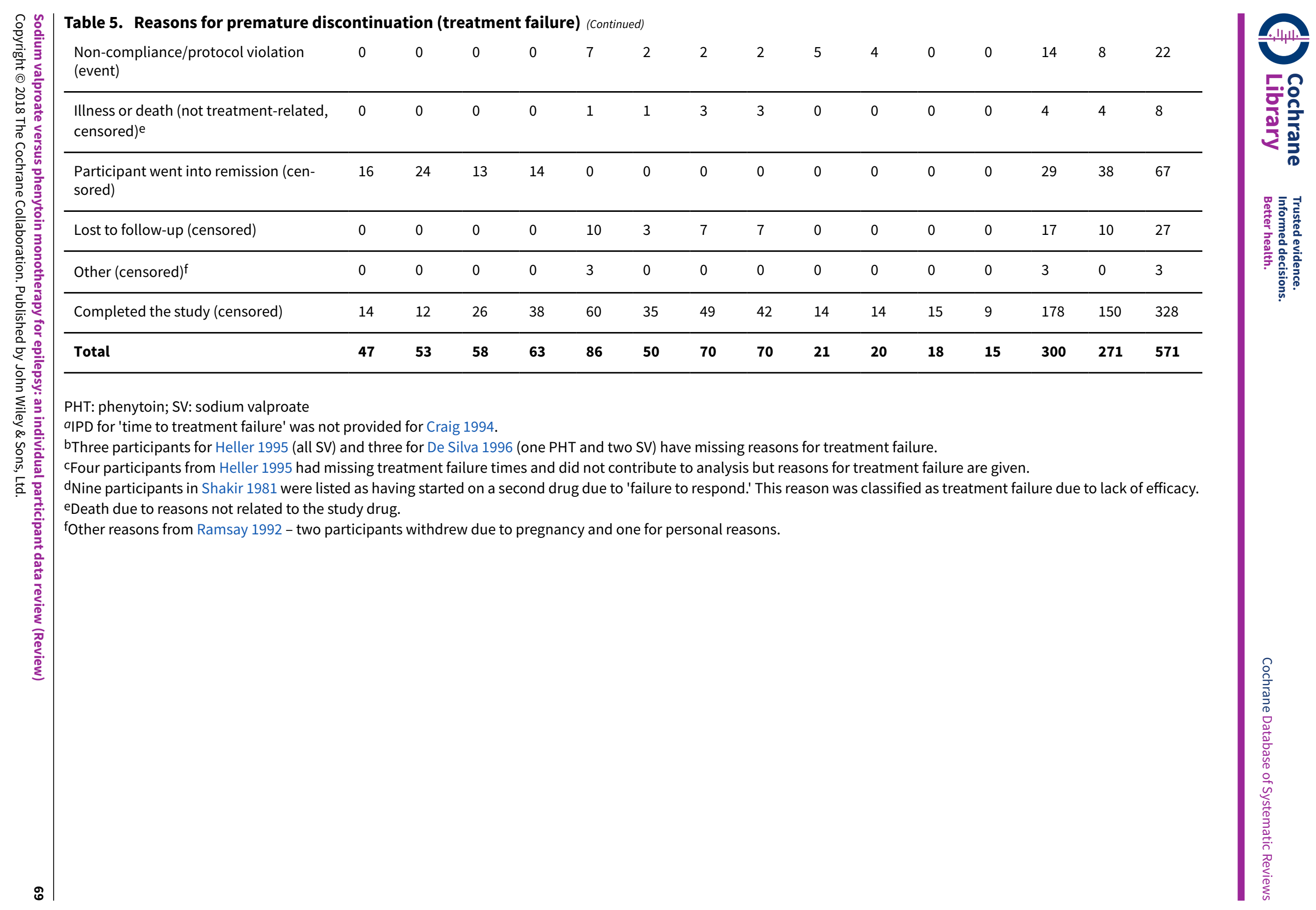


Table 6. Sensitivity analysis - epilepsy type misclassification

\begin{tabular}{|c|c|c|c|c|c|c|}
\hline \multirow[t]{2}{*}{ Outcome } & \multicolumn{2}{|l|}{ Original analysis } & \multicolumn{2}{|c|}{$\begin{array}{l}\text { Generalised onset and age at onset } \\
>30 \text { years } \\
\text { classified as focal onset }\end{array}$} & \multicolumn{2}{|c|}{$\begin{array}{l}\text { Generalised onset and age at onset } \\
>30 \text { years } \\
\text { classified as uncertain seizure type }\end{array}$} \\
\hline & $\begin{array}{l}\text { Pooled HR }(95 \% \\
\text { CI) } \\
\text { fixed-effects }\end{array}$ & $\begin{array}{l}\text { Test of } \\
\text { subgroup } \\
\text { differences }\end{array}$ & $\begin{array}{l}\text { Pooled HR }(95 \% \mathrm{CI}) \\
\text { fixed-effects }\end{array}$ & $\begin{array}{l}\text { Test of } \\
\text { subgroup } \\
\text { differences }\end{array}$ & $\begin{array}{l}\text { Pooled HR }(95 \% \mathrm{Cl}) \\
\text { fixed-effects }\end{array}$ & $\begin{array}{l}\text { Test of } \\
\text { subgroup } \\
\text { differences }\end{array}$ \\
\hline $\begin{array}{l}\text { Time to } \\
\text { treatment } \\
\text { failure } \\
\text { (for any } \\
\text { reason } \\
\text { related } \\
\text { to treat- } \\
\text { ment) }\end{array}$ & $\begin{array}{l}\text { F: } 0.83 \text { ( } 0.50 \text { to } 1.38) \\
\text { G: } 0.94 \text { ( } 0.55 \text { to } 1.61) \\
\text { O: } 0.88 \text { ( } 0.61 \text { to } \\
1.27)\end{array}$ & $\begin{array}{l}\mathrm{Chi}^{2}=0.10 \\
\mathrm{df}=1 \\
(P=0.75), \mathrm{I}^{2} \\
=0 \%\end{array}$ & $\begin{array}{l}\text { F: } 0.95 \text { (0.59 to } 1.52) \\
\text { G: } 0.77 \text { ( } 0.42 \text { to } 1.41) \\
\text { O: } 0.88 \text { (0.60 to } 1.27)\end{array}$ & $\begin{array}{l}\text { Chi }^{2}=0.29, \\
d f=1 \\
(P=0.59), I^{2} \\
=0 \%\end{array}$ & $\begin{array}{l}\text { F: } 0.83 \text { (0.50 to } 1.38) \\
\text { G: } 0.77 \text { ( } 0.42 \text { to } 1.41) \\
\text { U: } 6.83 \text { ( } 0.82 \text { to } 57.16) \\
\text { O: } 0.86 \text { (0.59 to } 1.27)\end{array}$ & $\begin{array}{l}\mathrm{Chi}^{2}=3.80, \\
\mathrm{df}=2 \\
(\mathrm{P}=0.15), \mathrm{I}^{2} \\
=47.3 \%\end{array}$ \\
\hline $\begin{array}{l}\text { Time to } \\
\text { treatment } \\
\text { failure due } \\
\text { to adverse } \\
\text { eventsb }\end{array}$ & $\begin{array}{l}\text { F: } 0.75(0.35 \text { to } 1.60) \\
\text { G: } 0.81(0.34 \text { to } 1.90) \\
\text { O: } 0.77 \text { ( } 0.44 \text { to } \\
1.37)\end{array}$ & $\begin{array}{l}\mathrm{Chi}^{2}=0.02, \\
\mathrm{df}=1 \\
(P=0.90), \mathrm{I}^{2} \\
=0 \%\end{array}$ & $\begin{array}{l}\text { F: } 0.87 \text { ( } 0.42 \text { to } 1.80) \\
\text { G: } 0.64 \text { ( } 0.26 \text { to } 1.59) \\
\text { O: } 0.77 \text { (0.44 to } 1.36)\end{array}$ & $\begin{array}{l}\mathrm{Chi}^{2}=0.26, \\
\mathrm{df}=1 \\
(P=0.61), \mathrm{I}^{2} \\
=0 \%\end{array}$ & Not calculated b & $\begin{array}{l}\text { Not calcu- } \\
\text { latedb }\end{array}$ \\
\hline $\begin{array}{l}\text { Time to } \\
\text { treatment } \\
\text { failure due } \\
\text { to lack of } \\
\text { efficacyb }\end{array}$ & $\begin{array}{l}\text { F: } 1.01 \text { ( } 0.55 \text { to } 1.85) \\
\text { G: } 1.51 \text { ( } 0.66 \text { to } 3.45) \\
\text { O: } 1.16 \text { ( } 0.71 \text { to } \\
1.89 \text { ) }\end{array}$ & $\begin{array}{l}\mathrm{Chi}^{2}=0.60, \\
\mathrm{df}=1 \\
(P=0.44), \mathrm{I}^{2} \\
=0 \%\end{array}$ & $\begin{array}{l}\text { F: } 1.00 \text { (0.51 to } 1.96) \\
\text { G: } 1.73 \text { ( } 0.56 \text { to } 5.35) \\
\text { O: } 1.16 \text { ( } 0.65 \text { to } 2.06)\end{array}$ & $\begin{array}{l}\text { Chi }^{2}=0.66, \\
d f=1 \\
(P=0.42), I^{2} \\
=0 \%\end{array}$ & Not calculatedb & $\begin{array}{l}\text { Not calcu- } \\
\text { lated b }\end{array}$ \\
\hline $\begin{array}{l}\text { Time } \\
\text { to first } \\
\text { seizurec }\end{array}$ & $\begin{array}{l}\text { F: } 1.20(0.90 \text { to } 1.60) \\
\text { G: } 0.97(0.72 \text { to } 1.30) \\
\text { O: } 1.08(0.88 \text { to } \\
1.33)\end{array}$ & $\begin{array}{l}\mathrm{Chi}^{2}=1.06, \\
\mathrm{df}=1 \\
(P=0.30), \mathrm{I}^{2} \\
=5.6 \%\end{array}$ & $\begin{array}{l}\text { F: } 1.23 \text { (0.96 to } 1.57) \\
\text { G: } 0.72 \text { (0.50 to } 1.05) \\
\text { O: } 1.05 \text { (0.86 to } 1.29)\end{array}$ & $\begin{array}{l}\mathrm{Chi}^{2}=5.46 \\
\mathrm{df}=1 \\
(\mathrm{P}=0.02), \mathrm{I}^{2} \\
=81.7 \%\end{array}$ & $\begin{array}{l}\text { F: } 1.20 \text { (0.90 to } 1.60) \\
\text { G: } 0.72 \text { (0.50 to } 1.05) \\
\text { U: } 1.35 \text { (0.85 to } 2.14) \\
\text { O: } 1.06 \text { (0.86 to } 1.30)\end{array}$ & $\begin{array}{l}\mathrm{Chi}^{2}=5.79, \\
\mathrm{df}=2 \\
(P=0.06), \mathrm{I}^{2} \\
=65.5 \%\end{array}$ \\
\hline $\begin{array}{l}\text { Time to } 12- \\
\text { month re- } \\
\text { missiond }\end{array}$ & $\begin{array}{l}\text { F: } 1.11 \text { ( } 0.78 \text { to } 1.60) \\
\text { G: } 0.96 \text { ( } 0.71 \text { to } 1.29) \\
\text { O: } 1.02 \text { ( } 0.81 \text { to } \\
1.28)\end{array}$ & $\begin{array}{l}\mathrm{Chi}^{2}=0.39, \\
\mathrm{df}=1 \\
(P=0.53), \mathrm{I}^{2} \\
=0 \%\end{array}$ & $\begin{array}{l}\text { F: } 0.99 \text { (0.75 to } 1.32) \\
\text { G: } 1.07 \text { (0.72 to } 1.59)\end{array}$ & $\begin{array}{l}\mathrm{Chi}^{2}=0.10 \\
\mathrm{df}=1 \\
(\mathrm{P}=0.75), \mathrm{I}^{2} \\
=0 \%\end{array}$ & $\begin{array}{l}F: 1.11(0.78 \text { to } 1.60) \\
G: 1.07 \text { ( } 0.72 \text { to } 1.59)\end{array}$ & $\begin{array}{l}\mathrm{Chi}^{2}=2.07, \\
\mathrm{df}=2 \\
(P=0.36), \mathrm{I}^{2} \\
=3.3 \%\end{array}$ \\
\hline $\begin{array}{l}\text { Time to 6- } \\
\text { month re- } \\
\text { missione }\end{array}$ & $\begin{array}{l}\text { F: } 1.00 \text { (0.73 to } 1.35) \\
\text { G: } 1.08 \text { ( } 0.84 \text { to } 1.38) \\
\text { O: } 1.05 \text { ( } 0.86 \text { to } \\
1.27 \text { ) }\end{array}$ & $\begin{array}{l}\mathrm{Chi}^{2}=0.16, \\
\mathrm{df}=1 \\
(P=0.69), \mathrm{I}^{2} \\
=0 \%\end{array}$ & $\begin{array}{l}\text { F: } 1.00 \text { (0.79 to } 1.26) \\
\text { G: } 1.14(0.80 \text { to } 1.61)\end{array}$ & $\begin{array}{l}\mathrm{Chi}^{2}=0.38, \\
\mathrm{df}=1 \\
(P=0.54), \mathrm{I}^{2} \\
=0 \%\end{array}$ & $\begin{array}{l}\mathrm{F}: 1.00 \text { (0.73 to } 1.35) \\
\mathrm{G}: 1.14 \text { (0.80 to } 1.61)\end{array}$ & $\begin{array}{l}\mathrm{Chi}^{2}=0.80, \\
\mathrm{df}=2 \\
(P=0.67), \mathrm{I}^{2} \\
=0 \%\end{array}$ \\
\hline
\end{tabular}

$\mathrm{Chi}^{2}$ : $\mathrm{Chi}^{2}$ statistic; df: degrees of freedom of $\mathrm{Chi}^{2}$ distribution; F: focal epilepsy; G: generalised epilepsy; O: overall (all participants); U: uncertain epilepsy; P: $P$ value ( $<0.05$ are classified as statistically significant). 
$a_{100}$ participants reclassified to focal epilepsy or uncertain epilepsy type for outcome 'time to treatment failure (for any reason related to treatment)'; see Analysis 1.4 for original analysis.

b100 participants reclassified to focal epilepsy or uncertain epilepsy type for outcomes 'time to treatment failure due to adverse events' and 'time to treatment failure due to lack of efficacy'; see Analysis 1.5 and Analysis 1.6 for original analyses. Forest plots not presented for sensitivity analysis for generalised and age at onset $>30$ years reclassified as focal epilepsy as results were numerically similar and conclusions are unchanged. Sensitivity analysis for generalised and age at onset $>30$ years reclassified as uncertain epilepsy type not performed due to small numbers of participants failing treatment for these reasons in the uncertain epilepsy type groups in each trial.

c171 participants reclassified to focal epilepsy or uncertain epilepsy type for outcome 'time to first seizure'; see Analysis 1.8 for original analysis and see Analysis 1.10 and Analysis 1.9 for forest plots of 'time to first seizure' sensitivity analyses for generalised and age at onset $>30$ years reclassified as focal epilepsy and uncertain epilepsy type, respectively.

$\mathrm{d}_{145}$ participants reclassified to focal epilepsy or uncertain epilepsy type for outcome 'time to achieve 12-month remission', see Analysis 1.12 for original analysis. As results were numerically similar and conclusions are unchanged, forest plots are not presented.

e171 participants reclassified to focal epilepsy or uncertain epilepsy type for outcome 'time to achieve 6-month remission', see Analysis 1.14 for original analysis. As results were numerically similar and conclusions are unchanged, forest plots are not presented.

Table 7. Adverse event data (narrative report)

\section{Trial Adverse event data $a$ Summary of reported results}

\section{Phenytoin (PHT)}

\section{Callaghan 1985}

All adverse events developed (by drug) and adverse events leading to discontinuation of treatment
PHT ( $n=58)$ : gum hypertrophy $(n=2)$, rash ( $n$ $=2)$, ataxia $(n=2)$

\section{SV (sodium valproate)}

SV $(n=64)$ : weight gain $(n=4$ : all discontinued treatment), drowsiness $(n=2)$, aggressive behaviour ( $n$ $=1$ : discontinued treatment)

\section{Craig 1994}

\section{Adverse event fre- quency (sponta- neous reports) ${ }^{b}$}

Discontinuations due to adverse eventsc
PHT $(n=25)$ : unsteadiness $(n=9)$, sleepiness $(n=7)$, drowsiness $(n=2)$, impaired concentration ( $n=2)$, confusion $(n=1)$, constipation $(n=1)$, diarrhoea $(n=1)$, dysarthria $(n=1)$, lethargy $(n=1)$, nystagmus $(n=1)$, rash $(n=$ $1)$, tired legs $(n=1)$

PHT discontinuations $(n=6)$ : rash $(n=1)$, diarrhoea $(n=1)$, confusion $(n=1)$, unsteadiness $(n=1)$, constipation $(n=1)$, sleepiness $(n=1)$
SV $(n=17)$ : unsteadiness $(n=2)$, sleepiness $(n=3)$, tremor $(n=5)$, oedema $(n=3)$, alopecia $(n=2)$, depression $(n=2)$, weight gain $(n=2)$

SV discontinuations $(n=2)$ : weight gain and depression $(n=1)$, unsteadiness $(n=1)$

Proportion "excluded": SV: 23.3\%

\begin{tabular}{lll}
\hline Czapinski 1997a & $\begin{array}{l}\text { "Exclusions" due to } \\
\text { adverse events or no } \\
\text { efficacyd }\end{array}$
\end{tabular}

De Silva 1996
"Unacceptable" ad-
verse events leading
to drug withdrawale PHT $(n=54)$ : drowsiness $(n=2)$, skin rash $(n=$ SV $(n=49)$ : behavioural $(n=1)$, 1) blood dyscrasia $(n=1)$, hirsutism $(n=1) \quad$ tremor $(n=1)$

\begin{tabular}{lll}
\hline Forsythe 1991 & $\begin{array}{l}\text { No adverse event da- } \\
\text { ta reported }\end{array}$ & $\begin{array}{l}\text { 1 participant (PHT) withdrew from the study } \\
\text { due to depression and anorexia } \\
\text { (treatment with- }\end{array}$
\end{tabular}
drawal data only reported)

\begin{tabular}{|c|c|c|c|}
\hline Heller 1995 & $\begin{array}{l}\text { "Unacceptable" ad- } \\
\text { verse events leading } \\
\text { to drug withdrawale }\end{array}$ & PHT $(n=63)$ : myalgia $(n=1)$, irritability $(n=1)$ & $\begin{array}{l}\text { SV }(n=61) \text { : dizziness }(n=2) \text { abnor- } \\
\text { mal liver function test }(n=1)\end{array}$ \\
\hline Ramsay 1992 & $\begin{array}{l}\text { Most common ad- } \\
\text { verse events (by } \\
\text { treatment group) }\end{array}$ & $\begin{array}{l}\text { PHT }(n=50) \text { : dyspepsia }(n=1) \text {, nausea }(n=2) \text {, } \\
\text { dizziness }(n=2) \text {, somnolence }(n=5) \text {, tremor } \\
(n=2) \text {, rash }(n=4)\end{array}$ & $\begin{array}{l}\text { SV }(n=86) \text { : dyspepsia }(n=7) \text {, nau- } \\
\text { sea }(n=10) \text {, dizziness }(n=5) \text {, som- }\end{array}$ \\
\hline
\end{tabular}


Table 7. Adverse event data (narrative report) (Continued)

nolence $(n=8)$, tremor $(n=5)$, rash

$(\mathrm{n}=3)$

\begin{tabular}{|c|c|c|c|}
\hline Rastogi 1991 & $\begin{array}{l}\text { Commonest adverse } \\
\text { events (reported as } \\
\text { percentages by treat- } \\
\text { ment group) }\end{array}$ & $\begin{array}{l}\text { PHT }(n=45) \text { : gum hyperplasia }(17.7 \%) \text {, nys- } \\
\text { tagmus }(13.33 \%) \text {, ataxia }(2.2 \%) \text {, gastrointesti- } \\
\text { nal disturbances }(4.44 \%) \text {, drowsiness }(4.44 \%)\end{array}$ & $\begin{array}{l}\text { SV }(n=49) \text { : gastrointestinal distur- } \\
\text { bances }(12 \%) \text {, drowsiness }(6.12 \%) \text {, } \\
\text { weight gain }(2.04 \%)\end{array}$ \\
\hline Shakir 1981 & $\begin{array}{l}\text { Adverse events (nar- } \\
\text { rative description)b }\end{array}$ & PHT $(n=15): 1$ case of ataxia, 5 cases of acne & $\begin{array}{l}\text { SV }(n=18): 2 \text { cases of gastrointesti- } \\
\text { nal symptoms, } 2 \text { cases of hair loss, } 4 \\
\text { cases of weight gain }\end{array}$ \\
\hline \multirow[t]{3}{*}{ Thilothammal 1996} & \multirow[t]{3}{*}{$\begin{array}{l}\text { Assessment of ad- } \\
\text { verse events }{ }^{b}\end{array}$} & $\begin{array}{l}\text { PHT }(n=52): 33 \text { participants reported at least } \\
\text { one side effect }\end{array}$ & $\begin{array}{l}\text { SV }(n=48): 15 \text { participants reported } \\
\text { at least one side effect }\end{array}$ \\
\hline & & $\begin{array}{l}\text { Reported frequencies: gingival hypertrophy } \\
(n=30) \text {, ataxia }(n=13) \text {, sedation }(n=12) \text {, nau- } \\
\text { sea and vomiting }(n=1)\end{array}$ & \multirow[t]{2}{*}{$\begin{array}{l}\text { Reported frequencies: hyperactiv- } \\
\text { ity }(n=6) \text {, impaired school perfor- } \\
\text { mance }(n=4) \text {, severe skin allergy ( } n \\
=1 \text { ) }\end{array}$} \\
\hline & & $\begin{array}{l}\text { Other reported adverse events (no frequen- } \\
\text { cies): nystagmus, confusion }\end{array}$ & \\
\hline
\end{tabular}

Turnbull $1985 \quad$ Treatment withdrawals due to doserelated and idiosyncratic adverse events
PHT $(n=70): 11$ treatment withdrawals due to dose-related adverse events (nystagmus, ataxia, tremor, diplopia and mental change)

5 treatment withdrawals due to idiosyncratic adverse events (skin eruption, erythroderma and jaundice)
SV $(n=70): 9$ treatment withdrawals due to dose-related adverse events (tremor, irritability, restlessness and alopecia)

No treatment withdrawals due to idiosyncratic adverse events

${ }^{a}$ Adverse event data, as reported narratively in the publications. Adverse event data were not requested in original IPD requests but will be for all future IPD requests. For numbers of treatment withdrawals due to adverse events in studies for which IPD were provided (De Silva 1996; Heller 1995; Ramsay 1992; Turnbull 1985) see Table 5.

bParticipants may report more than one adverse event.

CThe published paper, Craig 1994, reports on a subset of 38 participants, so the adverse event data summary applies only to this subset. IPD were provided for 166 participants (no additional adverse event data provided).

dCzapinski 1997a is an abstract only so very little information is reported.

eParticipants may have withdrawn due to adverse event alone or a combination of adverse events and poor efficacy (seizures).

fMost commonly reported adverse events only, no indication of overall frequency of all adverse events.

\section{A P PE N DICES}

\section{Appendix 1. Cochrane Epilepsy Group's Specialized Register search strategy}

1. MeSH DESCRIPTOR Phenytoin Explode All AND INREGISTER

2. phenytoin or Epanutin or Phenytek or Dilantin or Eptoin or Diphenin or Dipheninum or Diphenylhydantoin AND INREGISTER

3. \#1 OR \#2 AND INREGISTER

4. MeSH DESCRIPTOR Valproic Acid Explode All AND INREGISTER

5. Depakene or Depacon or Depakine or Valparin or Stavzor or Epilim or Epiject or Episenta or Epival or Valpro* or Orlept or Orfiril or Selenica or Convulex or Depakote AND INREGISTER

6. \#4 OR \#5 AND INREGISTER

7. \#3 AND \#6 AND INREGISTER 
8. (adjunct* or "add-on" or "add on" or adjuvant ${ }^{\star}$ or combination* or polytherap ${ }^{\star}$ ) not (monotherap* or alone or singl $\left.{ }^{\star}\right)$ :TI AND INREGISTER

\section{9. \#7 NOT \#8 AND INREGISTER}

\section{MeSH DESCRIPTOR Phenytoin Explode All AND CENTRAL:TARGET}

11. phenytoin or Epanutin or Phenytek or Dilantin or Eptoin or Diphenin or Dipheninum or Diphenylhydantoin AND CENTRAL:TARGET

12. \#10 OR \#11 AND CENTRAL:TARGET

13. MeSH DESCRIPTOR Valproic Acid Explode All AND CENTRAL:TARGET

14. Depakene or Depacon or Depakine or Valparin or Stavzor or Epilim or Epiject or Episenta or Epival or Valpro* or Orlept or Orfiril or Selenica or Convulex or Depakote AND CENTRAL:TARGET

\section{5. \#13 OR \#14 AND CENTRAL:TARGET}

\section{6. \#12 AND \#15 AND CENTRAL:TARGET}

17. (adjunct* or "add-on" or "add on" or adjuvant* or combination* or polytherap*) not (monotherap* or alone or singl*):TI AND CENTRAL:TARGET

\section{8. \#16 NOT \#17 AND CENTRAL:TARGET}

19. \#9 OR \#18

\section{Appendix 2. CENTRAL search strategy}

\#1 MeSH descriptor: [Phenytoin] explode all trees

\#2 Epanutin or Phenytek or Dilantin or Eptoin or Diphenin or Dipheninum or Diphenylhydantoin:ti,ab,kw (Word variations have been searched)

\#3 \#1 or \#2

\#4 MeSH descriptor: [Valproic Acid] explode all trees

\#5 Depakene or Depacon or Depakine or Valparin or Stavzor or Epilim or Epiject or Episenta or Epival or Valpro* or Orlept or Orfiril or Selenica or Convulex or Depakote:ti,ab,kw (Word variations have been searched)

\#6 \#4 or \#5

\#7 \#3 and \#6

\#8 (adjunct* or "add-on" or "add on" or adjuvant* or combination* or polytherap*) not (monotherap* or alone or singl $\left.{ }^{\star}\right)$ :ti (Word variations have been searched)

\#9 \#7 not \#8

\#10 (epilep* or seizure* or convuls*):ti,ab,kw (Word variations have been searched)

\#11 MeSH descriptor: [Epilepsy] explode all trees

\#12 MeSH descriptor: [Seizures] explode all trees

\#13 (\#10 or \#11 or \#12) in Trials

$\# 14$ \#9 and \#13

\section{Appendix 3. MEDLINE search strategy}

The following search is based on the Cochrane Highly Sensitive Search Strategy for identifying randomised trials in MEDLINE (Lefebvre 2011).

1. exp phenytoin/ or (Epanutin or Phenytek or Dilantin or Eptoin or Diphenin or Dipheninum or Diphenylhydantoin).mp.

2. exp Valproic Acid/ or (Depakene or Depacon or Depakine or Valparin or Stavzor or Epilim or Epiject or Episenta or Epival or Valpro\$ or Orlept or Orfiril or Selenica or Convulex or Depakote).mp. 
3. ((adjunct\$ or "add-on" or "add on" or adjuvant\$ or combination\$ or polytherap\$) not (monotherap\$ or alone or singl\$)).ti.

4. (1 and 2$)$ not 3

5. (randomized controlled trial or controlled clinical trial or pragmatic clinical trial).pt. or (randomi?ed or placebo or randomly).ab.

6. clinical trials as topic.sh.

7. trial.ti.

8.5 or 6 or 7

9. exp animals/ not humans.sh.

10. 8 not 9

11. exp Epilepsy/

12. exp Seizures/

13. (epilep\$ or seizure\$ or convuls\$).tw.

14. 11 or 12 or 13

15. exp *Pre-Eclampsia/ or exp *Eclampsia/

16. 14 not 15

\section{4 and 10 and 16}

18. remove duplicates from 17

Earlier versions of this review used the following search, based on the previous Cochrane Highly Sensitive Search Strategy for MEDLINE as set out in Appendix 5b of the Cochrane Handbook for Systematic Reviews of Interventions (version 4.2.4, updated March 2005) (Higgins 2011).

1. randomized controlled trial.pt.

2. controlled clinical trial.pt.

3. exp Randomized Controlled Trials/

4. exp Random Allocation/

5. exp Double-Blind Method/

6. exp Single-Blind Method/

7. clinical trial.pt.

8. Clinical Trial/

9. (clin\$ adj trial\$̣).ab,ti.

10. ((singl\$ or doubl\$ or trebl\$ or tripl\$) adj (blind\$ or mask\$)).ab,ti.

11. exp PLACEBOS/

12. placebo\$.ab,ti.

13. random\$.ab,ti.

14. exp Research Design/

15. or/1-14

16. (animals not humans).sh.

17. 15 not 16

Sodium valproate versus phenytoin monotherapy for epilepsy: an individual participant data review (Review) 
18. phenytoin/ or (phenytoin or diphenylhydantoin).tw.

19. valproic acid/ or valpro\$.tw.

20. exp epilepsy/ or epilep\$.tw.

21. exp seizures/ or seizure\$.tw.

22. convulsion\$.tw.

23. 18 and 19

24. 20 or 21 or 22

25. 23 and 24

26. 17 and 25

\section{Appendix 4. SCOPUS search strategy}

(((TITLE(phenytoin or Epanutin or Phenytek or Dilantin or Eptoin or Diphenin or Dipheninum or Diphenylhydantoin) or ABS(phenytoin or Epanutin or Phenytek or Dilantin or Eptoin or Diphenin or Dipheninum or Diphenylhydantoin)) and (TITLE(Depakene or Depacon or Depakine or Valparin or Stavzor or Epilim or Epiject or Episenta or Epival or Valpro* or Orlept or Orfiril or Selenica or Convulex or Depakote) or ABS(Depakene or Depacon or Depakine or Valparin or Stavzor or Epilim or Epiject or Episenta or Epival or Valpro* or Orlept or Orfiril or Selenica or Convulex or Depakote))) and not (TITLE-ABS-KEY((adjunct* OR "add-on" OR "add on") AND NOT monotherap*))) and (TITLE((randomiz* OR randomis* OR controlled OR placebo OR blind* OR unblind* OR "parallel-group" OR "parallel group" OR crossover OR cross-over OR "cross over" OR cluster OR "head to head" OR "head-to-head") PRE/2 (trial OR method OR procedure OR study)) OR ABS ((randomiz* OR randomis* OR controlled OR placebo OR blind* OR unblind* OR "parallel-group" OR "parallel group" OR crossover OR cross-over OR "cross over" OR cluster OR "head to head" OR "head-to-head") PRE/2 (trial OR method OR procedure OR study))) and ((TITLEABS-KEY(epilep* OR "infantile spasm" OR seizure OR convuls* OR (syndrome W/2 (aicardi OR angelman OR doose OR dravet OR janz OR jeavons OR "landau kleffner" OR "lennox gastaut" OR ohtahara OR panayiotopoulos OR rasmussen OR rett OR "sturge weber" OR tassinari OR "unverricht lundborg" OR west)) OR "ring chromosome 20" OR "R20" OR "myoclonic encephalopathy" OR "pyridoxine dependency") AND NOT (TITLE( ${ }^{*}$ eclampsia) OR INDEXTERMS(*eclampsia))) OR (TITLE-ABS-KEY(lafora* W/4 (disease OR epilep*)) AND NOT (TITLE(dog OR canine) OR INDEXTERMS(dog OR canine))))

\section{WHAT'S NEW}

\begin{tabular}{lll}
\hline Date & Event & Description \\
\hline 26 June 2018 & $\begin{array}{l}\text { New citation required but conclusions } \\
\text { have not changed }\end{array}$ & Review updated; conclusions are unchanged \\
\hline 19 February 2018 & New search has been performed & $\begin{array}{l}\text { Updated search on 19 February 2018; no new studies included } \\
\text { The title was changed in line with the titles of other pairwise } \\
\text { monotherapy comparisons in the series (i.e. 'monotherapy for } \\
\text { epilepsy' instead of 'for partial onset seizures and generalised } \\
\text { onset tonic-clonic seizures') and in line with Cochrane guidelines } \\
\text { of intervention (i.e. valproate) first and comparator (i.e. pheny- } \\
\text { toin) second. }\end{array}$ \\
$\begin{array}{l}\text { The term 'partial' has been replaced by 'focal', in accordance } \\
\text { with the most recent classification of epilepsies of the Interna- } \\
\text { tional League Against Epilepsy (Scheffer 2017). } \\
\text { Lead author, previously known as Sarah Nolan is now Sarah } \\
\text { Nevitt }\end{array}$ \\
\hline
\end{tabular}

\section{H I S T O R Y}

Protocol first published: Issue 3, 1999 
Review first published: Issue 4, 2001

\begin{tabular}{|c|c|c|}
\hline Date & Event & Description \\
\hline 26 April 2017 & Amended & Declarations of interest section updated \\
\hline 19 May 2015 & New search has been performed & No new studies included; conclusions unchanged \\
\hline 19 May 2015 & $\begin{array}{l}\text { New citation required but conclusions } \\
\text { have not changed }\end{array}$ & Searches updated on 19 May 2015 \\
\hline 13 August 2013 & $\begin{array}{l}\text { New citation required but conclusions } \\
\text { have not changed }\end{array}$ & Conclusions unchanged \\
\hline 21 February 2013 & New search has been performed & $\begin{array}{l}\text { Searches updated February 2013. Analyses and text updated. } \\
\text { 'Risk of bias' assessments and 'Summary of findings' table added }\end{array}$ \\
\hline 23 September 2008 & Amended & Converted to new review format \\
\hline 27 July 2007 & New search has been performed & $\begin{array}{l}\text { We reran our searches on } 27 \text { July } 2007 \text { and identified one new } \\
\text { study and added it to the 'Characteristics of studies awaiting } \\
\text { classification' section; we will assess it for inclusion in the review } \\
\text { at a later date. }\end{array}$ \\
\hline
\end{tabular}

\section{CONTRIBUTIONS OFAUTHORS}

SJ Nevitt assessed studies for inclusion in the review update, obtained individual participant data (IPD) from trial investigators for the review update, assessed risk of bias in all included studies, performed analyses in Stata version 14, added survival plots and a 'Summary of findings' table, and updated the text of the review.

AG Marson obtained IPD from trial investigators, provided guidance with the clinical interpretation of results, assessed eligibility and methodological quality of individual studies and co-wrote the original review.

$\mathrm{J}$ Weston independently assessed risk of bias in all included studies.

C Tudur Smith was the lead investigator on the original review, assessed eligibility and methodological quality of original individual studies, organised and cleaned the IPD sets, performed data validation checks and statistical analyses and co-wrote the original review.

\section{DECLARATIONS OF INTEREST}

SJ Nevitt has no declarations of interest.

AG Marson: A consortium of pharmaceutical companies (GSK, EISAI, UCB Pharma) funded the National Audit of Seizure Management in Hospitals (NASH) through grants paid to University of Liverpool. Professor Tony Marson is part funded by National Institute for Health Research Collaboration for Leadership in Applied Health Research and Care North West Coast (NIHR CLAHRC NWC).

J Weston has no declarations of interest.

C Tudur Smith has no declarations of interest.

\section{SOURCES OF SUPPORT}

\section{Internal sources}

- University of Liverpool, UK.

- Walton Centre for Neurology and Neurosurgery, UK.

\section{External sources}

- Medical Research Council, UK. 
- National Institute for Health Research (NIHR), UK.

This review was supported by the National Institute for Health Research, via Cochrane Infrastructure funding to the Epilepsy Group. The views and opinions expressed therein are those of the authors and do not necessarily reflect those of the Systematic Reviews Programme, NIHR, National Health Service (NHS) or the Department of Health.

\section{DIFFERENCES BETWEEN PROTOCOL AND REVIEW}

For the 2018 update: we changed the title in line with the titles of other pair-wise monotherapy comparisons in the series (i.e. ' monotherapy for epilepsy' instead of 'for focal onset seizures and generalised onset tonic-clonic seizures) and in line with Cochrane Style guidelines of intervention (i.e. sodium valproate) first and comparator (i.e. phenytoin) second.

We redefined 'time to withdrawal of allocated treatment' as 'time to treatment failure' due to feedback received from the Cochrane Editorial Unit regarding potential confusion regarding 'withdrawal' as a positive or negative outcome of antiepileptic monotherapy.

We conducted additional analyses of 'time to treatment failure' (due to lack of efficacy and due to adverse events) following feedback on published antiepileptic drug monotherapy reviews that these suboutcomes would be useful for clinical practice.

We replaced the term 'partial' by 'focal', in accordance with the most recent classification of epilepsies of the International League Against Epilepsy (Scheffer 2017).

We presented adverse event information as a separate secondary outcome, 'incidence of adverse events' in line with other Cochrane IPD reviews investigating pair-wise monotherapy comparisons.

In December 2014, we changed the title to specify that the review uses individual participant data (IPD).

For the 2013 update, in a post hoc change, we added 'Summary of findings' tables to the review.

We added sensitivity analyses following identification of potential misclassification of seizure type. The existence of misclassification in the individual studies could not have been known at the time of writing the original protocol.

We added the outcome 'time to six-month remission' for consistency with the other reviews in the series of Cochrane IPD reviews investigating pair-wise monotherapy comparisons and removed the outcome 'quality of Life' which was found to not be readily available in an analysable format from early IPD requests.

\section{NOTES}

The protocol for this review was published with Catrin Tudur as the contact review author. Catrin is now known as Catrin Tudur Smith.

Sarah J Nolan (lead author of the 2013 and 2016 update) is now Sarah J Nevitt.

Jennifer Pulman (author of the 2013 update) is now Jennifer Weston.

\section{IN DEX TERMS}

\section{Medical Subject Headings (MeSH)}

Anticonvulsants [*therapeutic use]; Epilepsies, Partial [ ${ }^{*}$ drug therapy]; Epilepsy, Generalized [ ${ }^{*}$ drug therapy]; Phenytoin [*therapeutic use]; Randomized Controlled Trials as Topic; Seizures [ ${ }^{\star}$ drug therapy]; Treatment Outcome; Valproic Acid [*therapeutic use]

\section{MeSH check words}

Humans 